ANDREZA BASTOS MOURÃO

\title{
EDUCAÇÃO PRESENCIAL MEDIADA POR TECNOLOGIA COM INTERATIVIDADE EM TEMPO REAL
}


ANDREZA BASTOS MOURÃO

\section{EDUCAÇÃO PRESENCIAL MEDIADA POR TECNOLOGIA COM INTERATIVIDADE EM TEMPO REAL}

Dissertação apresentada à Escola

Politécnica da Universidade de São Paulo para a obtenção do título de Mestre em Engenharia Elétrica.

Área de Concentração:

Sistemas Digitais.

Orientadora: Profa. Dra.Graça Bressan 
Este exemplar foi revisado e alterado em relação à versão original, sob responsabilidade única do autor e com a anuência do seu orientador.

São Paulo, 15 de Setembro de 2010.

Assinatura do Autor

Assinatura do Orientador

\section{Mourão, Andreza Bastos}

Educação presencial mediada por tecnologia com interatividade em tempo real / A.B. Mourão. -- São Paulo, 2010.

160 .

Dissertação (Mestrado) - Escola Politécnica da Universidade de São Paulo. Departamento de Engenharia de Computação e Sistemas Digitais.

1.Educação à distância 2.Aprendizagem 3.Televisão interativa I.Universidade de São Paulo. Escola Politécnica. Departamento de Engenharia de Computação e Sistemas Digitais II.t. 


\section{DEDICATÓRIA}

Dedico esse trabalho a minha família. 


\section{AGRADECIMENTOS}

Agradeço primeiramente a Deus pai todo poderoso, por abençoar-me em todos os momentos da minha vida.

Ao meu querido coordenador de curso professor Antonio Cauper Filho, que por sua persistência, sabedoria, apoio e amizade proporcionaram-me a felicidade de realizar este sonho tão esperado.

À minha orientadora professora Graça Bressan pela sua orientação, seu apoio, sua paciência e sua disponibilidade frequente.

À minha família querida que me apoia desde o início desta caminhada, cheia de turbulências, de desafios e de obstáculos.

Agradeço principalmente as minhas queridas filhas Mikaella e Daniella que foram as mais desprovidas da companhia da sua mãe durante este período.

Ao meu esposo em particular por compartilhar comigo as minhas amizades, os meus conhecimentos, os meus momentos de angústias, os meus desafios e as minhas incertezas.

Aos meus pais Mirteles e Jerson Aranha pela educação que me proporcionaram, pelo apoio constante, pelo período que passaram comigo em São Paulo em época de estágio obrigatório, pelo amor e dedicação eterna.

À minha querida tia Socorro, que é uma mãezona para mim e para minhas filhas, que cuidou e cuida das minhas princesas com toda paciência e amor do mundo.

À minha tia Zira pelo apoio e ajuda que sempre me proporcionou.

Aos meus alunos da Universidade do Estado do Amazonas pelo carinho.

Aos meus queridos professores do mestrado que contribuíram com seus saberes e suas experiências. A Malu secretária do Knoma que tanto nos deu apoio e suporte desde o início desta caminhada. 
À UEA por investir na qualificação dos seus professores, proporcionando oportunidades através de parcerias interinstitucionais.

À USP por todo suporte em relação à infra-estrutura e apoio educacional, oriundos da experiência e competência de seu quadro docente e técnico.

À FAPEAM pela bolsa de estudos que muito ajudou durante o período de realização do mestrado.

E finalizando, meus agradecimentos eternos e inesquecíveis aos meus amigos e colegas de mestrado, pelos dias e noites que estivemos juntos estudando, principalmente em período de disciplinas, pelo apoio nas horas mais difíceis que pareciam ser desesperadoras, pela companhia em momentos que só tínhamos uns aos outros, pela troca de experiências e saberes, enfim por fazerem parte da minha história. 
"...aprender não é um ato findo. Aprender é um exercício constante de renovação..."

(Paulo Freire) 


\section{RESUMO}

A Universidade do Estado do Amazonas - UEA, no âmbito de seu crescimento cultural, regional e educacional tem realizado um esforço visando expandir para grande parte dos Municípios do Amazonas, o conhecimento, e a busca pela qualificação profissional, através de projetos relacionados ao ensino presencial mediado por TV. A Educação à Distância - EAD hoje já é uma realidade e encontrase em uso e destaca-se com êxito no Estado do Amazonas, a idéia então é contextualizar o cenário e estudar recursos e/ou ferramentas que possibilitem desenvolver um protótipo que permita visualizar o conhecimento obtido pelo aluno na disciplina ministrada, permitindo uma interatividade em tempo real do professor com os alunos por meio da televisão. A proposta é o desenvolvimento de um modelo educacional interativo utilizando recursos da tecnologia de TV Digital que possibilite aos professores titulares dos cursos do sistema presencial mediado por tecnologia da UEA obter uma realimentação em tempo real do aprendizado dos alunos.

Palavras-chave: educação à distância, aprendizagem, televisão interativa. 


\section{ABSTRACT}

The University of the State of Amazon - UEA, in the extent of its growth cultural, regional and education has been accomplishing an effort seeking to expand for great part of the Municipal districts of Amazon, the knowledge, and the search for the professional qualification, through projects related to the teaching presence courses mediated by TV. The Education the Distance Learning today is already a reality and it is in use and stands out with success in the State of Amazon, the idea then is contextualize the scenery and to study resources and/or tools that make possible to develop a prototype gone back to an interactive application. Creating like this, an infrastructure using education platforms at the distance and adapting the proposed prototype. The proposal is to develop an educacional model learning using interactive technology features digital TV to professor's holders of the courses system presence mediated by technology of UEA to obtain a real time feedback of student learning.

Word-key: distance learning, learning, interactive television. 


\section{LISTA DE ILUSTRAÇÕES}

Figura 1 - Sala de Aula do PROFORMAR ...................................................... 33

Figura 2 - Interatividade realizada no Centro de Mídias da SEDUC........................36

Figura 3 - Antena VSAT responsável pela recepção das aulas nos municípios.......38

Figura 4 - Transmissão da aula interativa via IP.TV ${ }^{\circledR}$ - UEA ...............................43

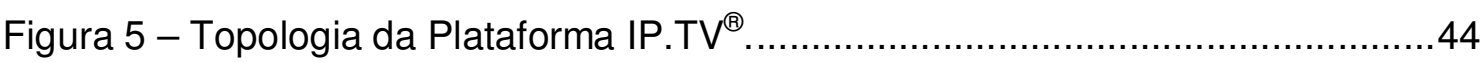

Figura 6 - Momentos iniciais da transmissão de aula do estúdio de Televisão da UEA. 46

Figura 7 - Ambiente Virtual de Aprendizagem TIDIA Ae. ...................................56

Figura 8 - Ambiente do Sistema Gerenciador de Aprendizagem TELEDUC...........58

Figura 9 - Ambiente do Sistema Gerenciador de Aprendizagem AulaNet (Interface

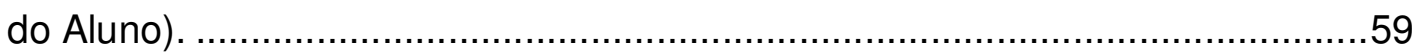

Figura 10 - Ambiente Virtual de Aprendizagem Moodle. ...................................60

Figura 11 - Representação de um sistema de TV Digital interativa........................69

Figura 12 - Camada de aplicações Middleware................................................ 71

Figura 13 - Transmissão de Aula do Curso TADS do SPMT - UEA ........................87

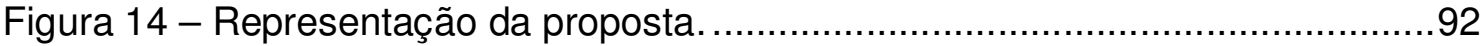

Figura 15 - Diagrama de Caso de Uso da Aplicação..............................................95

Figura 16 - Modelagem de Contexto da Interação dos Usuários ...........................109

Figura 17 - Modelo arquitetural do sistema interativo.....................................110

Figura 18 - Exemplo do arquivo XML de exercício gerado pelo sistema TIDIA Ae.111

Figura 19 - Exemplo do arquivo XML gerado e exportado pelo sistema SCRI......112

Figura 20 - Exemplo do arquivo XML importado pelo cliente SCRI.......................113

Figura 21 - Exemplo do arquivo XML exportado pelo cliente SCRI. .....................113

Figura 22 - Modelo de infra-estrutura interativa proposta..................................115

Figura 23 - Esquema de cenário proposto do modelo interativo. .......................116

Figura 24 - Diagrama de classes do modelo televisivo. ....................................118

Figura 25 - Cenário da interatividade realizada entre professor e alunos. ............119

Figura 26 - Cenário representativo da criação do exercício no TIDIA Ae..............120

Figura 27 - Cenário representativo da transmissão da resposta e leitura no sistema SCRI. 
Figura 28 - Cenário representativo da recepção e transmissão de conteúdo

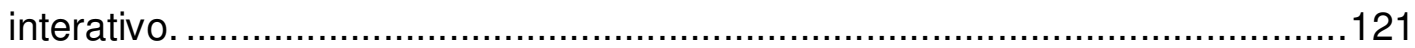

Figura 29 - Criar um banco de questões no TIDIA Ae .......................................125

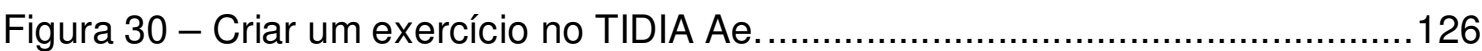

Figura 31 - Exportar em formato XML o Exercício1 criado no TIDIA Ae.................126

Figura 32 - Simulação da tela principal do Conteúdo Interativo emulado no

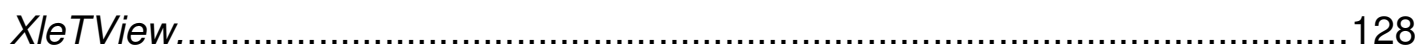

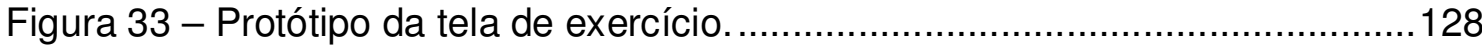

Figura 34 - Protótipo da tela de resposta dos exercícios por município...................129

Figura 35 - Tela principal do SCRI. ...............................................................130

Figura 36 - Tela de Cadastro de Município......................................................131

Figura 37 - Tela de Cadastro de Informação de Município.....................................131

Figura 38 - Tela de Cadastro de Professor Assistente. ....................................132

Figura 39 - Tela de Cadastro de Disciplina......................................................132

Figura 40 - Tela para informar a quantidade de alunos presentes em sala............133

Figura 41 - Tela de Importação dos Arquivos de Resposta.....................................133

Figura 42 - Tela de Cálculo de Notas por Município...............................................134

Figura 43 - Tela de consulta de notas. ..............................................................134 


\section{LISTA DE TABELAS}

Tabela 1 - Plataforma tecnológica do SPMT - UEA ………................................. 42

Tabela 2 - Produção de aulas do SPMT - UEA. ……........................................4

Tabela 3 - Corpo docente e técnico do SPMT - UEA. ............................................ 45

Tabela 4 - Comparação entre as ferramentas utilizadas em AVA ...........................55

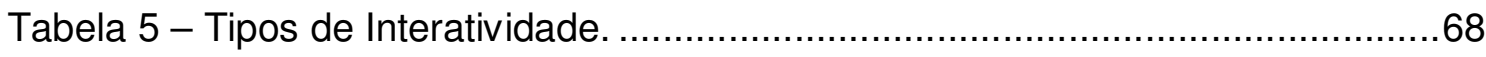

Tabela 6 - Descrição dos atores do Diagrama de Caso de Uso...............................94

Tabela 7 - Descrição dos requisitos funcionais do sistema. ......................................99

Tabela 8 - Descrição de tecnologias propostas................................................122

Tabela 9 - Descrição das responsabilidades no sistema SCRI .............................130 


\section{LISTA DE ABREVIATURAS E SIGLAS}

\begin{tabular}{|c|c|}
\hline AVA & Ambientes Virtuais de Aprendizagem \\
\hline$A D L$ & Advanced Distributed Learning \\
\hline ATSC & Advanced Television Systems Committee \\
\hline DTV & Digital television \\
\hline DVB & Digital Video Broadcasting \\
\hline DTMB & Digital Terrestrial Multimedia Broadcast \\
\hline EAD & Educação à Distância \\
\hline EML & Educational Modeling Language \\
\hline FAPEAM & Fundação de Amparo à Pesquisa do Estado do Amazonas \\
\hline FAPESP & Fundação de Amparo à Pesquisa do Estado de São Paulo \\
\hline HDTV & High Definition Television \\
\hline IEEE & Institute of Eletronic \& Eletrical Engineering \\
\hline IMS & Instructional Management Systems \\
\hline ISDB & Integrated Services Digital Broadcasting \\
\hline LD & Learning Design \\
\hline LDB & Lei de Diretrizes e Bases \\
\hline LMS & Learning Management System \\
\hline$L O M$ & Learning Object Metadata \\
\hline MOODLE & Modular Object-Oriented Dynamic Learning Environment \\
\hline MHP & Multimedia Home Platform \\
\hline NCL & Nested Context Language \\
\hline PEFD & Programa Especial de Formação Docente \\
\hline \multirow[t]{2}{*}{ PROFORMAR } & Programa de Formação e Valorização de Profissionais da \\
\hline & Educação \\
\hline QTI & Question \& Test Interoperability \\
\hline SBTVD & Sistema Brasileiro de TV Digital \\
\hline SCRI & Sistema de Controle de Respostas Interativas \\
\hline SCORM & Shareable Content Object Reference Model \\
\hline$S D V T$ & Standard Definition Television \\
\hline JC & Secretaria de Estado da Educação e Qualidade do E \\
\hline
\end{tabular}




$\begin{array}{ll}\text { SGA } & \text { Sistema de Gerenciamento de Aprendizagem } \\ \text { SPMT } & \text { Sistema Presencial Mediado por Tecnologia } \\ \text { SPMTV } & \text { Sistema Presencial Mediado por TV } \\ \text { SQI } & \text { Sistema de Questões Interativas } \\ \text { TICs } & \text { Tecnologia de Informação e Comunicação } \\ \text { TIDIA Ae } & \text { Tecnologia da Informação para o Desenvolvimento da Internet } \\ & \text { Avançada Aprendizado eletrônico } \\ \text { TVD } & \text { Televisão Digital } \\ \text { TVDi } & \text { Televisão Digital interativa } \\ \text { UA } & \text { Unidade de Aprendizagem } \\ \text { UEA } & \text { Universidade do Estado do Amazonas } \\ \text { UFAM } & \text { Universidade Federal do Estado do Amazonas } \\ \text { UML } & \text { Unified Modeling Language } \\ \text { USP } & \text { Universidade do Estado de São Paulo } \\ \text { XML } & \text { Extensible Markup Language } \\ \text { W3C } & \text { World Wide Web Consortium }\end{array}$




\section{SUMÁRIO}

1. INTRODUCÃO

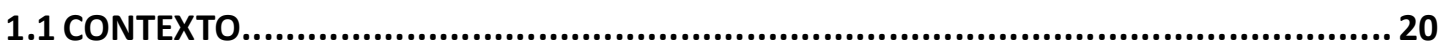

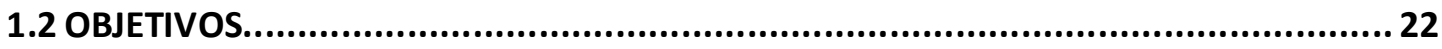

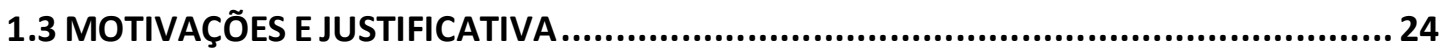

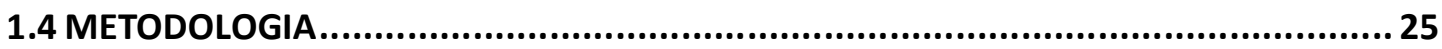

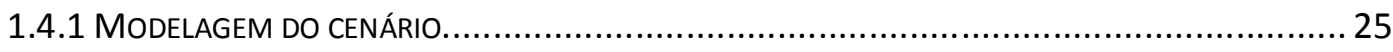

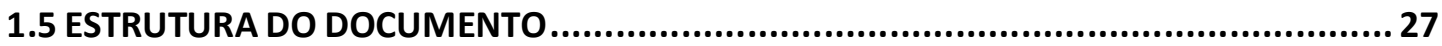

2. ENSINO MEDIADO POR TECNOLOGIA NO AMAZONAS …..............................29

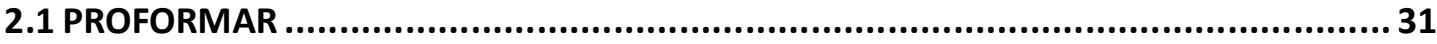

2.2 SISTEMA PRESENCIAL MEDIADO POR TV - SEDUC ......................................... 34

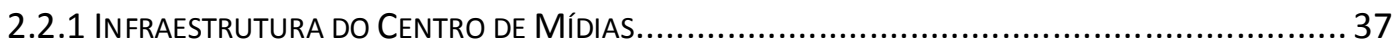

2.3 SISTEMA PRESENCIAL MEDIADO POR TECNOLOGIA - UEA .................................... 39

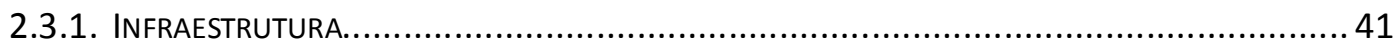

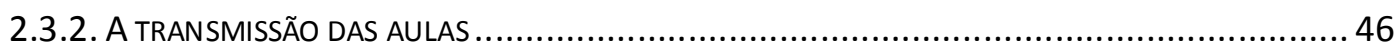

2.3.3 EMPRESA PRESTAdORA DE SERVIÇOS DE TELECOMUNICAÇõES........................................ 47

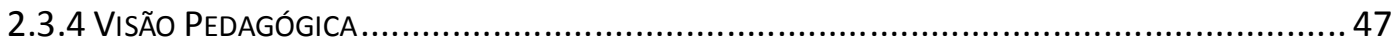

3. TECNOLOGIAS VOLTADAS AO SUPORTE DO ENSINO ................................50

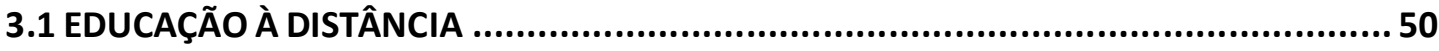

3.2 SISTEMAS GERENCIADORES DE APRENDIZAGEM ............................................ 52

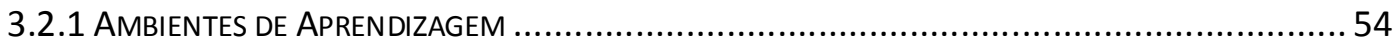

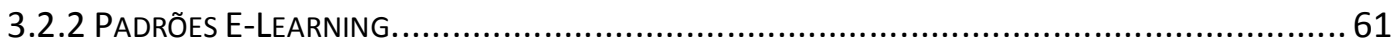

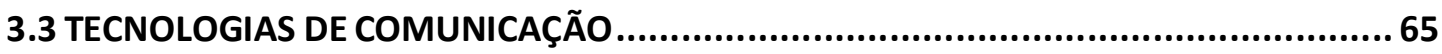

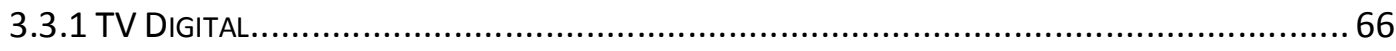

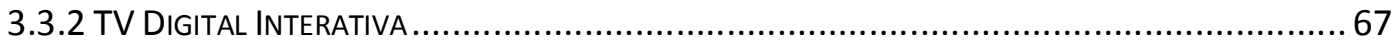

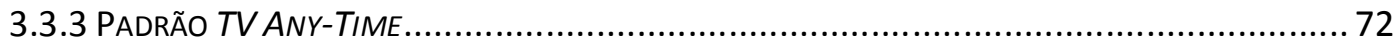

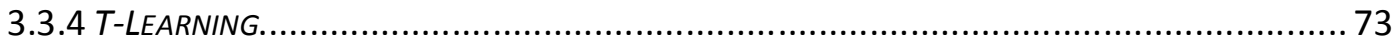

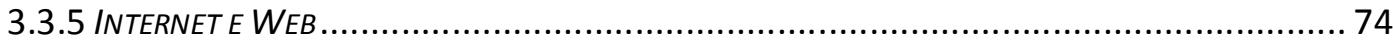

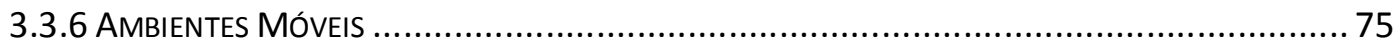


4. TRABALHOS RELACIONADOS ....................................................................

4.1 METODOLOGIA FRANTZI DE INTEGRAÇÃO DO SCORM COM TV ANYTIME .............. 80

4.2 PROPOSTAS DE LÓPES PARA T-LEARNING ................................................ 81

4.3 PROPOSTA DE OLIVEIRA SOBRE T-LEARNING NA AMAZÔNIA ............................. 81

4.4 PROPOSTA DE GOMES DE UM OBJETO DE APRENDIZAGEM CONSTRUTIVISTA .......... 82

4.5 PROPOSTA DE BORGES ENGLOBANDO EDUCAÇÃO ATRAVÉS DA TV DIGITAL ............ 82

4.6 PROPOSTA DE RIBEIRO FILHO SOBRE A AVALIAÇÃO DE APRENDIZAGEM POR MEIO DA

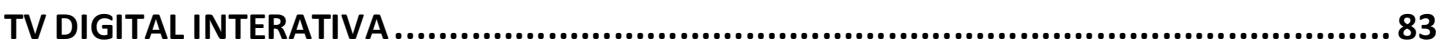

4.7 PROPOSTA DE LEITE PARA O PROCESSO PEDAGÓGICO DE ADAPTAÇÃO AO AMBIENTE VIRTUAL: CONTRIBUIÇÕES PARA TUTORES E ALUNOS. ........................................ 83

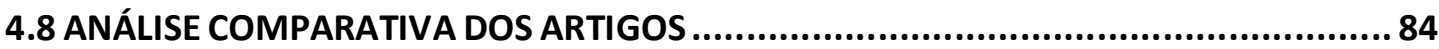

5. MODELO DE INTERATIVIDADE

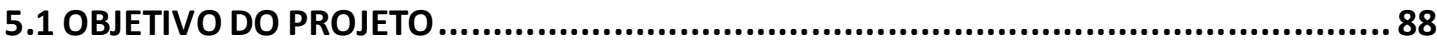

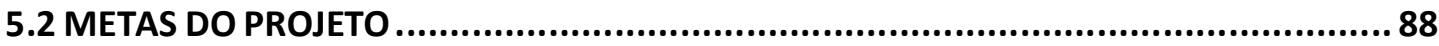

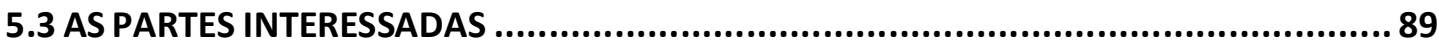

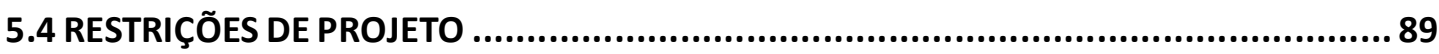

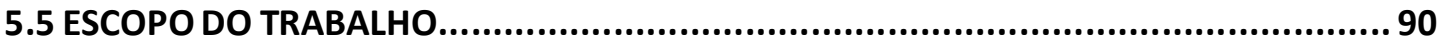

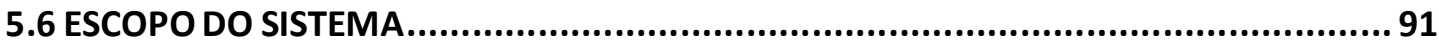

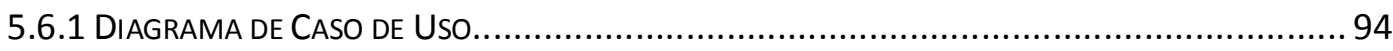

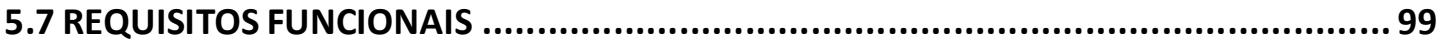

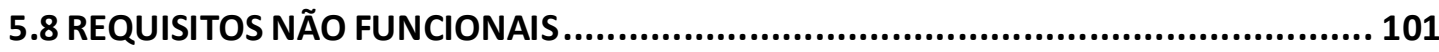

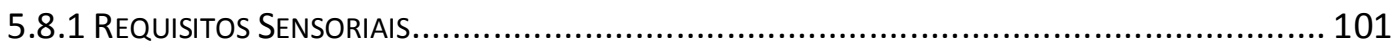

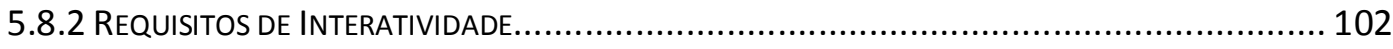

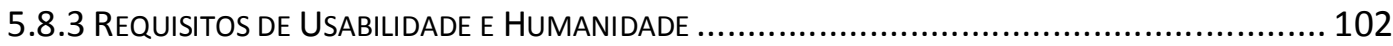

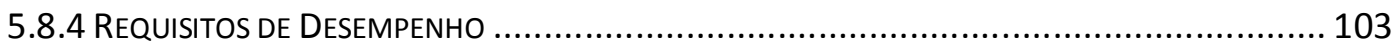

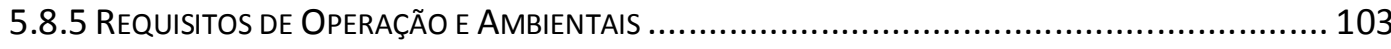

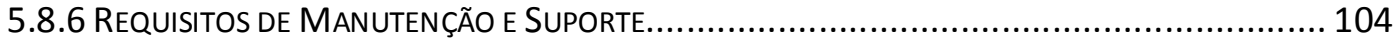

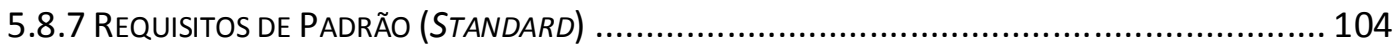

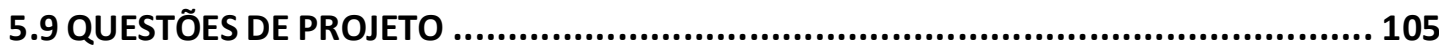

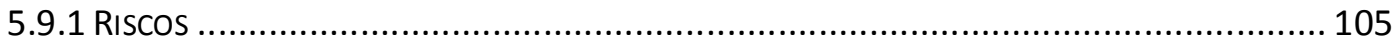

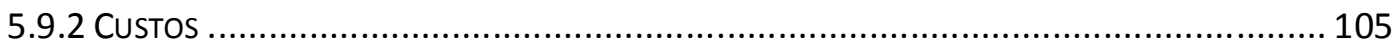




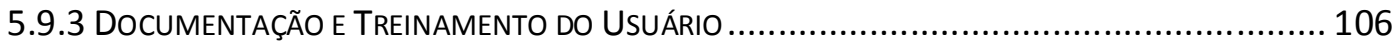

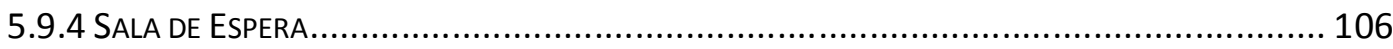

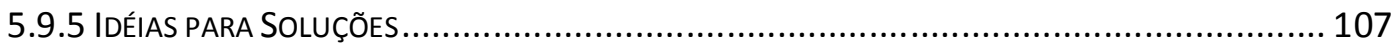

6 MODELAGEM E PROJETO DO MODELO INTERATIVO.............................108

6.1 CENÁRIO DA APLICAÇÃO.......................................................................... 108

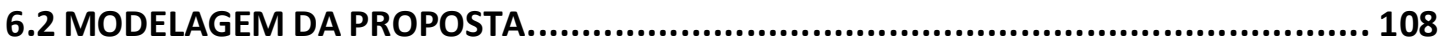

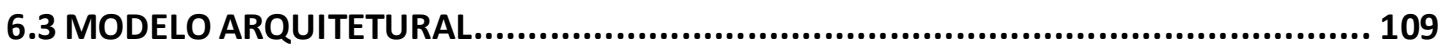

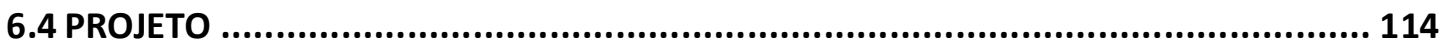

6.5 TECNOLOGIAS PARA O DESENVOLVIMENTO DO CENÁRIO ............................. 121

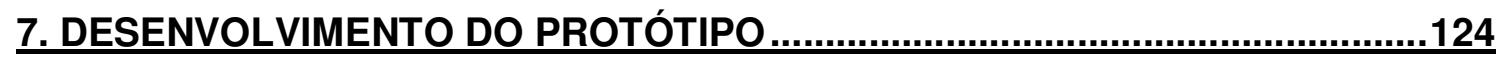

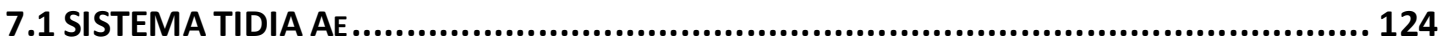

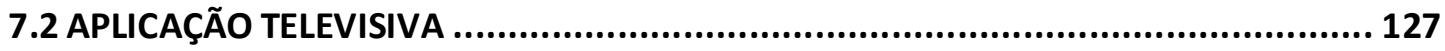

7.3 SISTEMA DE CÁLCULO DE RESPOSTAS INTERATIVAS - SCRI ............................ 129

7.4 RESULTADOS E DISCUSSÃO DO PROTÓTIPO................................................... 135

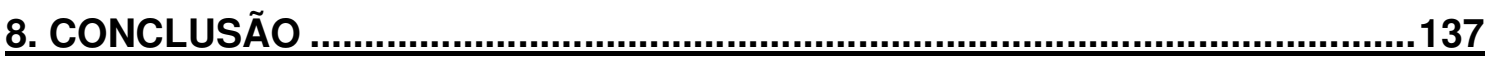

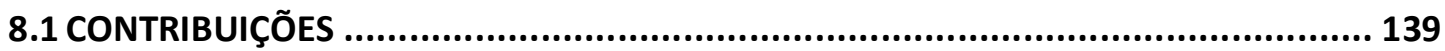

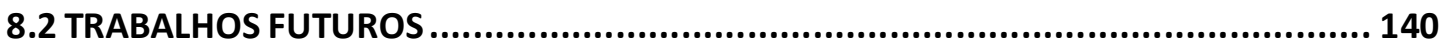

REFERÊNCIAS BIBLIOGRÁFICAS ..............................................................142

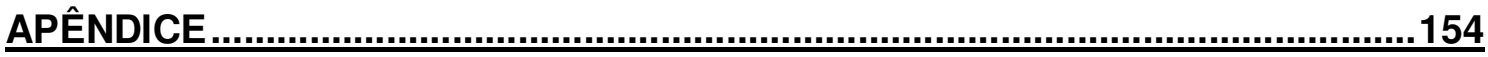




\section{INTRODUÇÃO}

A tecnologia da informação cresce gradativamente e ganha seu espaço no mercado atual, novos meios de difusão da informação são lançados e muitos deles tornam-se soluções possíveis para resolver, e em outros casos minimizar eventuais problemas onde os meios tecnológicos são fatores fundamentais para o processo.

As propostas educacionais ganham mercado e oportunidades, sendo possível perceber o elevado índice de oferta e demanda de cursos de graduação e pósgraduação oferecidos à distância. Novas ferramentas, recursos tecnológicos e ambientes são pensados, selecionados e desenvolvidos com o objetivo de elevar a qualidade dos cursos, contribuindo para a melhoria do processo ensinoaprendizagem e propiciando uma interatividade diferenciada entre tutores e alunos.

A Universidade do Estado do Amazonas - UEA ${ }^{1}$ trabalha com a modalidade presencial mediada por TV, atualmente conhecida como Sistema Presencial Mediado por Tecnologia - SPMT ${ }^{2}$. Podem-se citar alguns projetos já concluídos e outros em andamento na Universidade como: o PROFORMAR ${ }^{3}$, Ciências Políticas, Licenciatura em Matemática, Licenciatura em Educação Física, Tecnologia em Análise e Desenvolvimento de Sistemas - TADS ${ }^{4}$, Licenciatura Indígena e alguns cursos de especialização recentemente lançados.

No sistema presencial mediado por tecnologia da UEA, os recursos tecnológicos são utilizados visando o melhor aproveitamento do aluno nas disciplinas que são ministradas via televisão. Os cursos utilizam ferramentas e técnicas específicas, visando uma melhor atuação do professor na disciplina e um melhor aproveitamento educacional dos alunos.

\footnotetext{
$1 \mathrm{http}: / /$ www.uea.edu.br/

2 http://www1.uea.edu.br/data/categoria/int/download/1409-1.pdf

3 http://www1.uea.edu.br/data/categoria/programa/download/525-4.doc

4 http://tads.uea.edu.br/
} 
A TV digital já é uma realidade e daqui a alguns anos já estará sendo totalmente implantada e em uso na região Amazônica. A idéia então é contextualizar o cenário e estudar recursos e ferramentas que possibilitem o desenvolvimento de uma aplicação interativa voltada para os alunos dos cursos desta modalidade utilizando a tecnologia de TV Digital.

Com o advento da TV Digital, torna-se possível potencializar a exploração de recursos de EAD voltados para ambiente Web, além de integrar, adaptar e reutilizar em aplicações educacionais transmitidas pela TV, tornando interativo o processo de aprendizagem do aluno e possibilitando ao professor uma visão mais realista do seu trabalho.

Desta forma, o desenvolvimento de um modelo educacional interativo voltado para a modalidade de EAD aplicada no Amazonas, resultará num ganho educacional e cultural não só para a Universidade do Estado do Amazonas - UEA, quanto para outros ambientes educacionais com requisitos semelhantes.

\subsection{CONTEXTO}

A UEA destaca-se pela quantidade de cursos oferecidos à distância e pela quantidade de municípios que atende, através do sistema presencial mediado por tecnologia, assim como pela qualidade atribuída a eles em relação ao seu corpo docente, técnico, administrativo e todo suporte educacional e infraestrutura oferecida.

Considerando as distâncias geográficas existentes entre a capital e os demais municípios que integram o estado do Amazonas, a UEA preocupou-se em levar educação aos diversos povos e culturas que compõem o estado, profissionalizando e oferecendo aos diversos municípios uma mão-de-obra qualificada e de nível superior. 
Um dos primeiros projetos que alavancou a Educação à Distância no Estado do Amazonas, é conhecido como Programa de Formação e Valorização dos Profissionais da Educação - PROFORMAR da UEA. O projeto surgiu na então conhecida "década da educação", período assim denominado para que os Estados da Federação pudessem se organizar e oferecer programas de qualificação para seus professores.

Barbosa (2008) descreve que o projeto do PROFORMAR foi pensado para atender a uma solicitação da Secretaria de Estado da Educação e Qualidade do Ensino SEDUC $^{5}$, com o objetivo de cumprir os dispositivos legais da Lei de Diretrizes e Bases da Educação Nacional - $\operatorname{LDB}^{6}$, que assim determinou a qualificação dos professores em nível superior obrigatória.

Ensinar via televisão é um desafio que muitos professores enfrentam quando são convidados a ministrar disciplinas neste sistema. Os professores que ministram aula pela televisão visualizam outro cenário, ou seja, não há a presença dos alunos, apenas de câmeras, logo eles se questionam sobre as dúvidas que os alunos possuem e seus questionamentos imediatos, o que resulta em vários fatores a serem adotados como: postura, métodos, domínio de conteúdo, planejamento, metodologia de ensino, concentração e conhecimento de ferramentas tecnológicas utilizadas para o suporte pedagógico.

A avaliação neste processo de ensino-aprendizagem engloba vários parâmetros: a didática do professor, as metodologias pedagógicas utilizadas em todo o processo, os recursos didáticos e tecnológicos utilizados e principalmente o acompanhamento da coordenação pedagógica do curso perante a atuação do professor, buscando sempre prover mecanismos de apoio e suporte para atingir qualidade no processo educacional. Perrenoud (1999) aborda a avaliação da aprendizagem, no novo paradigma, como sendo um processo mediador na construção do currículo e se encontra intimamente relacionada à gestão da aprendizagem dos alunos.

O ensino via televisão teve sua origem décadas atrás por meio de telecursos, e propaga-se permitindo hoje uma amplitude de aplicabilidades. O setor educacional

\footnotetext{
5 http://www.seduc.am.gov.br/

6 http://portal.mec.gov.br/arquivos/pdf/ldb.pdf
} 
vem ganhando seu espaço e explorando o uso de tecnologia para levar conhecimento a áreas onde nem se imaginava que um dia seria possível transmitir conhecimentos e formar cidadãos.

$\mathrm{Na}$ maioria dos cursos presenciais a evasão escolar ocorre por diversos motivos (desistência, troca de curso, fatores financeiros, etc.), porém não se torna tão preocupante, quando comparado com o sistema presencial mediado por tecnologia oferecido pela UEA, uma vez que os cursos existentes hoje são projetos com data de inicio e término e não visam ser oferecidos anualmente para que não sature o mercado local. A idéia é o oferecimento de diferentes cursos para aumentar o número de pessoas capacitadas para atuar nas diversas áreas.

Neste modelo as atividades em grupo são incentivadas, assim como a participação dos alunos em atividades de aprendizagem colaborativa, aumentando o seu grau de responsabilidade, facilitando a compreensão dos conteúdos sob pontos de vista culturalmente diversos, gerando discussões promissoras, enfim elevando a busca pelo conhecimento.

\subsection{OBJETIVOS}

O objetivo deste trabalho é o desenvolvimento de um modelo educacional interativo utilizando recursos da tecnologia de TV Digital que possibilite aos professores titulares dos cursos do sistema presencial mediado por tecnologia da UEA obterem uma realimentação em tempo real do aprendizado dos alunos.

O modelo sistematizado de aprendizagem a ser desenvolvido tem como foco oferecer uma opção diferenciada ao processo de Educação à Distância oferecida no Estado do Amazonas, para que a interatividade entre professores e alunos possa contar com a tecnologia de TV Digital para prover uma maior quantidade e qualidade de serviços oferecidos pela TV. Em virtude da Universidade possuir um fornecedor que provê um sistema de interatividade denominado IP.TV ${ }^{\circledR}$, cujo software é proprietário, não é possível então integrar uma ferramenta opcional de interatividade utilizando a mesma tecnologia. 
O uso de outras tecnologias que permitam agregar interatividade ao processo educacional pode contribuir significativamente para o sucesso dos cursos e para a obtenção de uma realimentação imediata por parte dos professores.

Um dos objetivos específicos é contribuir para a melhoria do processo de ensinoaprendizagem do SPMT da UEA, por meio do uso de ferramentas interativas que possibilitem uma interatividade em tempo real entre professores e alunos. A ferramenta de exercício do ambiente virtual de aprendizagem TIDIA $\mathrm{Ae}^{7}$, gera conteúdos que podem ser utilizados no processo de ensino.

O processo de ensino poderá contar com um modelo que possibilita ao professor visualizar em tempo real o percentual de conhecimento obtido pelos alunos no instante em que um conteúdo de uma disciplina for ministrado. Permitindo ao professor e aos alunos a troca de conhecimento de forma síncrona, podendo o professor titular mensurar o conhecimento obtido pelos alunos em relação a um determinado conteúdo ministrado, assim como melhorar a qualidade e os métodos pedagógicos utilizados em suas aulas.

Outro objetivo específico é possibilitar que o modelo educacional possa ser futuramente adotado e incorporado pelo SPMT da UEA. Logo, é imprescindível a realização do levantamento, estudo de ferramentas e a aplicação de técnicas e padrões necessários para a realização da adaptação da(s) ferramentas Web (elearning) ao modelo de TVD (t-learning).

Para o cumprimento deste objetivo será necessário explorar a ferramenta do Tidia Ae; conhecer bem as metodologias utilizadas; o ambiente do sistema presencial mediado por tecnologia da UEA; assim como explorar conceitos e ferramentas de TV Digital que permita criar um protótipo como prova de conceito do sistema.

\footnotetext{
7 Tecnologia da Informação para o Desenvolvimento da Internet Avançada - Aprendizado Eletrônico, projeto financiado pela FAPESP.
} 


\subsection{MOTIVAÇÕES E JUSTIFICATIVA}

O setor educacional vem ganhando o seu espaço na era da tecnologia e crescem gradativamente os cursos oferecidos a distância e as universidades que vem investindo neste setor, vários aparatos tecnológicos estão sendo utilizados objetivando melhorar conteúdos e aulas ministradas, resultando em índices satisfatórios de aceitação dos alunos que se enquadram neste perfil, assim novas ferramentas e ambientes estão sendo desenvolvidos e utilizados buscando alcançar méritos positivos para esta nova modalidade.

Em alguns municípios do Estado do Amazonas, torna-se viável a criação e permanência de cursos de graduação regulares, com professores residentes, acervos bibliográficos, estrutura física e outros fatores que permitem a consolidação dos cursos em determinadas localidades, no entanto em outros municípios a permanência de alguns cursos não se torna viável e ou necessária, em virtude de não se ter mercado profissional suficiente para a absorção destes profissionais. Consequentemente, projetos presenciais mediados por tecnologia transmitidos via satélite, foram e estão sendo criados, e estão atuantes visando levar para as diversas localidades, uma qualificação profissional não abrangente e sim suficiente para suprir as necessidades profsissionais de determinados municípios.

Considerando as distâncias existentes entre a capital e os demais municípios que compõem o estado, onde o transporte muitas vezes é precário, as comunidades ficam isoladas, as necessidades e diversidades são inúmeras, então a universidade preocupou-se em levar até essas regiões: educação, oferecendo aos diversos municípios uma mão-de-obra qualificada.

Hoje já é possível visualizar frutos deste projeto, o PROFORMAR é um exemplo, o qual permitiu aos municípios elevar o número de professores qualificados para atuarem no mercado de trabalho local, onde tal modelo está sendo migrado para outros países e estados interessados em sua implementação. Abrindo portas para a consolidação de outros projetos na região, no que se refere à Educação à Distância via televisão (t-learning). 
Os modelos e-learning oferecem ambientes virtuais de aprendizagem completíssimos, com muitas facilidades, repositórios e ferramentas que permitem ao professor ampliar seus métodos e metodologias, empregados ao ensino à distância.

Atualmente a televisão digital também é uma inovação tecnológica que está repercutindo bons frutos em alguns estados do Brasil e que pode ser futuramente uma boa parceira para possibilitar uma maior interatividade dos alunos com os cursos oferecidos via televisão pela Universidade do Estado do Amazonas.

\subsection{METODOLOGIA}

As etapas constituintes do processo de realização deste trabalho envolvem: a modelagem do cenário (elicitação, análise e especificação de requisitos), o estudo de ferramentas, os recursos, ambientes e padrões relacionados à EAD, as tecnologias de TVD e interatividade, e o estudo de trabalhos relacionados.

\subsubsection{Modelagem do cenário}

\subsubsection{Elicitação de requisitos}

Levantamento de Requisitos: do modelo e ambiente do sistema presencial mediado por tecnologia, das aulas via televisão, do material utilizado, posicionamentos, índices, enfim todo e qualquer documento ou acervo que contribua para o enriquecimento do contexto analisado. 


\subsubsection{Análise de Requisitos}

Pesquisa de Campo: entrevista e aplicação de questionários com docentes envolvidos no processo (professores titulares e assistentes) da área, coordenação do curso, alunos (objeto de estudo) do sistema atual.

Levantamento orientado aos pontos de vista: levantamento do conhecimento e experiência dos especialistas da área.

\subsubsection{Especificação de Requisitos}

Criar cenários que represente de forma fiel o que realmente foi levantado, eliminando contradições e contribuindo assim para uma melhor especificação do cenário atual. Permitindo definir restrições e requisitos funcionais e não-funcionais do sistema, entre outras questões de projeto.

\subsubsection{Estudo de ferramentas, padrões e ambientes de EAD, TVD e interatividade.}

Levantar acervos, artigos, publicações, sites, e todo material e aplicação relacionado com os assuntos especificados com o objetivo de solidificar, enriquecer e atingir o objetivo proposto.

Investigar algumas ferramentas utilizadas no modelo e-Learning e as que serão utilizadas para o desenvolvimento da aplicação t-Learning. Para especificar uma solução viável a ser aplicada no SPMT, utilizou-se a ferramenta de modelagem orientada a objetos (JUDE Community $\left.{ }^{8}\right)$, para criar o cenário, permitindo assim

\footnotetext{
${ }^{8}$ http://jude.change-vision.com/jude-web/product/community.html.
} 
tornar representativo o escopo do problema. E utilizou-se o Template Volere, como modelo para especificar os requisitos do sistema.

Realização do levantamento e estudo de técnicas, ferramentas, modelos, padrões e linguagens referentes à EAD, aprendizado eletrônico e móvel e programação televisiva necessárias para serem aplicadas no processo.

Buscando alcançar os resultados desejados, realizou-se a coleta das informações pertinentes ao contexto, para isso tornou-se imprescindível dispor de referências relacionadas ao assunto e de equipamentos que possibilitem capturar informações importantes. Tais como: Acervo bibliográfico (livros, mídias, artigos, periódicos, anais, etc.), câmera fotográfica, filmadora, gravador, aplicação de questionários, realização de entrevistas entre outros.

\subsection{ESTRUTURA DO DOCUMENTO}

Os capítulos da dissertação estão distribuídos da seguinte forma:

- Capítulo 1 - Introdução: este capítulo descreve o cenário estudado para o desenvolvimento da aplicação, assim como as motivações, objetivos, trabalhos relacionados e metodologia adotada para atingir os objetivos apresentados.

- Capítulo 2 - Ensino Mediado por Tecnologia no Amazonas: este capítulo descreve o modelo de Educação à Distância em funcionamento no Amazonas e o cenário do sistema presencial mediado por tecnologia do PROFORMAR, da SEDUC e da UEA;

- Capítulo 3 - Tecnologias voltadas ao suporte do ensino: este capítulo descreve as tecnologias que foram levantadas e estudadas permitindo uma visão macro dos modelos, padrões, ambientes e técnicas utilizadas neste contexto. 
- Capítulo 4 - Trabalhos relacionados: este capítulo descreve os trabalhos que evidenciam o estado da arte e mostra as suas contribuições.

- Capítulo 5 - Modelo Interativo: este capítulo descreve os requisitos levantados na fase de entrevista e necessidades apresentadas pelos especialistas do processo, através da especificação dos requisitos utilizando como referência o Template Volere.

- Capítulo 6 - Modelagem e Projeto do Modelo Interativo: este capítulo descreve os modelos desenvolvidos com base no contexto do trabalho, relacionados com as especificações de requisitos apresentadas.

- Capítulo 7 - Desenvolvimento do Protótipo: este capítulo tem como objetivo mostrar os protótipos construídos com base na proposta desejada e nos requisitos especificados, assim como os resultados e discussão sobre o modelo.

- Capítulo 8 - Conclusão: este capítulo descreve as considerações obtidas com a realização deste trabalho desde a sua origem até a sua concepção, e apresenta uma visão de suas contribuições e trabalhos futuros. 


\section{ENSINO MEDIADO POR TECNOLOGIA NO AMAZONAS}

Um Estado rico de belezas naturais, banhado pelos rios: Negro e Solimões de água barrenta, que resulta num fenômeno mundialmente conhecido como: Encontro das Águas, cercado por Florestas, por povos culturalmente diversificados em relação aos seus costumes e crenças, de etnias distintas e de habitantes conhecidos popularmente como caboclos. Esta é a uma síntese de uma região tão distante geograficamente e muito visitada por estrangeiros interessados em explorar tantas riquezas naturais.

A Amazônia é um patrimônio universal, principalmente quando se trata de "governança mundial". Essa recorrência política à internacionalização tem raízes históricas que devem ser tomadas como fonte explicativa: A Amazônia territorial como espaço de conquista (BARBOSA, 2008).

O Estado do Amazonas realizou nos últimos vinte anos um grande esforço para melhorar a qualidade na educação, realizando a qualificação profissional de professores sem formação superior oferecendo cursos de nível superior pedagógico, visando atender metas educacionais nacionalmente estabelecidas. A Universidade Federal do Amazonas - UFAM ${ }^{9}$ ofereceu cursos presenciais de licenciatura e o Programa Especial de Formação Docente - PEFD, a UEA por sua vez ofereceu o PROFORMAR.

Apesar de todas essas ações, não foi possível suprir os sistemas municipais e estaduais de ensino com professores suficientes considerando a elevada demanda existente, principalmente nas séries finais do Ensino Fundamental e do Ensino Médio.

Os fatores culturais são propriedades únicas de cada povo, e de cada região. É possível evidenciarmos quanta carência cultural e educacional ainda existe em muitas regiões, embora os programas televisivos, o rádio, e os cinemas transmitam muita informação.

\footnotetext{
${ }^{9}$ http://portal.ufam.edu.br/
} 
Porém, estes meios de comunicação não estão ao alcance de todos e isso dificulta o desenvolvimento sustentável de muitos povos. A Educação à Distância surge então como um mecanismo de troca, de conhecimentos e saberes com vantagens para a população e para o governo que a implementa, e para todos que participam deste processo direta ou indiretamente.

O Estado do Amazonas vem escrevendo sua história na educação, utilizando um novo conceito que vem trazendo grandes resultados, considerando os obstáculos e características evidentes na região.

O Sistema Presencial Mediado por Tecnologia no Amazonas - SPMT segundo (Barbosa, 2008) surgiu adaptado às condições regionais, com um custo mais baixo e com maiores benefícios do que previstos anteriormente, baseado no ensino presencial convencional.

A proposta do SPMT apresenta alguns diferenciais quando comparado com a EAD convencional, pois exige que alguns requisitos sejam cumpridos para que resulte num modelo de sucesso e apresente resultados satisfatórios para os alunos, professores, coordenadores e universidade.

O SPMT caracteriza-se pela utilização de recursos tecnológicos que contribuem com o processo de ensino aprendizagem transmitido pela televisão em tempo real, assim como pela obrigatoriedade dos alunos em sala de aula no horário em que são transmitidas as aulas, pelas aulas interativas realizadas pela equipe de professores titulares, pela continuidade de trabalhos presenciais realizados em sala de aula com tutoria dos professores assistentes, pelo acompanhamento e orientação individualizada em período de realização de estágios, de projetos de pesquisa e extensão.

Recentemente o termo Blended Learning tem sido muito disseminado e começa a se consolidar, referindo-se a combinações de ambientes de aprendizagem. Graham (2006) estabelece que Blended Learning seja a combinação da aprendizagem presencial com a aprendizagem mediada por computador. Os autores Mason e Rennie (2006) relatam a importância em estender essa definição para incluir outras combinações de tecnologias, locais ou abordagens pedagógicas. 
Garrison e Vaughan (2008) definem o termo evidenciando as relações pessoais estabelecidas e experiências de aprendizado online.

Os ambientes tradicionais de sala de aula e ambientes virtuais de aprendizagem historicamente convencionados, conforme relata Litto (2009) estão se complementando, resultante do desenvolvimento de cursos híbridos que aproveitam o que há de mais vantajoso em cada modalidade, considerando contexto, custo, adequação pedagógica, objetivos educacionais e perfis dos alunos. Considerando esta abordagem os educadores podem usufruir de uma gama maior de recursos de aprendizagem, planejando atividades, levando em consideração as limitações e potenciais, conteúdo, custos e resultados pedagógicos estimados, diferentes misturas de tecnologia e pedagogia têm sido documentadas em ambos ambientes (tradicional e virtual) baseadas em programas a distância (Stacey e Gerbic, 2006).

O Blended Learning busca se consolidar evidenciando seu grande potencial para melhorar a qualidade e eficiência da aprendizagem, termo este empregado e evidenciado quando se fala do SPMT no Amazonas, que busca integrar um ambiente presencial e de EAD visando proporcionar aos seus alunos e professores uma interatividade, autonomia (docente e discente), uma cooperação mútua e um ambiente em que professores e alunos aprendam, ensinem e compartilhem experiências. Os modelos de aprendizagem Blended devem ser desenvolvidos ressaltando as necessidades do local, da comunidade ou organização envolvida (Sharpe, Benfield, Robert e Francis, 2006).

\subsection{PROFORMAR}

O PROFORMAR é um projeto que foi oriundo de uma ação eficaz de política pública na Educação e que vem a ser ponto de destaque quando se trata de Educação à Distância no Amazonas, denomina-se Programa de Formação de Professores, voltado para as séries iniciais do Ensino Fundamental e implementada pelo Governo do Estado dentro da recém criada UEA. 
Barbosa (2008) define o PROFORMAR como sendo uma ação governamental, parte integral do que se pode chamar de boa política educacional em nosso estado. $E$ relata em seu trabalho que a Educação no Estado do Amazonas não será mais a mesma depois do PROFORMAR, e de fato não é mesmo. A implementação deste programa abriu caminhos e uma visão macro do sistema foi vislumbrada por muitas instituições.

Este projeto conseguiu criar um espaço de informação, capacitação, reflexão e investigação no que diz respeito ao processo educacional. Assim como provar que é possível formar professores com uma educação com qualidade mantendo os objetivos do Estado; valorizando a liberdade de pensamento e de expressão de professores e alunos; conseguiu provar também ser possível elaborar uma ação pedagógica formativa, enfim trouxe muitos benefícios para a região e para a população como um todo.

O PROFORMAR teve seu inicio em 2001, com exame de vestibular em todos os municípios do interior do Estado e no dia 30 de julho de 2005, realizou a formatura "colação de grau" de 7.150 alunos espalhados nas 61 sedes municipais do Estado do Amazonas.

Ainda no mesmo ano, houve uma segunda seleção de alunos no projeto que se denominou PROFORMAR II com término no ano de 2008, cujo objetivo era completar o quadro de professores licenciados nos sistemas educacionais de ensino do Amazonas.

A proposta do programa visava reduzir custos, permitir a ampliação de vagas para atender a formação de quadros das recém-criadas secretarias municipais de ensino.

Na figura 1 é possível visualizar uma turma do PROFORMAR, com o professor local "assistente", alunos e o televisor por onde estão sendo transmitidas as aulas ao vivo. 


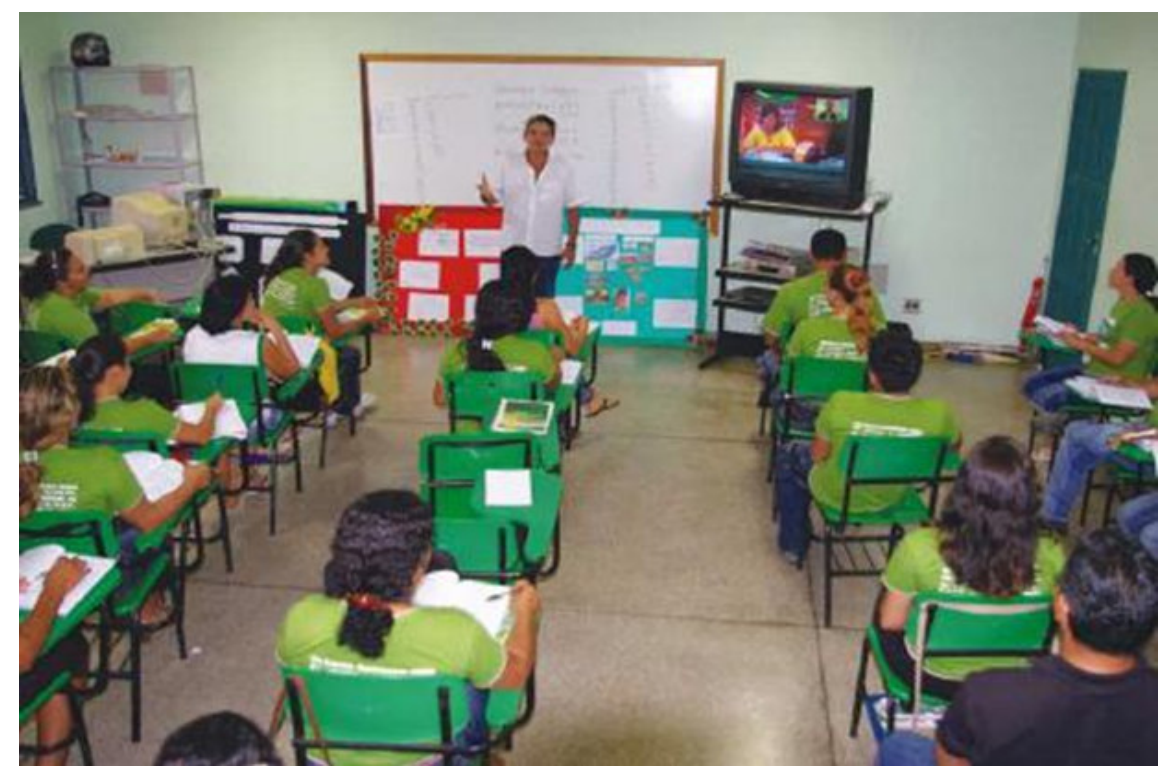

Figura 1 - Sala de Aula do PROFORMAR.

Fonte: http://www.odmbrasil.org.br/instituicao-detalhes/35/programa-de-formacao-e-valorizacao-deprofissionais-da-educacao-PROFORMAR.

O PROFORMAR foi um projeto ousado e que trouxe resultados positivos para o estado do Amazonas. Deu início a uma nova era da educação abrindo portas para outros projetos que a partir de então começaram a se consolidar no estado aplicando esta mesma concepção de ensino. Permitindo que muitos Amazonenses que antes "sonhavam" em realizar uma formação de excelência, tivessem então a oportunidade de obtê-la.

Este projeto de ensino mediado por tecnologia diminuiu custos com logísticas, contou com profissionais qualificados, com infraestrutura de ponta, com transmissão e recepção de sinal a lugares longínquos, apostava na tecnologia e na capacidade de aprendizagem das pessoas da terra, entre outros artefatos que validaram a sua aplicação.

Litto (2009) em seu trabalho consegue transmitir toda essa visão sobre as necessidades de uma educação que contemple a todos, principalmente quando ele enfatiza que a cultura é um processo de que a educação faz parte e que são grandes as carências brasileiras em ambos os campos. 
O autor comenta em seu texto das perspectivas em relação à ampliação do nosso universo cultural, e destaca a TV Digital como uma tecnologia de ponta, que já está disponível no Brasil, principalmente em São Paulo e expande-se a outros estados do território brasileiro.

O tema em questão ainda gera muita discussão, o que se pode constatar é que não há restrições para a construção de plataformas, já existem tecnologias disponíveis, e que o conteúdo envolve a "soberania nacional". Segundo Litto (2009) a regulamentação do que se relaciona ao conteúdo nacional é fundamental, compreendendo-se que sua transmissão deve ser prerrogativa das emissoras. Será a melhor maneira de ampliar as fronteiras do conhecimento, com proteção à nossa língua e à diversidade regional.

\subsection{SISTEMA PRESENCIAL MEDIADO POR TV - SEDUC}

A Secretaria de Estado da Educação e Qualidade do Ensino - SEDUC, localizada no Estado do Amazonas, é um órgão integrante da Administração Direta do Poder Executivo, responsável por formular, supervisionar; e coordenar a execução e a avaliação da Política Estadual de Educação do ensino fundamental, médio e das modalidades de ensino, assim como prover assistência, orientação e acompanhamento das atividades dos estabelecimentos de ensino.

A SEDUC vem realizando alguns estudos e levantamentos relativos à demanda escolar nos 62 Municípios do Estado desde 2004. Constatando desta forma, quantativamente que milhares de amazonenses estudavam até 0 ensino fundamental e não prosseguia nos seus estudos, por diversos motivos como a falta de escola nas comunidades que oferecesse ensino médio, a exclusão de muitas comunidades rurais pela dificuldade de acesso (transporte) até as zonas urbanas e pelo fornecimento irregular de energia. Enfim, as características geográficas da própria região são fatores que resultam nos obstáculos encontrados e que precisam ser vencidos. 
A SEDUC encontrou então uma solução para atender tamanha demanda de alunos excluídos socialmente, a idéia era então ensinar pela TV utilizando recursos tecnológicos com transmissão por satélite, utilizando a vídeo-conferência como ferramenta pedagógica e metodologia presencial com mediação tecnológica de forma inédita no mundo. Foi criado e implantado então o ensino médio via satélite.

O Centro de Mídias ${ }^{10}$ da SEDUC foi criado em 2007, ampliando e diversificando o atendimento escolar e utilizando uma solução tecnológica disponível com ênfase nas mídias educacionais, no sistema público e voltado para a Educação Básica.

As aulas são transmitidas através do Centro de Mídias via satélite para as comunidades rurais do estado do Amazonas, que acontecem por meio do sistema de IP.TV ${ }^{\circledR 11}$, com recursos interativos de som, imagens e dados.

O Centro de Mídias está localizado em Manaus, onde ficam os professores titulares das componentes curriculares (nome denominado a uma disciplina), responsáveis pela elaboração das aulas que são transmitidas pela TV e demais atividades, ou exercícios. Na outra ponta, ou seja, nos municípios encontram-se os professores tutores que desempenham o papel de mediador e facilitador, responsáveis por coordenar os alunos nas salas de aula, minimizar as dúvidas dos alunos, acompanharem o aprendizado, realizar frequência, coordenar as atividades, realizar a aplicação de provas entre outros.

As aulas são planejadas pelos professores que podem explorar todos os recursos tecnológicos disponíveis visando facilitar a assimilação do conteúdo pelo aluno. São utilizados recursos como trechos de filmes, obras de artes, animações em 3D, etc.

$\mathrm{Na}$ figura 2 é possível visualizar a interatividade realizada entre professor e alunos no modelo de IP.TV ${ }^{\circledR}$ adotado pela SEDUC. A imagem transmitida pela TV, mostra do lado esquerdo o professor do estúdio em Manaus e do outro lado o aluno localizado no interior do estado, realizando uma interatividade.

\footnotetext{
10 http://www.cemeam.com.br/

11 http://www.ip.tv/iptv_site/ptb/index.htm
} 


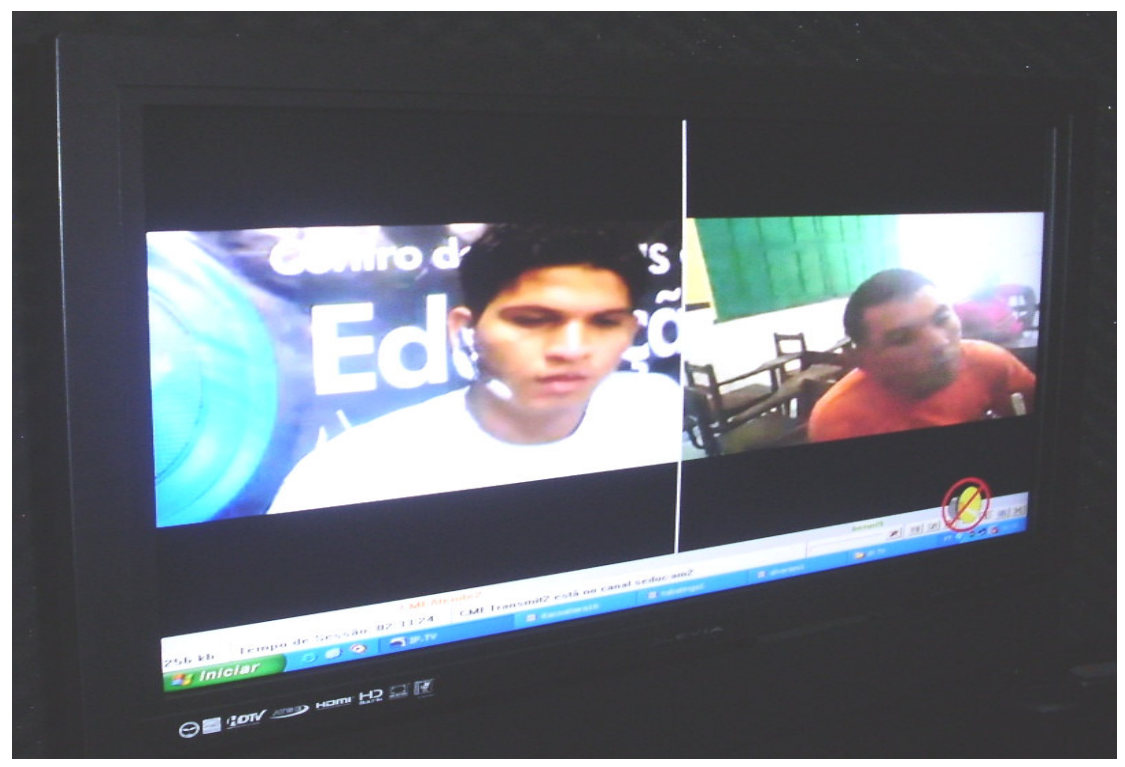

Figura 2 - Interatividade realizada no Centro de Mídias da SEDUC.

Fonte: Foto tirada durante visita realizada no Centro de Mídias da Seduc - AM, Março 2009.

O Centro de Mídias da SEDUC foi ganhador pelo terceiro ano consecutivo do prêmio $^{12}$ de Educação à Distância E-Learning ${ }^{13}$, sendo vencedor e indicado como referência nacional. A modalidade é sem dúvida inédita e está recebendo seus méritos, pois está conseguindo solucionar um problema de demanda de alunos para cursarem o ensino médio, residentes em áreas remotas e de difícil acesso localizadas nos interiores do estado do Amazonas.

Os maiores desafios encontrados na implementação deste modelo foi à aprovação da metodologia no Conselho Estadual de Educação, uma vez que o modelo não utiliza uma proposta de EAD clássica.

Além de outros desafios enfrentados pela secretaria podem ser citados alguns como: as instalações das antenas nos interiores do estado, a montagem de todas as salas de aulas, o transporte escolar dos alunos até as sedes devem ser garantidos,

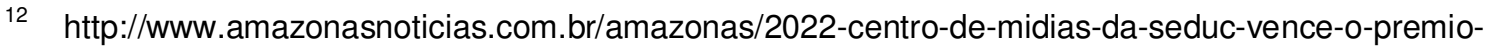
e-learning-brasil-pelo-terceiro-ano-consecutivo.html

${ }^{13}$ É o maior prêmio de EAD e Tecnologia Educacional do país, organizado pela MicroPower e Microsoft.
} 
sendo a que maioria deles desloca-se por via fluvial. Outro desafio que se pode citar são os geradores de energia elétrica que foram enviados para as sedes em virtude da falta de energia elétrica constante nos interiores do estado.

Os professores que ministram aula neste contexto são professores efetivos da rede pública estadual, selecionados e capacitados para atuarem nesta modalidade, todos passaram por um processo de seleção, e residem no interior do estado, sendo a maioria professores formados pelo projeto do PROFORMAR.

Os professores formados pelo projeto PROFORMAR foi um requisito que contou bastante na hora da seleção, pois foi levada em consideração a experiência obtida pelos profissionais com este modelo de ensino. Além da dificuldade de se ter professores, com nível de formação superior locados no interior do estado.

A SEDUC conta com uma equipe qualificada, os professores titulares das disciplinas elaboram seus planos de aulas podendo contar com uma assessoria pedagógica. As aulas passam por um processo de roteirização, momento este que o conteúdo passa por um processo de adaptação para a linguagem televisiva.

É na Central de Produção Educativa para TV que são geradas centenas de objetos de aprendizagem, antes de editar o conteúdo os editores realizam a pré-produção, edição de arte, áudio e vídeo fatores necessários para a realização da transmissão das aulas, com base em um roteiro preparado pelo professor.

\subsubsection{Infraestrutura do Centro de Mídias}

A infraestrutura do Centro de Mídias e dos Municípios do interior do Estado permitiu a ampliação de atendimento aos alunos amazonenses na capital e no interior.

Uma Central de Produção Educativa para TV transmite diariamente aulas ao vivo, por meio de uma TV interativa por IP, conectada a uma rede via satélite de 306 VSATs bidirecionais, o que permite a interatividade entre mais de 500 salas de aula. 
Nas escolas, em cada sala de aula, há um kit tecnológico composto por: computador, impressora, Webcam, microfone, telefone, impressora, "no break" e um televisor LCD de 42".

Em cada escola localizada nos municípios há uma Antena VSAT bidirecional, um roteador-receptor de satélite e cabeamento estruturado (LAN). A figura 3 a seguir mostra a antena instalada na região que recebe o sinal de recepção das aulas.

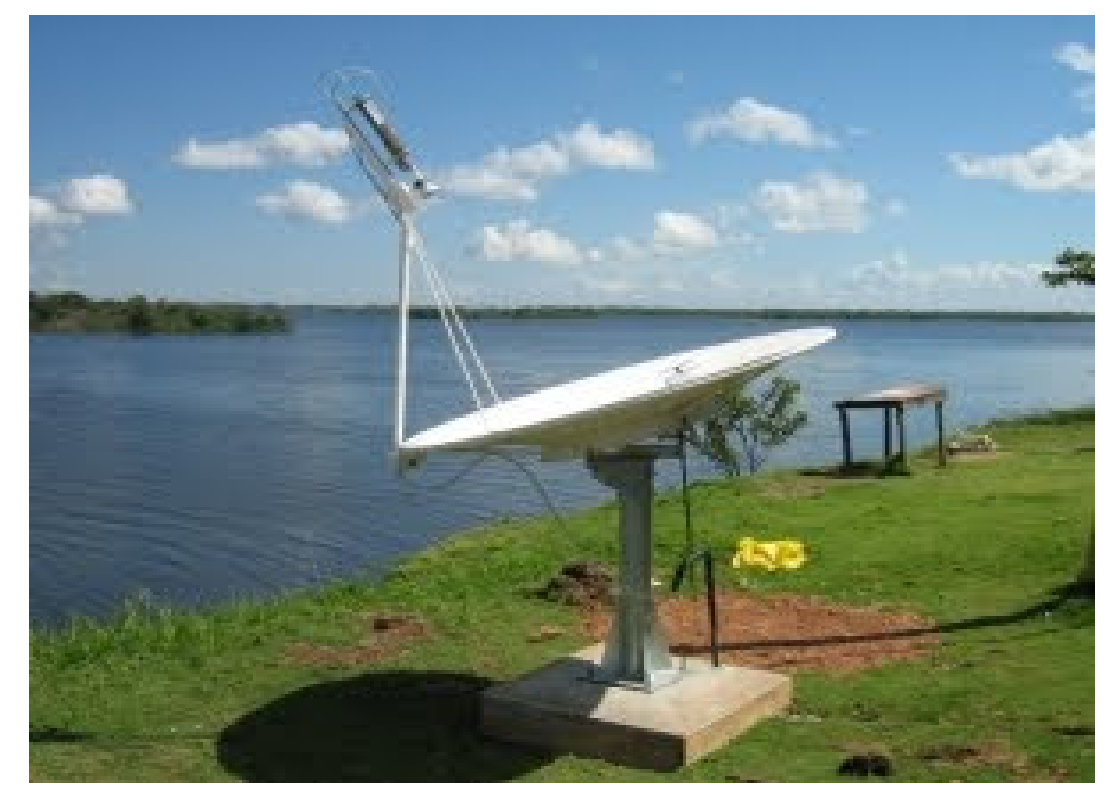

Figura 3 - Antena VSAT responsável pela recepção das aulas nos municípios.

Fonte: (Knol,2009)

O acesso à Internet, disponível em todas as salas, complementa a Plataforma Tecnológica com modernos serviços de comunicação. A carga horária do curso é idêntica à do ensino regular consistindo em 200 dias de aula por ano. A diferença está na mediação tecnológica e na preparação das aulas, resultado de um projeto educacional diferenciado.

Como resultado inicial, 10 mil alunos de 42 municípios puderam continuar seus estudos e cursar o $1^{\circ}$ ano do Ensino Médio em 2007 e 17 mil alunos de todos os 62 municípios amazonenses estão cursando o $1^{\circ}$ e $2^{\circ}$ ano em 2008, nas suas próprias comunidades. (KNOL, 2009) 
No ano de 2009, foi oferecido o $3^{\circ}$ ano do ensino médio e turmas do $3^{\circ}$ ano do ensino fundamental com crianças na faixa de 9 a 10 anos com um sucesso positivo. A primeira formatura aconteceu dia 5 de Março de 2010, e foi transmitida ao vivo para os 62 municipios da região.

A SEDUC (2009) em seu Portal relata que expandiu seu contrato com a americana HUGHES $^{\circledR 14}$, ampliando novamente o número de estações de satélites que compõem o projeto "Ensino médio presencial com mediação tecnológica", aumentando a quantidade de canais, e dobrando a capacidade de banda larga de Internet.

É um projeto pioneiro no mundo quando se trata de educação básica. O retorno obtido com este projeto superou as expectativas da própria SEDUC, que só vem ampliando a quantidade de comunidades que estão sendo atendidas.

As aulas são ministradas diariamente, a partir do Centro de Mídias da Seduc em Manaus para mais de 17 mil estudantes e transmitidas via satélite, esta tecnologia possibilita que professores e alunos interajam como se estivessem compartilhando 0 mesmo espaço físico.

\subsection{SISTEMA PRESENCIAL MEDIADO POR TECNOLOGIA - UEA}

A UEA tem como foco trabalhar com cursos superiores e investe maciçamente na formação de seus alunos. Os objetivos de cursos de graduação refletem a linha de pensamento que a UEA sustenta na implementação de seus cursos uma vez que estimula o desenvolvimento de uma mentalidade científica, de modo que se possa assumir uma postura investigativa frente aos fenômenos.

Nas últimas décadas, pode-se presenciar a rápida evolução das TICs (Tecnologia de Informação e Comunicação), o que gerou vários produtos que incrementaram a interatividade associada aos programas de formação à distância, principalmente

14 http://www.hughes.com.br/ 
aqueles assistidos por computador e satélite, alavancando o aumento da interatividade entre estudantes e professores.

Esta nova abordagem educacional, que enfatiza o modelo de educação à distância abre espaço para que o acesso passe a ser remoto em ambientes interativos.

O tratamento e a difusão de conteúdos passam a ser editadas em uma linguagem televisiva, permitindo que a gestão do conhecimento passe a ser administrada pelo aluno.

Quando um professor ministra uma disciplina em sala de aula, temos um sistema presencial com uma retroalimentação imediata. Esse fator é importantíssimo para a melhoria da qualidade do ensino.

No SPMT-UEA, observam-se alguns obstáculos enfrentados pelos docentes no decorrer de suas atividades, tais como:

- Ministrar aulas frente a várias câmeras;

- Não tem um retorno imediato do andamento da sua aula;

- Não conhece os seus alunos, tão pouco sabe o seu nome, sua idade, seu perfil, ou seu nível de conhecimento;

- Não pode medir conhecimento e/ou dificuldades;

- Divide metodologias e assuntos a serem ministrados com outros colegas;

- Não conta com recursos interativos para lançar desafios individuais e com uma realimentação imediata;

Vale ressaltar que é uma experiência desafiante para qualquer docente, alguns questionamentos são levantados, tais como:

- Será que o professor está preparado para ministrar aulas na televisão?

- O professor nunca ministrou uma aula pela TV. Será que ele sabe qual postura adotar e como preparar o material para suas aulas? 
- Como minimizar tamanho impacto por parte do professor quando este é colocado pela primeira vez frente às câmeras?

Litto (2009) comenta em seu trabalho sobre a formação de professores e especialistas em EAD, retratando que sendo ou não tecnólogo, o profissional hoje perpassa a dimensão técnica, a dimensão humana, o contexto político-econômico e a parte de conhecimentos a serem transmitidos.

O professor que faz parte deste processo educacional deve necessariamente: saber o que fazer; conhecer bem a teoria e a prática; e estar ciente dos princípios e de todo processo da tecnologia educacional utilizada.

A este profissional podemos denominar de "Tecnólogo educacional", é um novo tipo de educador, onde sua capacidade de agir esteja baseada num processo científico.

Os professores e os alunos estão expostos a um cenário culturalmente novo, portanto o educador precisa ter domínio do conteúdo e da metodologia a ser empregada no decorrer de suas aulas, possibilitando assim que as aulas possam fluir naturalmente com qualidade e sincronia.

A UEA vem destacando-se nesta modalidade de ensino, pois através deste sistema muitos profissionais estão se qualificando e levando para suas comunidades um saber diferenciado, levando o conhecimento e tornando possível muitos sonhos jamais imaginados.

\subsubsection{Infraestrutura}

Os projetos do sistema presencial mediado por tecnologia da UEA oferecem suporte operacional para os cursos como plataforma tecnológica, produção das aulas, corpo docente e técnico, divergindo entre os cursos plataformas e equipamentos, dependendo do curso em questão, pois cada um necessita de recursos específicos.

As especificações vistas nas tabelas 1, 2 e 3 são referentes aos cursos presenciais mediados por TV oferecidos pela UEA, porém vale ressaltar que dependendo do 
curso, serão adicionados ou removidos: equipamentos tecnológicos, operacionais, corpo docente, técnico etc.

Tabela 1 - Plataforma tecnológica do SPMT - UEA.

\section{PLATAFORMA TECNOLÓGICA}

\begin{tabular}{l|l|l}
\hline Equipamentos & $\begin{array}{l}\text { Televisor 42", } \\
\text { Video-cassete, } \\
\text { Micro-computador, } \\
\text { Impressora. } \\
\text { Telefone-fax. }\end{array}$ & $\begin{array}{l}\text { Em cada sala de aula; } \\
\text { Por unidade, ligada a uma central } \\
\text { telefônica; } \\
\text { Antena parabólica. } \\
\text { Gerador de energia. }\end{array}$ \\
$\begin{array}{l}\text { Em cada unidade da UEA; } \\
\text { Em cada município em virtude de } \\
\text { oscilação de energia elétrica, } \\
\text { freqüente no interior do estado. }\end{array}$ \\
\hline
\end{tabular}

Em meados de Agosto de 2009, um novo sistema interativo foi instalado. A Universidade conta agora com um Kit tecnológico idêntico ao utilizado no presencial mediado do ensino médio da Seduc, comentado na seção 2.2.1. Todas as salas de aulas de todos os municípios onde a UEA transmite aulas no modelo presencial mediado por TV, possuem a antena e o kit tecnológico.

$\mathrm{Na}$ figura 4 é possível visualizarmos a plataforma tecnológica em uso no município de Manacapuru interior do Amazonas, na aula transmitida no dia 03/11/2009 do Curso de Tecnologia em Análise e Desenvolvimento de Sistemas da UEA. 


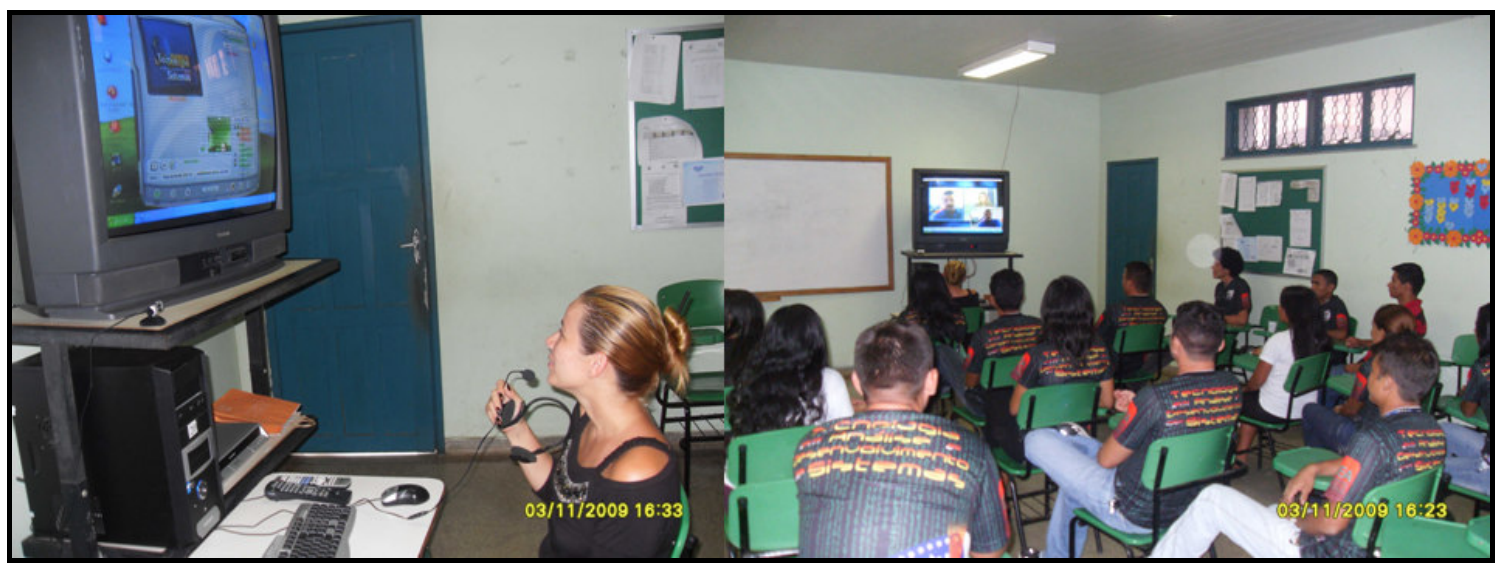

Figura 4 - Transmissão da aula interativa via IP.TV ${ }^{\circledR}$ - UEA.

Fonte: Aulas do Curso TADS - UEA (2009) adaptado.

Esta plataforma chama-se IP.TV ${ }^{\circledR}$, baseada em software de TV interativa e vídeoconferência que opera em redes IP. Em seu ambiente operacional, um usuário é capaz simultaneamente e em tempo real, de acessar e gerar vários tipos de informações como: a realização de videoconferência; enquetes com resultados gerados em forma de gráficos e de dados; utilizar quadro digital e interagir com os demais usuários em sessão; transmitir vídeos pré-gravados a partir de outros equipamentos tecnológicos como DVD; VHS; filmadoras; entre outros; trocar mensagens via chat (público e privado);

A IP.TV ${ }^{\circledast}$ (2009) é a primeira operadora de redes e canais digitais de TV Interativa por IP. Sua plataforma consiste numa solução que engloba uma estrutura de telecomunicações, hardware e software, dedicada a gerenciar a transmissão de pacotes (pequenas unidades de informação) via quaisquer circuitos IP (acesso discado, linha privado, adsl, satélite, etc).

Pode-se também realizar transmissão através de unidades remotas, utilizando uma antena bidirecional fácil de ser montada e transportada. Na figura 5 a seguir é possível visualizar a topologia das redes IP.TV ${ }^{\circledR}$ e suas descrições. 


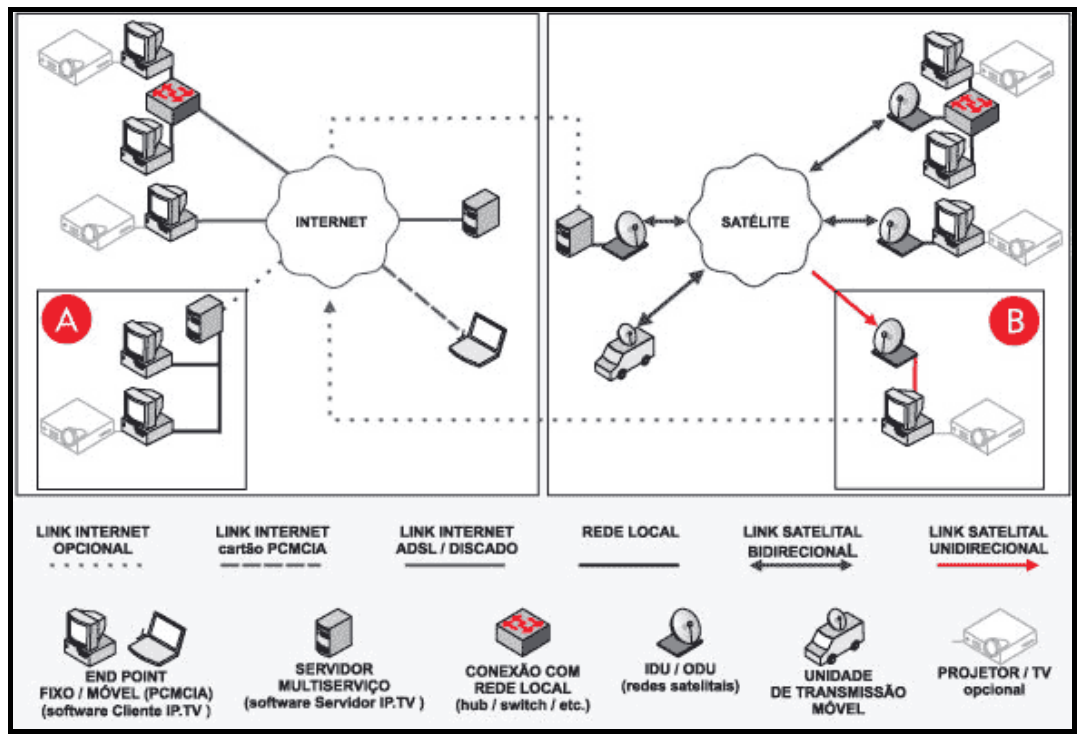

A - Ponto em rede local : Permite que um canal exista apenas em uma rede local. Opcionalmente, com um link Internet, este ponto também passa a interagir com canais fora desta rede
B - Ponto satelital unidirecional : Permite apenas o recebimento da transmissão. Opcionalmente, com um link Internet, este ponto também passa a transmitir.

Figura 5 - Topologia da Plataforma IP.TV ${ }^{\circledR}$.

Fonte: IP.TV ${ }^{\circledast}(2009)$

Tabela 2 - Produção de aulas do SPMT - UEA.

\begin{tabular}{l|l}
\hline $\begin{array}{c}\text { PRODUÇÃO DE AULAS } \\
\text { Televisádio de }\end{array}$ & $\begin{array}{l}\text { Permite a transmissão das aulas para todo o estado e viabiliza a } \\
\text { preparação de recursos didáticos em múltiplas linguagens: } \\
\text { filmes, documentários, ilustrações e animações, pesquisadas } \\
\text { e/ou produzidas para o curso. }\end{array}$ \\
$\begin{array}{l}\text { Central de } \\
\text { Atendimento }\end{array}$ & $\begin{array}{l}\text { Com telefonistas que atendem às ligações e, após a triagem, } \\
\text { remetem-nas aos Professores Titulares ou às Equipes Técnicas, } \\
\text { conforme o caso. }\end{array}$ \\
\hline
\end{tabular}


Tabela 3 - Corpo docente e técnico do SPMT - UEA.

\section{CORPO DOCENTE E TÉCNICO}

Professor

Titular

Professor

Assistente

Coordenação

Geral

Coordenação

Pedagógica

Coordenação

de

Tecnologia

Educacional
São três professores por disciplina, responsáveis pela produção dos materiais didáticos, explanação das aulas ao vivo, pela TV, elaboração das avaliações e correção da prova final.

Em cada município há um professor assistente ficando responsável pela mediação das aulas. Controlam a freqüência dos alunos, organizam e supervisionam as dinâmicas locais, orientam os alunos no estudo, realizam a aplicação das avaliações, correção e lançamento das provas.

Responsável pela administração geral do projeto, com incumbência de planejar, acompanhar, avaliar e monitorar os níveis desejados de qualidade e satisfação.

Responsável pela seleção e capacitação dos professores assistentes e pelo acompanhamento pedagógico do Curso.

Responsável pela preparação dos professores titulares para atuarem na TV, roteirização e produção das aulas 
A figura 6 mostra os alguns dos profissionais listados na tabela 3, preparando suas atividades no estúdio da UEA, momentos antes do inicio da transmissão das aulas.

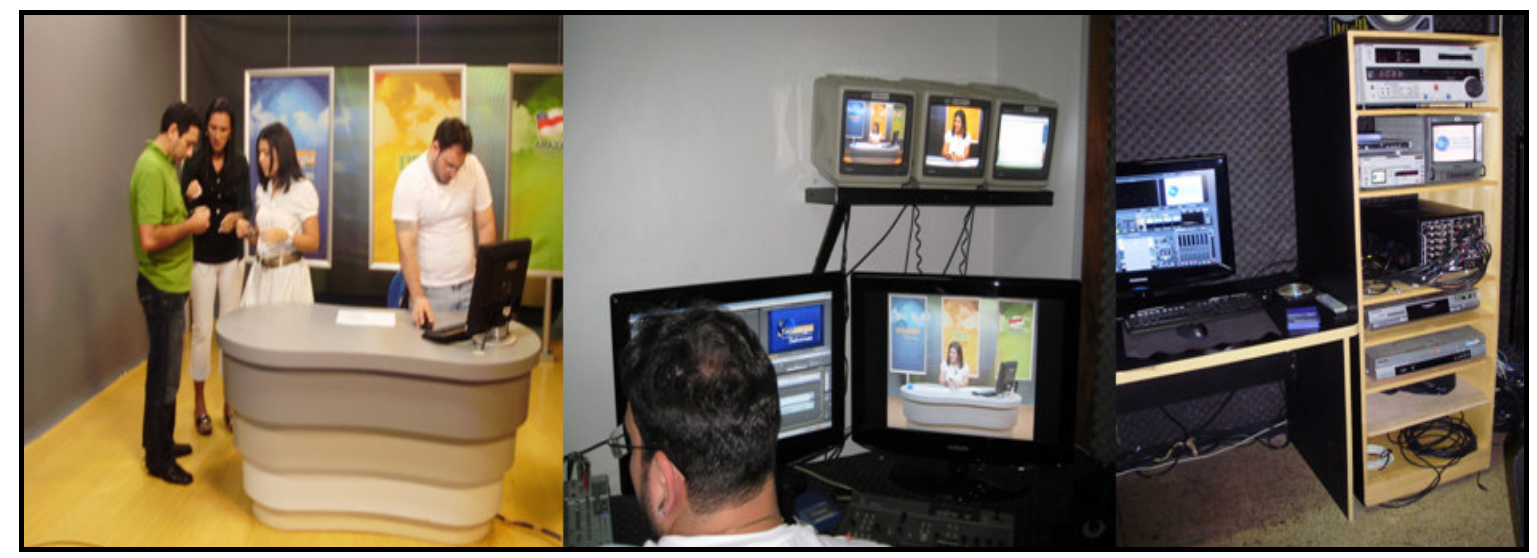

Figura 6 - Momentos iniciais da transmissão de aula do estúdio de Televisão da UEA.

Fonte: Aulas do Curso TADS (Tecnologia em Análise e Desenvolvimento de Sistemas) - UEA

\subsubsection{A transmissão das aulas}

A transmissão das aulas dos Cursos do SPMT da UEA ocorre em um estúdio de televisão da própria universidade, em tempo real e seguindo um roteiro padrão montado pelos professores titulares, obedecendo a limites de tempo, composto de intervalo e um horário estimado para a realização das dinâmicas locais.

Cada disciplina ministrada é composta por três professores titulares, responsáveis pela elaboração do material didático, dos roteiros das aulas e correção das avaliações finais.

Em cada unidade do interior estão locados professores denominados assistentes que exercem a função de monitores das aulas, e também dão retorno ao professor titular das aulas ministradas, exercícios propostos e resolvidos, exemplos mostrados, avaliações a serem realizadas e freqüência, esta retroalimentação permite ao titular avaliar seu desempenho e obter uma visão parcial do aprendizado dos alunos. 
$\mathrm{Na}$ sede da UEA situada na capital do Estado se encontram as coordenações dos cursos, que são compostas pela seguinte equipe: coordenação geral, pedagógica, de tecnologia educacional, projeto gráfico, revisão, secretárias e assistentes. As aulas são realizadas ao vivo pelos professores titulares e transmitidas do estúdio da UEA via satélite às localidades remotas distribuídas pelo interior do estado. (Mourão, 2009)

\subsubsection{Empresa Prestadora de Serviços de Telecomunicações}

A HUGHES ${ }^{\circledR}$ é a empresa que fornece serviços corporativos de telecomunicações para a UEA.

O estúdio de televisão em Manaus é o local onde os professores titulares ministram suas aulas e o sinal é transmitido para a empresa HUGHES ${ }^{\circledR}$ em São Paulo, onde esta distribui o sinal via satélite para os municípios onde são transmitidas as aulas. Na sala técnica conhecida como "ilha" se encontram os técnicos responsáveis pelo controle, produção e tratamento das imagens, do som, e dos conteúdos referenciados como "cartelas".

\subsubsection{Visão Pedagógica}

O modelo de aprendizagem SPMT da UEA apresenta uma afinidade com a pesquisa realizada pelo autor Vaughan (2007), que relata que os alunos de ensino superior indicam que um modelo de aprendizado blended proporciona-lhes uma maior flexibilidade de tempo e melhores resultados de aprendizagem, mas que, inicialmente, encontram problemas na gestão de tempo, tendo uma maior responsabilidade por sua própria aprendizagem, e utilização de tecnologias sofisticadas. 
A metodologia utilizada nos cursos do ensino presencial mediado por tecnologia é aplicada baseada na disposição do quadro funcional dos cursos constituídos por professores titulares e assistentes; coordenadores: do curso e o de qualidade de ensino; do coordenador pedagógico; dos assistentes pedagógicos e dos demais funcionários e técnicos que complementam o quadro (descritas na tabela 2.3), cada um realizando suas atividades especificas que somam um esforço necessário para o bom andamento do projeto e cumprimento dos requisitos necessários para o aprendizado dos alunos.

O processo pedagógico inicia com a seleção dos professores atuantes na área e que apresentam conhecimento especializado sobre a disciplina em questão.

A ementa da disciplina é repassada para os três professores titulares da disciplina que em grupo irão dividir assuntos e tarefas; realizar o roteiro das aulas obedecendo às datas e os horários; elaborar todas as provas e exercícios a serem lançados; alimentar o ambiente virtual de aprendizagem com enquetes, artigos, apostilas, slides, fórum, wikis, vídeos, entre outros meios necessários para estimular e ampliar o conhecimento do aluno.

O TADS (Curso de Tecnologia em Análise e Desenvolvimento de Sistemas) da UEA possui um ambiente virtual de aprendizagem ${ }^{15}$ que tem como objetivo fornecer aos alunos do curso um ensino de extensão, onde os alunos podem contar com mais uma ferramenta de apoio ao processo de ensino-aprendizagem.

O Curso de Licenciatura em Matemática ${ }^{16}$ possui um site na Internet onde disponibiliza noticias, exercícios, banco de questões, entre outras informações necessárias para os alunos e demais interessados.

Os alunos da instituição podem contar também com uma biblioteca e com laboratórios montados em cada unidade de ensino. A biblioteca possui um acervo

\footnotetext{
15 http://tads.uea.edu.br/moodle19/moodle/login/index.php

16 http://www.suporteeducacional.com.br/matematica/
} 
de no mínimo cinco títulos por disciplina, com dois exemplares cada, a serem relacionados pelos professores titulares.

Os laboratórios onde ocorrem as aulas práticas (de Informática e Educação Física) estão equipados igualmente em todos os municípios e configurados para atender as necessidades dos professores e alunos.

O ensino por TV requer habilidades diferentes, a equipe pedagógica dos cursos trabalham cotidianamente para conhecê-la, e incorporá-la ao contexto pedagógico.

A abordagem pedagógica necessária da TV não se deve limitar ao suporte físico, recurso usual na prática escolar com os meios. Precisa-se incorporá-la em sua dimensão cultural, objeto de estudo de seus processos de produção e de recepção, e linguagem. É dessa forma, que os professores dos cursos elaboram seus livros e exercícios, explorando a cultura e a linguagem das comunidades Amazônidas ${ }^{17}$.

17 Termo popularmente utiizado, quando se refere à população do Amazonas. 


\section{TECNOLOGIAS VOLTADAS AO SUPORTE DO ENSINO}

As Tecnologias da Informação e Comunicação - TIC utilizadas em massa estão sendo incorporadas expressivamente no cotidiano das pessoas, apresentando recursos e funcionalidades que permitem a diversas áreas, dentre elas a educação explorar e agregar ao modelo educacional ferramentas poderosas que auxiliem no processo de ensino-aprendizagem.

Os paradigmas que lastreiam as mudanças na prática pedagógica com o uso de novas tecnologias perpassam pela pesquisa e pela produção, proporcionando uma metodologia e uma experiência renovadora no âmbito da educação. (LOPES, 2009)

\subsection{EDUCAÇÃO À DISTÂNCIA}

A EAD no Brasil foi impulsionada pelo artigo 80 da Lei de Diretrizes e Bases da Educação Nacional - LDB $^{18}$ que dispõem: "O Poder Público incentivará o desenvolvimento e a veiculação de programas de ensino à distância, em todos os níveis e modalidades de ensino, e de educação continuada." e a partir de então, a EAD passa a ser incluída nas políticas públicas de ensino.

Um novo modelo de educação atinge um número elevado de pessoas em lugares onde a educação era uma busca almejada, comentada e tão somente sonhada. Isso se deve ao desenvolvimento e ao progresso tecnológico que vem possibilitando o baixo custo ao acesso, à aquisição de equipamentos e a serviços de Internet.

As TIC's são compostas de ferramentas com um alto poder de aceitação em diversas áreas, principalmente na área da educação. Permitiu assim o desenvolvimento de softwares educacionais que podem ser utilizados em Sistemas Gerenciadores de Aprendizagem - SGA.

18 http://portal.mec.gov.br/arquivos/pdf/ldb.pdf 
Os aparatos tecnológicos contribuem crescentemente para que cursos na área de Educação à Distância se estabeleçam no mercado atual e ofereçam cursos com qualidade e satisfação direcionados para um público alvo específico.

As Instituições de Ensino Superior estão sendo diretamente influenciadas pelo impacto causado pelas tecnologias da informação e da comunicação, e com isso começam a oferecer cursos à distância para atender diferentes perfis de usuários. $O$ processo educacional vive uma nova geração, onde as instituições são cobradas a oferecer um macro acesso ao conhecimento e a qualificação profissional.

O processo de ensino-aprendizagem nos tempos atuais permite e exige a utilização adequada de recursos tecnológicos de ponta, que auxiliem e contribuam para um ensino de qualidade.

A Educação à Distância é um modelo que exprime bem a utilização de ferramentas didáticas e ambientes de aprendizagem. Caracteriza-se pelo oferecimento de uma educação diferenciada e que vem obtendo uma elevada demanda e uma aceitação satisfatória e crescente pela comunidade acadêmica em geral.

As interações entre professor e aluno neste processo, podem ser síncronas ou assíncronas, ambas fornecem um retorno e uma motivação aos alunos, e auxiliam em tomadas de decisões relacionadas diretamente com o seu aprendizado.

Os métodos pedagógicos se integram aos meios tecnológicos e juntos caminham em direção a inclusão social e digital da população. Os recursos da comunicação mediada pelo computador ou por tecnologia permitem novas abordagens educacionais amplas e divergentes que inferem diretamente na forma de ensinar e aprender. Exigindo dos professores e tutores habilidades, domínio e muita imaginação, para tornar o conteúdo que se tem em mãos, um acervo rico em conhecimento.

A Educação quando mediada por recursos da Internet (tecnologias digitais) é responsável pela geração de um novo espaço sem a presença física do educador.

O crescimento na oferta e demanda de cursos de especialização no Brasil tem sido notável, em especial, no que se refere a cursos a distância, por razões de 
praticidade e facilidade de acesso, especialmente em regiões remotas, pouco providas de ensino superior. (LEITE, 2009)

A Educação à Distância compõe um novo paradigma educacional, e dá ênfase à colaboração, cooperação e comunicação. As inovações tecnológicas aliadas a ações pedagógicas e quando combinadas com estratégias de ensino tendem a aumentar a qualidade do ensino. Tais combinações permitem a construção do conhecimento na referida modalidade.

A implantação de cursos na modalidade de educação à distância, quando subsidiada pelas tecnologias da informação e comunicação requerem como requisitos essenciais: um Sistema Gerenciador de Aprendizagem ou um Ambiente Virtual de Aprendizagem, um rico material didático elaborado com qualidade, além da utilização de uma metodologia de ensino apropriada.

Litto (2009) comenta que há muito ainda a ser feito nessa área, porém os últimos resultados demarcam tendências positivas de progresso, que visa beneficiar a sociedade como um todo.

\subsection{SISTEMAS GERENCIADORES DE APRENDIZAGEM}

Os Sistemas Gerenciadores de Aprendizagem, conhecidos como LMS (Learning Management Systems) são ambientes integradores de ferramentas com o propósito de prover mecanismos e ferramentas que suportem o aprendizado eletrônico na Web. (ZAINA, 2008)

Os LMS caracterizam-se pelas suas funções interativas que possibilitam a aprendizagem à distância dos alunos e a condução pelos professores do processo de aprendizagem através da Internet. O sistema provê o acesso a serviços de aprendizagem on-line, permitindo um maior controle e fornecimento de conteúdo de aprendizagem, ferramentas de comunicação e coordenação de usuários em grupos. 
Os sistemas gerenciadores de aprendizagem surgiram no intuito de suportar o processo de ensino e aprendizagem através da Internet. Conforme Zaina (2008) o desenvolvimento dos LMS necessita da adoção de especificações padronizadas para descrição das entidades de ensino e do funcionamento destas (como SCORM, LOM e Learning Design).

Em função destes ambientes é possível organizar de forma gerencial os cursos, definir e mesclar os tipos de aula, integrar novas ferramentas e escolher qual delas utilizar dependendo do curso a ser oferecido, construindo um espaço de ensinoaprendizagem com toda uma infra-estrutura permitida.

As formas de comunicação que são possíveis nesses ambientes são a: síncrona e a assíncrona. A comunicação síncrona ocorre simultaneamente e em tempo real, porém a assíncrona não ocorre em tempo real, ocorrendo um tempo entre o envio da mensagem e a sua resposta.

A quantidade de ferramentas disponíveis para $L M S$ cresce consideravelmente, dentre elas podemos citar: chats, fóruns, conferências, arquivos de textos, wikis, blogs, diário de bordo, grupo, mural dentre outros. Um LMS apresenta muitas vantagens, que resultam no sucesso do modelo.

Neste ambiente é possível se ter um controle de acesso dos alunos do curso, em relação ao conteúdo, aos recursos interativos e de avaliação. É possível realizar a liberação do acesso aos conteúdos como: criação de sites, leitura de artigos, material impresso, vídeo-aulas, áudio, animações, glossários, entre outros. E também o acesso às ferramentas (fóruns, enquetes e chat's, entre outras).

$O$ adequado gerenciamento desses ambientes possibilita o acesso e uso adequado das ferramentas de avaliação, de correção de exercícios e trabalhos, da realização de comentários, do estabelecimento de prazos e horários para a aplicação ou recebimento de avaliações. 
Gerenciamento e monitoramento são palavras-chaves neste cenário, onde o professor é o gerenciador principal. Cabe a ele administrar com excelência os cursos, o conteúdo, as avaliações, as participações e todas as atividades planejadas para serem cumpridas pelo curso em questão.

\subsubsection{Ambientes de Aprendizagem}

No contexto de Educação à Distância, alguns Ambientes de Aprendizagem se destacam, por sua importância, por seu uso, por suas funcionalidades, e por suas inúmeras aplicabilidades.

Os ambientes e sistemas de ambientes de aprendizagem aqui listados foram escolhidos pela ampla funcionalidade apresentada e por serem os mais conhecidos e utilizados. Há muitos no mercado, porém alguns são mais evidentes e destacamse pelas muitas funcionalidades, portabilidade e manutenibilidade apresentadas.

$\mathrm{Na}$ tabela 4 a seguir foi realizada uma adaptação encontrada em Franciscato (2008) que apresenta uma comparação entre três dos ambientes virtuais apresentados nas próximas seções (onde foi o inserido o Aulanet), sendo possível visualizar uma comparação das ferramentas presentes nos ambientes TIDIA Ae ${ }^{19}$ (desenvolvido pelo grupo TIDIA e financiado pela FAPESP), Teleduc $^{20}$ (desenvolvido pela UNICAMP), Aulanet ${ }^{21}$ (desenvolvido pela PUC) e o Moodle $^{22}$ (projeto de código aberto).

\footnotetext{
19 http://tidia-ae.usp.br/portal

20 http://www.teleduc.org.br/

21 http://www.eduweb.com.br/elearning_tecnologia.asp

22 http://moodle.org/
} 
Tabela 4 - Comparação entre as ferramentas utilizadas em AVA.

\begin{tabular}{|c|c|c|c|c|c|c|c|c|c|c|c|c|c|c|c|c|c|c|c|c|c|}
\hline & $\begin{array}{l}\frac{\pi}{0} \\
\frac{0}{0} \\
\frac{0}{4}\end{array}$ & 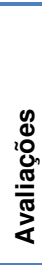 & 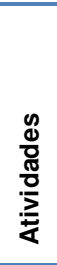 & 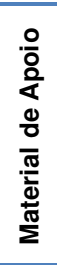 & 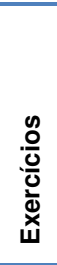 & 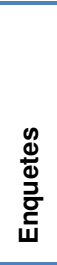 & $\begin{array}{l}\overline{\widetilde{\Xi}} \\
\bar{\Sigma}\end{array}$ & 웅 & 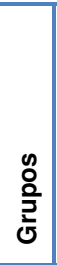 & ह气 & $\begin{array}{l}\frac{\pi}{0} \\
\frac{\pi}{0}\end{array}$ & $\begin{array}{l}\overline{\overline{\bar{d}}} \\
\mathbf{Q}\end{array}$ & $\begin{array}{l}\stackrel{0}{0} \\
\stackrel{0}{0} \\
\frac{0}{0} \\
\frac{\pi}{0} \\
\check{x}\end{array}$ & 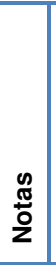 & $\stackrel{\circ}{\stackrel{2}{J}}$ & 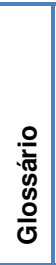 & $\frac{\circ}{\overline{0}}$ & 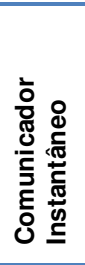 & 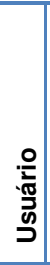 & $\bar{s}$ & $\frac{\pi}{0}$ \\
\hline AulaNet & $X$ & $X$ & $x$ & $x$ & $x$ & $x$ & $X$ & $X$ & $X$ & $X$ & $X$ & $X$ & $X$ & $X$ & $X$ & $X$ & & $X$ & $X$ & & $X$ \\
\hline Moodle & $X$ & $X$ & $x$ & $x$ & $x$ & $X$ & $x$ & $X$ & $X$ & $X$ & $X$ & $X$ & $x$ & $X$ & $X$ & $X$ & $X$ & & $\mathrm{X}$ & $X$ & $X$ \\
\hline Teleduc & $X$ & $X$ & $X$ & $x$ & $X$ & $X$ & $X$ & $X$ & $X$ & $X$ & $X$ & $X$ & $X$ & $X$ & & & & & $\mathrm{X}$ & & $X$ \\
\hline TIDIA-ae & $X$ & $X$ & $X$ & $X$ & $X$ & $x$ & $x$ & $X$ & $X$ & $X$ & $X$ & $X$ & $x$ & $X$ & & $X$ & $X$ & $X$ & $\mathrm{X}$ & $X$ & $X$ \\
\hline
\end{tabular}

Fonte: Franciscato, 2008 (Adaptado).

\subsubsection{Tidia-Ae}

O TIDIA Ae (Tecnologia da Informação no Desenvolvimento da Internet Avançada Aprendizado Eletrônico) é um sistema que auxilia as atividades de aprendizado eletrônico, oferecendo suporte ao ensino presencial. É financiado pela Fundação de Amparo à Pesquisa do Estado de São Paulo - FAPESP ${ }^{23}$, e utiliza a infra-estrutura do Sakai ${ }^{24}$ que é um projeto internacional. Este projeto está associado ao IMS e ao Sakai que são instituições internacionais que discutem de forma colaborativa o uso das tecnologias e seus resultados nas atividades educacionais.

O TIDIA Ae é uma iniciativa de pesquisa e desenvolvimento financiada pela FAPESP dentro do programa TIDIA, cujo objetivo é promover a formação de recursos humanos e a produção cientifica e tecnológica na área de tecnologia da informação aplicada à educação explorando características da Internet Avançada.

\footnotetext{
23 http://www.fapesp.br/

24 http://www.sakaiproject.org
} 
Proporciona um ambiente composto por ferramentas que suportam o Aprendizado Eletrônico e disponibiliza uma gama de recursos para a criação cooperativa de conteúdos digitais abertos, de interesse acadêmico, tecnológico ou social.

$\mathrm{Na}$ figura 7 a seguir é possível visualizarmos a página inicial do Sistema Gerenciador de Aprendizagem TIDIA Ae.

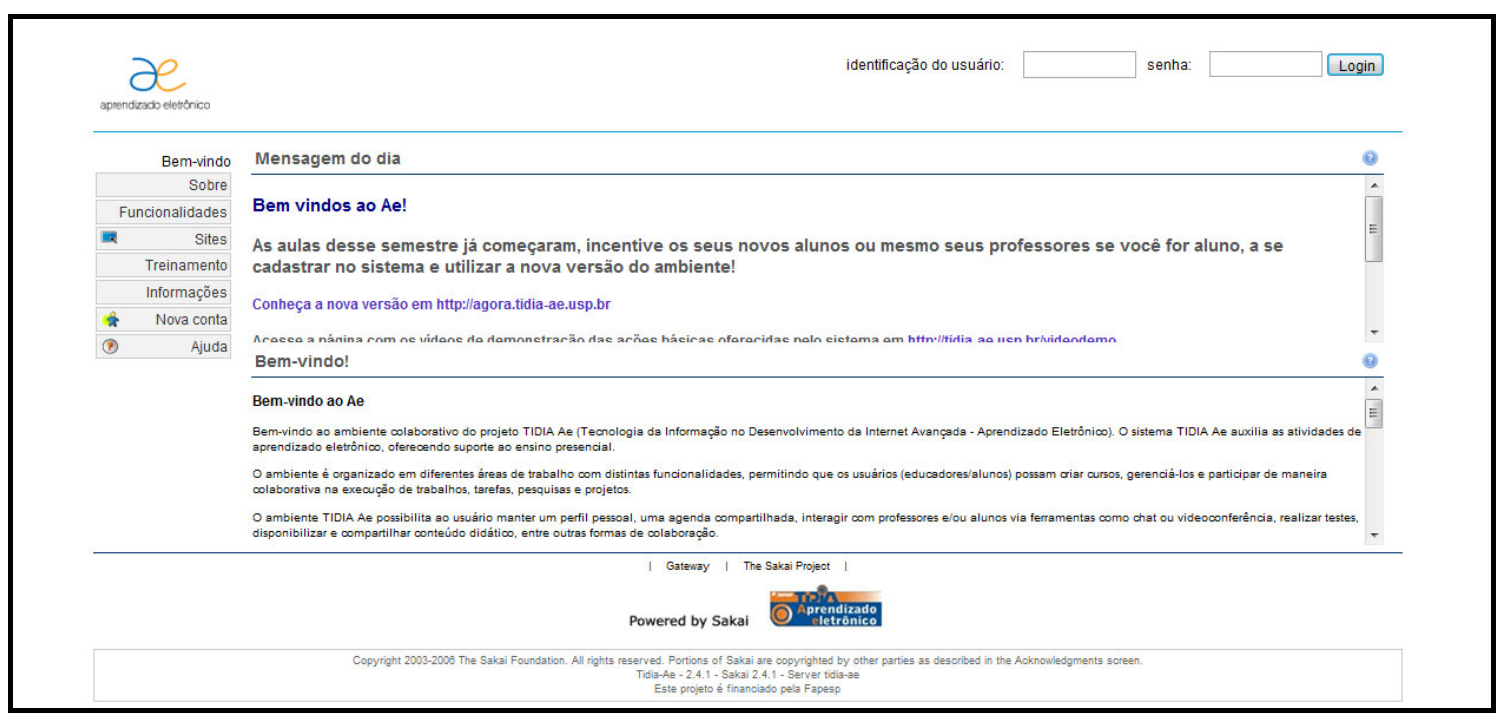

Figura 7 - Ambiente Virtual de Aprendizagem TIDIA Ae.

Fonte: http://tidia-ae.usp.br/portal

O ambiente é organizado em diferentes áreas de trabalho com distintas funcionalidades, permitindo que os usuários (educadores/alunos) possam criar cursos, gerenciá-los e participar de maneira colaborativa na execução de trabalhos, tarefas, pesquisas e projetos.

Possibilita ao usuário manter um perfil pessoal, uma agenda compartilhada, interagir com professores e alunos por meio de ferramentas como chat ou videoconferência, realizar testes, disponibilizar e compartilhar conteúdo didático, entre outras formas de colaboração.

Sintetizando, em relação aos requisitos de Aprendizagem eletrônica - Ae pode-se destacar a seguinte estrutura de pesquisa: interoperabilidade com conteúdos e ferramentas, elevada interatividade, ferramentas de mídia, colaboração à distância, 
segurança, privacidade, flexibilidade e usabilidade. Permite ainda a integração com sistemas acadêmicos e administrativos, além de outras inovações.

O Ae acopla um conjunto de ferramentas que permitem uma maior integração, usabilidade, interatividade e colaboração entre alunos e professores.

O usuário do sistema pode criar seu perfil, compartilhar sua agenda, delimitar e acompanhar o plano de estudos de cada disciplina, interagir com os demais membros por meio de ferramentas como: chat, fóruns, vídeo-conferência, testes online, disponibilizar conteúdo didático e exercícios.

Os docentes podem receber e corrigir provas ou atividades delimitando data e hora, entre a realização de outras formas de colaboração. O TIDIA Ae atualmente encontra-se em versões que roda nas plataformas Linux/Unix e Windows.

\subsubsection{Teleduc}

O Teleduc é um ambiente para cursos a distância via Internet. Foi desenvolvido com o objetivo de realizar um processo de formação de professores para a informática educativa, por pesquisadores do Nied (Núcleo de Informática Aplicada à Educação) da Unicamp. É um ambiente que foi desenvolvido antes do TIDIA Ae, e a equipe do Teleduc colaborou para o desenvolvimento do TIDIA Ae.

O ambiente apresenta uma gama de ferramentas dentre elas: o Correio Eletrônico, Grupos de Discussão, Mural, Portfólio, Diário de Bordo, Bate-Papo, além de outras ferramentas de consulta.

$\mathrm{Na}$ figura 8 a seguir é possível visualizarmos a página inicial do Sistema Gerenciador de Aprendizagem Teleduc. 


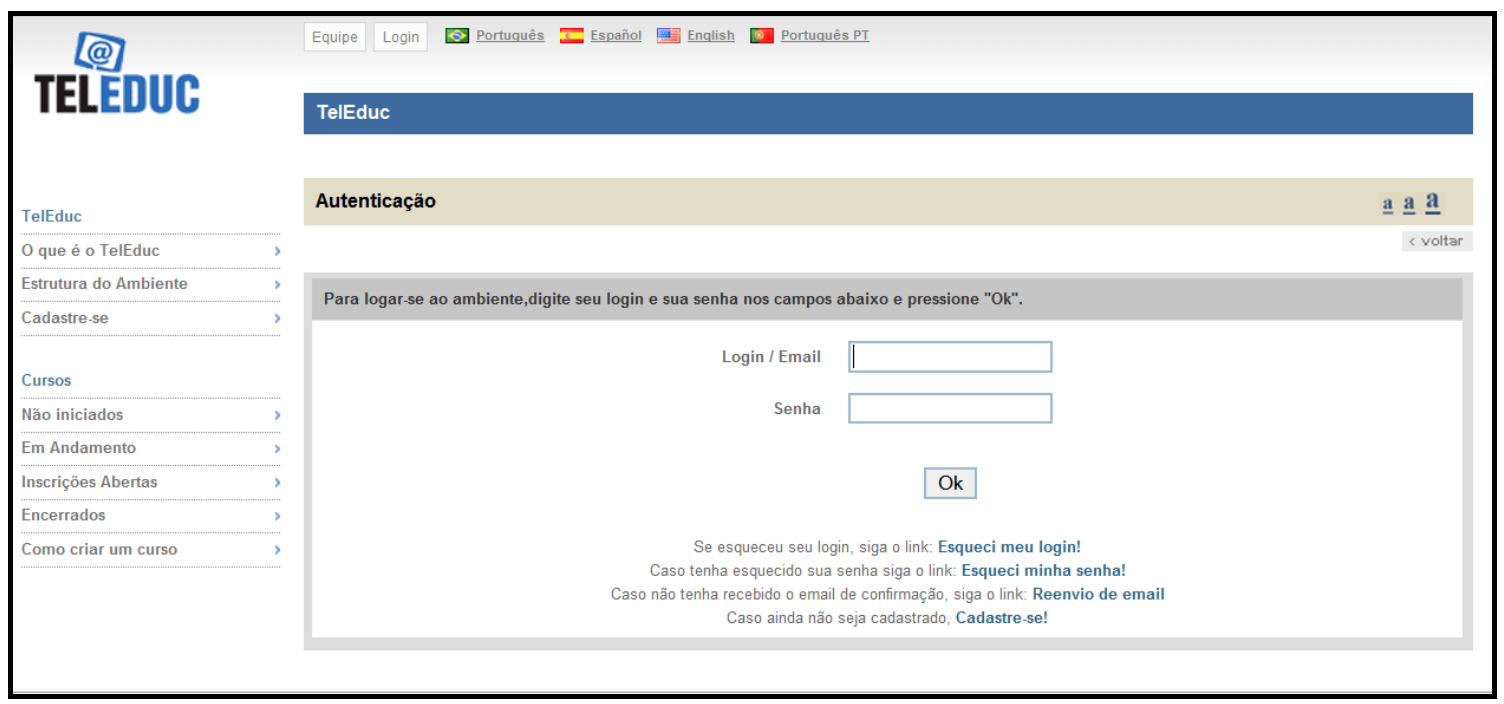

Figura 8 - Ambiente do Sistema Gerenciador de Aprendizagem TELEDUC.

Fonte: http://fenix.nied.unicamp.br/ teleduc4/pagina_inicial/autenticacao.php

\subsubsection{AulaNet}

O AulaNet é um Sistema Gerenciador de Aprendizagem, criado no Laboratório de Engenharia de Software do Departamento de Informática da PUC-Rio, em 1997 e provê uma excelente plataforma de ensino.

É a pioneira no Brasil, estando disponível em cinco idiomas, apresenta flexbiidade de adaptação gráfica e funcional e é compatível com o padrão SCORM, utilizado por mais de 60 universidades corporativas. Seu objetivo é gerenciar a criação, manutenção e participação em cursos à distância.

A ferramenta agrega aos cursos que são oferecidos os serviços de comunicação, avaliação, materiais didáticos e funcionalidades em geral. O AulaNet corresponde à sala virtual de um professor, que tem acesso aos diversos recursos necessários para ministrar a sua aula.

Na figura 9 é possível visualizarmos o Sistema Gerenciador de Aprendizagem AulaNet. 


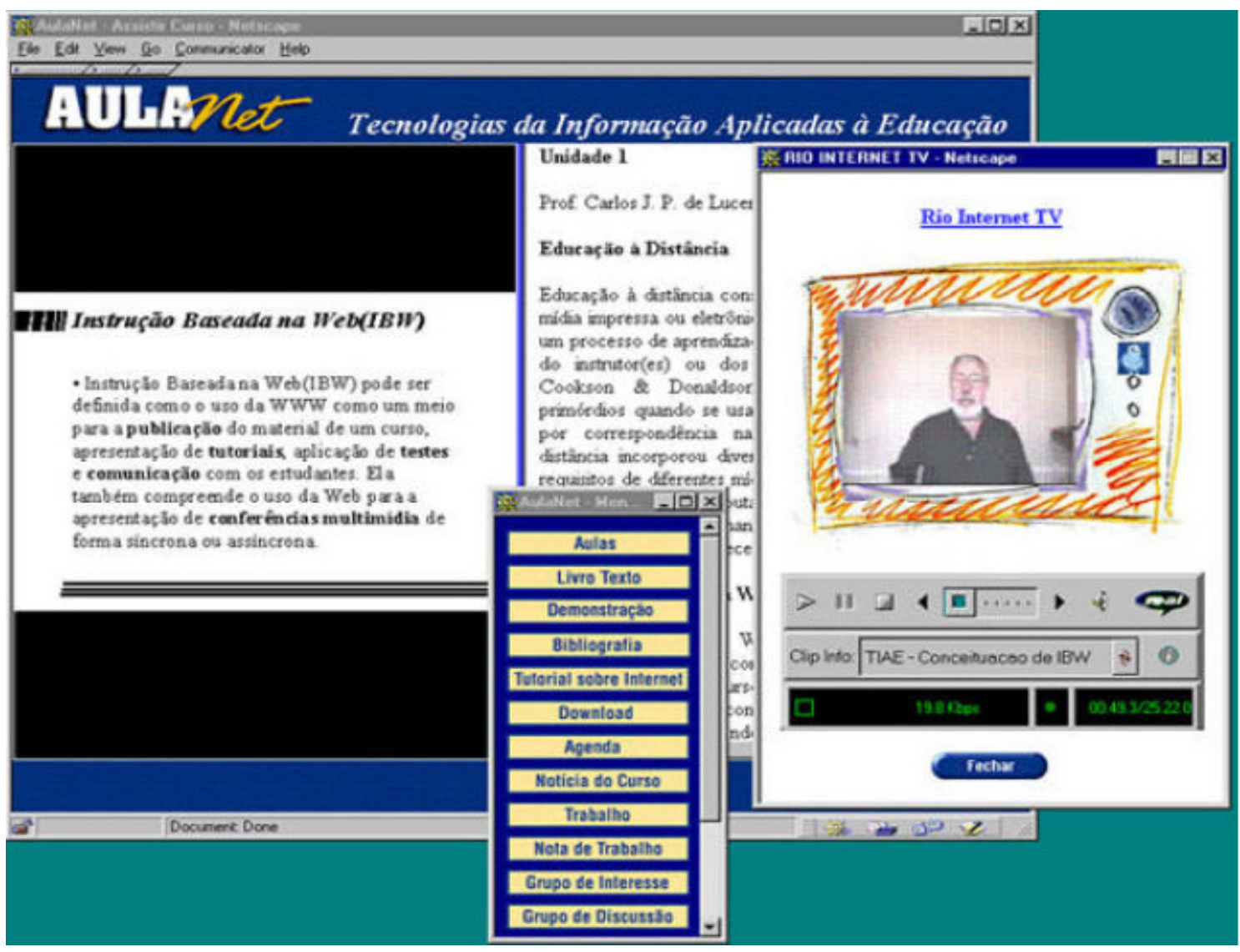

Figura 9 - Ambiente do Sistema Gerenciador de Aprendizagem AulaNet (Interface do Aluno).

Fonte: http://139.82.24.160/aulanet2/

O Aulanet é utilizado tanto para ensino a distância como para complementação às atividades de educação presencial e treinamento de profissionais. É muito utilizado por professores e alunos de universidades no Brasil e no exterior, e por empresas e órgãos governamentais interessados em treinar seus funcionários.

\subsubsection{Moodle}

O Modular Object Oriented Distance Learning - Moodle é um ambiente virtual de aprendizagem ou modulador de objetos de aprendizado para o ensino à distância.

É um programa que roda em plataforma de software livre e atualmente já se encontra em versão para rodar em Windows. Em virtude da portabilidade e 
funcionalidade apresentada é bastante utilizado pelas Instituições de Ensino Superior - IES no Brasil e exterior que adotaram o modelo de educação à distância.

O ambiente foi desenvolvido voltado para a aprendizagem colaborativa, podendo ser configurado em três formatos: social, semanal e em tópicos, sendo cada um deles configurados conforme atividade a ser realizada.

Algumas características apresentadas pelo Moodle são: maior facilidade na produção e distribuição de conteúdos, gerenciamento das atividades, realização de avaliações, atribuição de notas, transmissão e organização de conteúdos, e materiais de apoio às aulas.

$\mathrm{Na}$ figura 10 é possível visualizarmos a página inicial do Ambiente Virtual de Aprendizagem Moodle.

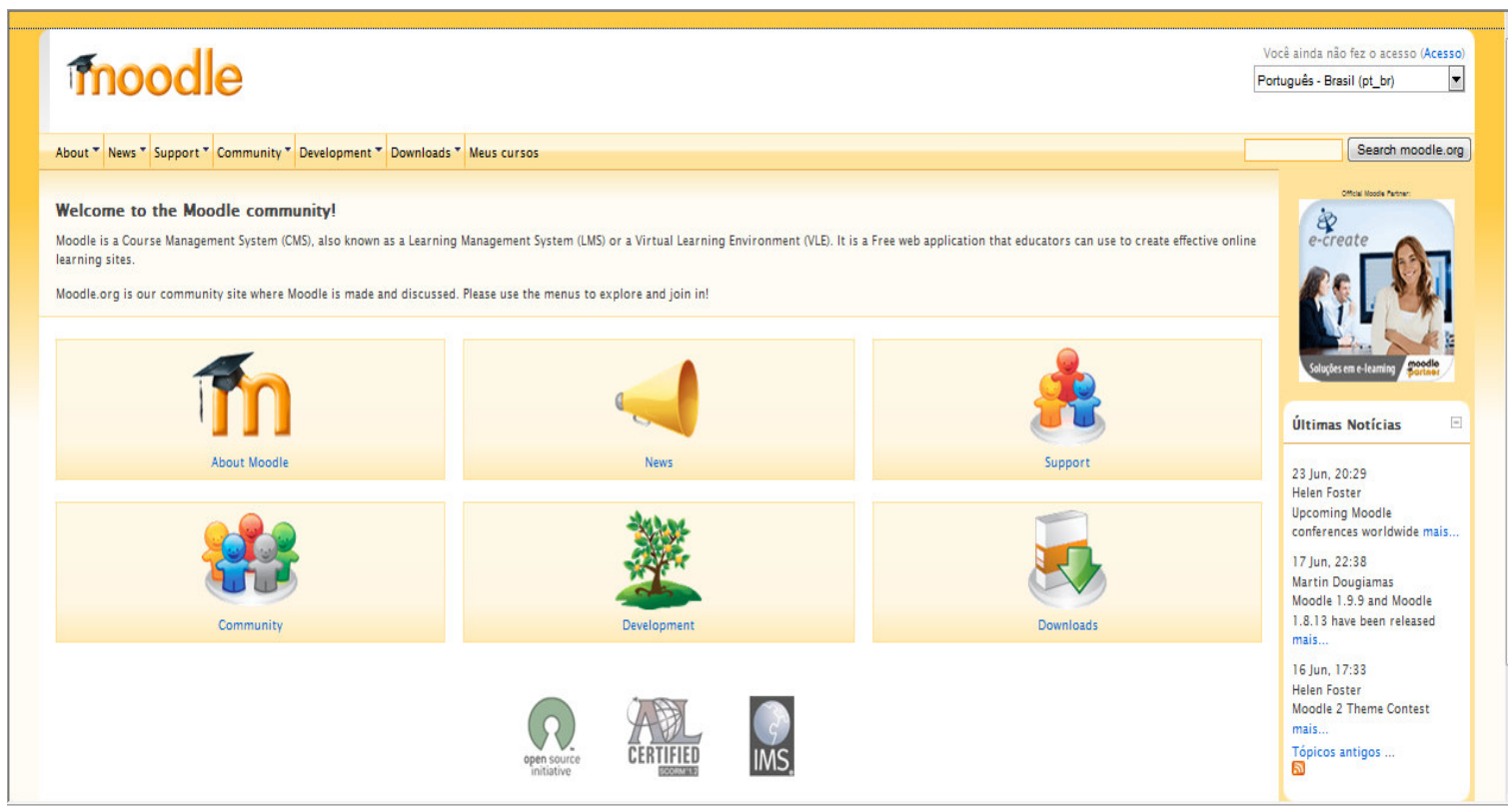

Figura 10 - Ambiente Virtual de Aprendizagem Moodle.

Fonte: http://moodle.org/ 


\subsubsection{Padrões E-Learning}

Padrões são especificações técnicas e formais, aplicando ao contexto de aprendizagem eletrônica podemos dizer que o padrão E-Learning é um modelo de referência que determina como estes ambientes devem ser organizados no que diz respeito a sua arquitetura, organização, funcionamento e conteúdo.

A sua origem surgiu da necessidade do reuso de conteúdos em distintos cursos e ambientes. De acordo com pesquisas atuais, evidencia-se uma demanda por padrões que permitam o reuso de conteúdos e facilita a adaptação de diferentes perfis de alunos, uma vez que o uso destes possa ocorrer de maneira individualizada conforme a necessidade apresentada pelo aluno. Conforme Freire (1996) o ensino tem uma natureza afetiva e implica promover a noção da autonomia do indivíduo no processo de aprendizagem.

Outro fator muito discutido é a melhoria do processo de aprendizagem, necessária para obter resultados satisfatórios e condizentes com as técnicas aplicadas.

Conforme as pesquisas iniciais sobre ambientes on-line 0 enfoque estava diretamente relacionado com a descrição dos aplicativos da nova tecnologia educacional e do seu potencial para promover ambientes de aprendizagem, nos quais os estudantes colaboram com os demais e assumem uma crescente responsabilidade em seu próprio processo de aprendizagem (HARASIM, et al.,2005)

O aprendizado eletrônico, assim como o presencial requerem técnicas de ensino diversificadas, em virtude da introdução de recursos como a mídia e de uma pedagogia apropriada aos ambientes colaborativos on-line. $O$ surgimento tecnologias e sistemas de comunicações mediados pelo computador emergem novas práticas de ensino que implicam diretamente numa melhoria e adaptação do processo de ensino-aprendizagem. 


\subsubsection{Padrão LOM}

O Learning Object Metadata - LOM são metadados usados para descrever objetos de aprendizagem e recursos digitais que são utilizados como suporte a aprendizagem e é definido pelo padrão IEEE 1484/12/1 - $2002^{25}$.

O padrão LOM (2002) possui uma estrutura que descreve objetos de aprendizagem através de categorias descritoras que detalham dados sobre um determinado objeto de aprendizagem. Sendo que um objeto de aprendizagem refere-se a uma entidade, sendo ela digital ou não, que pode ser utilizada, reutilizada e referenciada no processo de aprendizagem.

Ambientes interativos de aprendizagem, sistemas inteligentes, sistemas de educação à distância, e ambientes de aprendizagem colaborativa são exemplos de tecnologias que fazem uso dos objetos de aprendizagem.

O objetivo do LOM é apoiar o reuso de objetos de aprendizagem visando facilitar a interoperabilidade no que se refere a sistemas on-line e no gerenciamento de aprendizagem. Uma das categorias descritoras do LOM é a categoria educacional composto pelos campos tipo de interatividade, tipo de recurso da aprendizagem (exercício, simulação, questionário) e grau de dificuldade. Sendo responsável pela descrição das funções educacionais e características pedagógicas do objeto.

O padrão LOM tem sido adotado por diversos ambientes de aprendizagem, e por padrão pelo Learning Design ${ }^{26}$ - LD e SCORM para a definição e catalogação dos conteúdos associados às atividades contidas em um dado escopo de ensino.

O padrão Learning Design foi especificado pelo Global Learning Consortium ${ }^{27}$ - IMS e se constitui em uma linguagem para especificação de processos de aprendizagem que sejam flexíveis pedagogicamente (ZAINA, 2008).

\footnotetext{
25 http://ltsc.ieee.org/wg12/

26 http://www.imsglobal.org/lerningdesign

27 http://www.imsglobal.org
} 


\subsubsection{Padrão SCORM}

O padrão Shareable Content Object Reference Model - SCORM é um conjunto de padrões e especificações para conteúdo, tecnologias e serviços voltadas para elearning.

A entidade responsável pela sua definição é a Advanced Distributed Learning $A D L^{28}$. Este padrão está diretamente relacionado com a padronização dos conteúdos, com a reutilização de objetos de aprendizagem, com a flexibilidade e alta capacidade de portabilidade. Agregando ao seu padrão os modelos definidos pela IEEE $^{29}$ Learning Technology Standards Comitee e Global Consortium Learning IMS para definir sua organização.

Segundo Zaina (2008), o padrão SCORM é um modelo de referência constituído por um conjunto de especificações que permite a organização de objetos de aprendizagem, através da especificação de metadados, para que seja possível reutilizar conteúdos, permitindo que seja criado um seqüenciamento para a apresentação de conteúdos de ensino.

O SCORM caracteriza-se como sendo um modelo de agregação de conteúdo. Um de seus objetivos é propiciar a independência de plataforma onde os objetos podem ser utilizados, de modo a facilitar a migração de cursos entre diferentes ambientes de gerenciamento de aprendizagem compatíveis com esse padrão.

A especificação do padrão SCORM, conforme Zaina (2008) está dividida em três grandes modelos: o modelo de agregação de conteúdo; o de ambiente de execução e o modelo de seqüência de navegação.

${ }^{28}$ http://www.adlnet.gov/Pages/Default.aspx

${ }^{29} \mathrm{http}: / /$ www.ieeeltsc.org 


\subsubsection{Padrão IMS-Learning Design e IMS-QTI}

O padrão Learning Design - LD foi especificado pelo IMS Global Learning Consortium como sendo um arcabouço de elementos que podem descrever qualquer cenário de um processo de ensino-aprendizagem de uma maneira formal. (IMSLD, 2003).

O padrão LD segundo Zaina (2008) se constitui em uma linguagem para especificação de processos de aprendizagem que sejam flexíveis pedagogicamente. Evidencia-se que este padrão permite autonomia ao docente em adotar o modelo pedagógico mais adequado, modelando com LD. Os modelos são desenvolvidos baseados na Educational Modeling Language - $E M L^{30}$, que é uma linguagem de modelagem educacional, padronizada para o desenvolvimento e a administração de processos de aprendizagem, cuja origem vem da Language Modeling Unified $U M L^{31}$, que é uma ferramenta que auxilia na modelagem de sistemas dos mais simples aos mais complexos.

O padrão torna possível a formalização, independente da modalidade ou da teoria do aprendizado, através de elementos que compõem uma unidade de aprendizagem. Uma Unidade de Aprendizagem - UA é constituída pelo elemento que descreve a organização e pela referência dos objetos e ferramentas que são utilizadas durante o processo de aprendizagem, representando assim a organização dos elementos que irão considerar um determinado objetivo.

O IMS Question and Test Interoperability - IMS QTI, é um padrão cuja especificação foi concebida para apoiar tanto a interoperabilidade como a inovação através da disponibilização de pontos de extensão bem definidos, cujos pontos de extensão podem ser usados para empacotar dados especializados ou proprietários (IMS QTI, 2010).

O IMS QTI é um padrão de testes desenvolvido com a finalidade de padronizar através de uma estrutura básica a representação de perguntas e respostas para

\footnotetext{
${ }^{30}$ http://eml.ou.nl/eml-ou-nl.htm

${ }^{31}$ http://www.uml.org/
} 
geração de testes de fácil interação. Sendo constituída de modelos em Extensible Markup Language - XML, uma linguagem de marcação prestigiosa e flexível utilizada para codificar modelos de dados para aplicações web e distribuídas. A especificação deste padrão é extensível e customizável o que facilita o seu uso e adaptação em diferentes sistemas, sejam eles proprietários ou especialistas.

\subsection{TECNOLOGIAS DE COMUNICAÇÃO}

Entende-se por comunicação o intercâmbio de informação entre sujeitos ou objetos. As tecnologias de comunicação visam prover o que há de mais atual, e moderno em aparatos tecnológicos para suportar uma elevada quantidade de informações que são frequentemente geradas.

Percebe-se que os meios tecnológicos voltados para a comunicação estão dispostos em vários cenários como no cinema, na televisão, na publicidade, na Internet entre outros.

A tecnologia está presente no cotidiano das pessoas ao realizarem tarefas triviais, como por exemplo: fazer compras em um supermercado (há um sistema para realizar pagamento), ir ao Banco, comprar uma passagem de avião (é pela Internet), efetuar uma ligação (telefone móvel), etc.

Existem algumas tecnologias que se destacam pelo provimento de seus serviços em função de sua usabilidade, disponibilidade, interoperabilidade, manutenibilidade e outros requisitos necessários para o sucesso do seu funcionamento e da sua permanência no mercado atual.

As tecnologias de TV Digital, dispositivos móveis e Internet são providas de ferramentas que permitem uma comunicação mais expressiva, interativa e de longo alcance. 


\subsubsection{TV Digital}

A TV Digital surge de um processo evolutivo, agregando novas tecnologias que visam atender às necessidades sociais; principalmente as tecnologias ligadas à codificação, edição, transmissão e recepção. Existem atualmente alguns sistemas abertos de TV Digital que são destaque no cenário mundial, são eles:

1. Europeu: Digital Vídeo Broadcasting - DVB;

2. Norte-americano: Advanced Television Systems Committee - ATSC;

3. Japonês: Integrated Services Digital Broadcasting - ISDB;

4. Chinês: Digital Terrestrial Multimedia Broadcast - DTMB;

5. Brasileiro: Integrated Services Digital Broadcasting Terrestrial - ISDB-TB adaptado do padrão japonês acrescido de tecnologias desenvolvidas pelas universidades brasileiras.

Gomes (2006) aborda em seu trabalho que o sucesso da TVD no Brasil pode estar relacionado com o processo de inclusão digital e outros serviços que são oferecidos e pode ser alcançado por intermédio da educação pela TV, termo este conhecido como t-learning.

O Sistema Brasileiro de TV Digital - SBTVD ${ }^{32}$ a partir de vários estudos definiu o ISDB-TB como padrão do sistema de TV Digital a ser adotado no Brasil.

A sua estabilização vem contribuindo para a melhoria da qualidade da mídia digital "áudio e vídeo", em transmissões de canais codificados em definição padrão Standard Definition Television - SDTV e em alta definição High Definition Television HDTV.

Borges (2008) comenta que parte do processo de implantação da TV Digital no Brasil está no desenvolvimento e disponibilização de aplicações interativas. A

32 http://www.forumsbtvd.org.br/ 
interatividade é um dos argumentos utilizados a favor desta mudança de bases tecnológicas no sistema brasileiro de televisão.

A educação quando transmitida pela televisão atinge populações geograficamente distantes, e permite uma interatividade ainda baixa mais já evidente que contribui para o avanço desta tecnologia.

Gomes (2006) relata que TV é um elemento motivador e que prende bastante a atenção dos telespectadores sendo por isso, um poderoso recurso audiovisual para o processo de ensino e aprendizagem.

\subsubsection{TV Digital Interativa}

A TV Digital Interativa atualmente é um assunto que desperta grande interesse na academia, no comércio e na indústria quando se refere a um modelo de tecnologia voltado para TV.

A interatividade é considerada por alguns autores (CROCOMO 2007; GAWLINSKI 2003; BECKER 2006) como sendo a principal evolução da televisão analógica, refere-se "aos meios adicionais de fidelização do telespectador, com conteúdos oferecidos adicionalmente visando tornar a produção audiovisual mais atrativa". (BECKER, 2007)

A interatividade pode ser proporcionada de várias formas, formatos e meios. O termo interatividade surgiu nos anos 60 e é derivado do neologismo inglês interactivity. Segundo Steuer (1992) a interatividade mede o quanto um usuário pode influenciar na modificação imediata, na forma e no conteúdo de um ambiente computacional.

Os livros, jornais e a TV aberta podem ser exemplos de meios pouco interativos, já a teleconferência, bate-papo, e-mail e vídeo game podem ser considerados meios bastante interativos. A interatividade caracteriza-se pela troca de informações entre 
um usuário e um sistema informatizado, e por um terminal de máquina com uma tela de visualização.

Em Cibercultura (LÉVY, 1999, p. 83), o autor propõe uma tabela contendo os diferentes tipos de interatividade. Na tabela 5 a seguir é possível visualizarmos alguns tipos de interatividade, segundo o autor.

Tabela 5 - Tipos de Interatividade.

\begin{tabular}{|c|c|c|c|}
\hline $\begin{array}{l}\text { Relação com a } \\
\text { Mensagem } \\
\text { Dispositivo de } \\
\text { Comunicação }\end{array}$ & $\begin{array}{l}\text { Mensagem linear } \\
\text { Não-alterável em } \\
\text { tempo real }\end{array}$ & $\begin{array}{l}\text { Interrupção e } \\
\text { reorientação do } \\
\text { fluxo informacional } \\
\text { em tempo real }\end{array}$ & $\begin{array}{l}\text { Implicação do } \\
\text { participante na } \\
\text { mensagem }\end{array}$ \\
\hline Difusão unilateral & $\begin{array}{l}\text { - Imprensa } \\
\text { - Rádio } \\
\text { - Televisão } \\
\text { - Cinema }\end{array}$ & $\begin{array}{l}\text { - Bancos de dados } \\
\text { multimodais } \\
\text { - Hiperdocumentos } \\
\text { fixos } \\
\text { - Simulações sem } \\
\text { imersão nem } \\
\text { possibilidade de } \\
\text { modificar o modelo }\end{array}$ & $\begin{array}{l}\text { - Videogames com } \\
\text { um só participante } \\
\text { - Simulações com } \\
\text { imersão (simulador } \\
\text { vôo) sem } \\
\text { modificações } \\
\text { possíveis do } \\
\text { modelo }\end{array}$ \\
\hline Diálogo, Reciprocidade & $\begin{array}{l}\text { Correspondência } \\
\text { postal entre duas } \\
\text { pessoas }\end{array}$ & $\begin{array}{l}\text { - Telefone } \\
\text { - Videofone }\end{array}$ & $\begin{array}{l}\text { Diálogos entre } \\
\text { mundos virtuais, } \\
\text { cibersexo }\end{array}$ \\
\hline $\begin{array}{l}\text { Diálogo entre vários } \\
\text { participantes }\end{array}$ & $\begin{array}{l}\text { - Rede de } \\
\text { correspondência } \\
\text { - Sistema das } \\
\text { publicações em uma } \\
\text { comunidade de } \\
\text { pesquisa } \\
\text { - Correio eletrônico } \\
\text { - Conferências } \\
\text { eletrônicas }\end{array}$ & $\begin{array}{l}\text { - Teleconferência ou } \\
\text { videoconferência } \\
\text { com vários } \\
\text { participantes } \\
\text { - Hiperdocumentos } \\
\text { abertos acessíveis } \\
\text { on-line, frutos da } \\
\text { escrita/leitura de } \\
\text { uma comunidade } \\
\text { - Simulações (com } \\
\text { possibilidade de } \\
\text { atuar sobre o } \\
\text { modelo) como de }\end{array}$ & $\begin{array}{l}\text { - RPG multiusuário } \\
\text { no ciberespaço } \\
\text { - Videogame em } \\
\text { "realidade virtual" } \\
\text { com vários } \\
\text { participantes } \\
\text { - Comunicação em } \\
\text { mundos virtuais, } \\
\text { negociação contínua } \\
\text { dos participantes } \\
\text { sobre suas imagens } \\
\text { e a imagem de sua } \\
\text { situação comum }\end{array}$ \\
\hline
\end{tabular}




\begin{tabular}{l|l|l|l}
\hline & & $\begin{array}{l}\text { suportes de debates } \\
\text { de uma comunidade }\end{array}$ & \\
\hline
\end{tabular}

Fonte: (LÉVY, 1999).

Conforme (Vorderer, 2000), TV Digital interativa consiste em aplicações de software executadas em servidores multimídias e de vídeo, terminal de acesso avançados, computadores pessoais e telefones móveis.

Esta nova tecnologia representa o mais significativo avanço em direção a uma informática imperceptível e onipresente, na medida em que a televisão é um meio de difusão de informação e de entretenimento de massa. (BECKER, 2008)

Conforme (Souto Maior, 2002) um dos maiores desafios da TV interativa é aprender a trabalhar com ela. Compreender e trabalhar com esta tecnologia é realmente um desafio, pois muitos recursos podem ser integrados, basta saber quais e como eles necessariamente funcionam.

Trabalhar com TV interativa está diretamente relacionado, com a experiência com que o usuário interage com um sistema, com um aplicativo ou com qualquer outro dispositivo. Analisando por este contexto de usabilidade, é mais fácil escolher e explorar os recursos tecnológicos necessários para desenvolver uma aplicação interativa. A figura 11 ilustra o modelo de um sistema de interatividade.

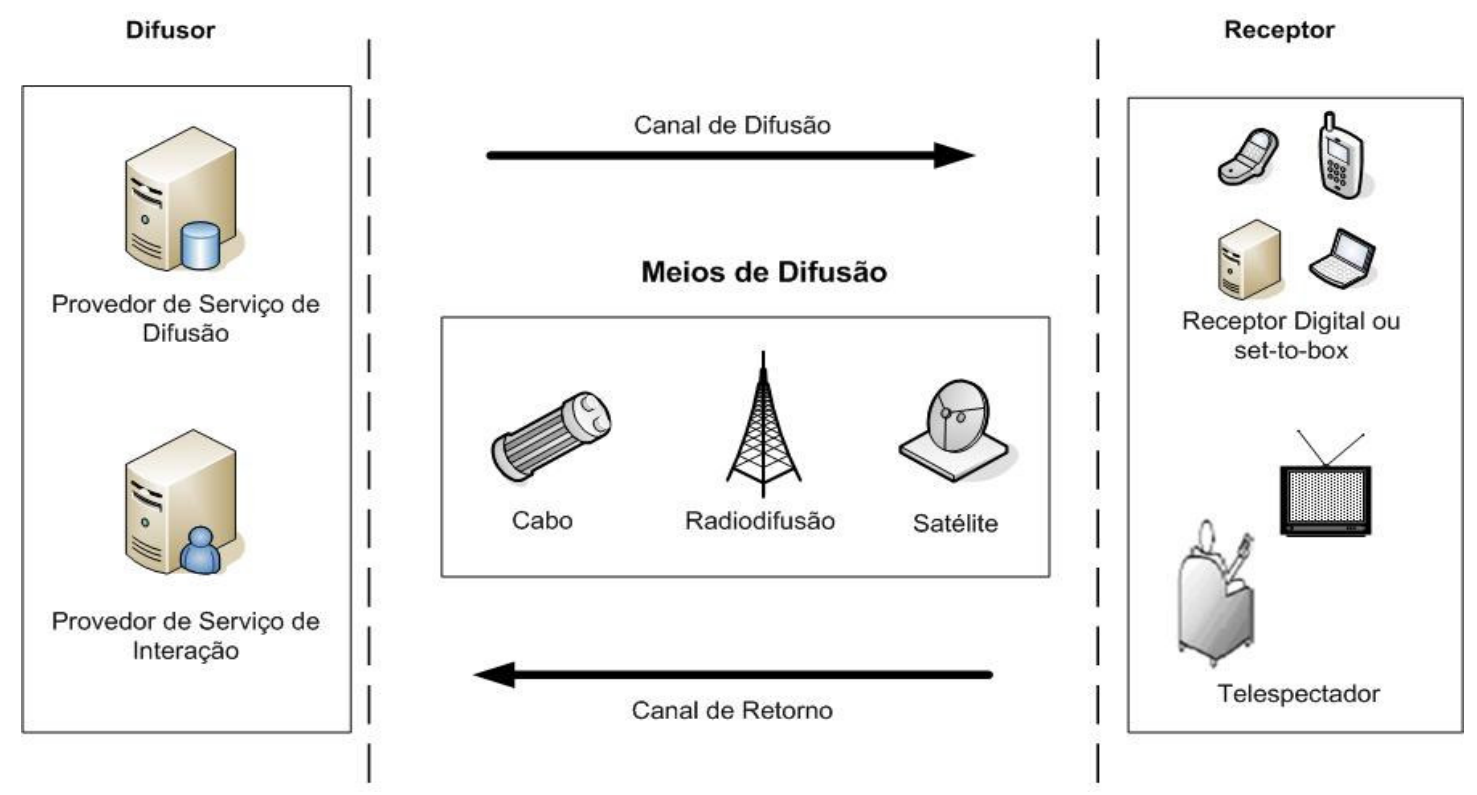

Figura 11 - Representação de um sistema de TV Digital interativa 
Conforme podemos visualizar na figura acima a TV Digital Interativa caracteriza-se pela comunicação bidirecional, ou seja, não há mais o disparo da transmissão em um só sentido ou direção.

A comunicação ocorre por intermédio dos meios de difusão (canal de difusão e canal de retorno). Tais meios de difusão podem ser por cabo, radiodifusão ou por satélite.

O sistema difusor é composto dos provedores de serviço de difusão e de interação, e o sistema receptor que consiste de um receptor digital ou terminal de acesso, e do telespectador que interage com a transmissão operando um dispositivo.

Com a interatividade a quantidade e a qualidade dos serviços prestados pela TV aumentam consideravelmente, crescendo assim o número de serviços e aplicações oferecidas.

\subsubsection{Middleware GINGA}

Com o intuito de tornar fácil o desenvolvimento de conteúdos interativos voltados para TV Digital, logo, os sistemas especificam a utilização de um middleware.

Becker (2008) define um middleware como sendo uma camada de software intermediário que faz a ponte entre o sistema operacional do terminal de acesso e as aplicações transmitidas pela TV.

Com o middleware é possível que qualquer aplicação seja executada em todos os tipos de receptores (móvel, portátil, fixo), independente de arquitetura (oferece portabilidade) e da arquitetura do hardware. A principal finalidade do Middleware é oferecer um serviço padronizado para as aplicações, escondendo as heterogeneidades e complexidade das camadas inferiores (MONTEZ; BECKER, 2005). 
A figura 12 mostra um exemplo ilustrativo utilizado por Alves (2008) referente à camada de aplicação Middleware típica presente em um dispositivo. Descrevendo as demais camadas que compõem a arquitetura tornam assim o entendimento mais claro por meio da visualização ilustrativa dos exemplos.

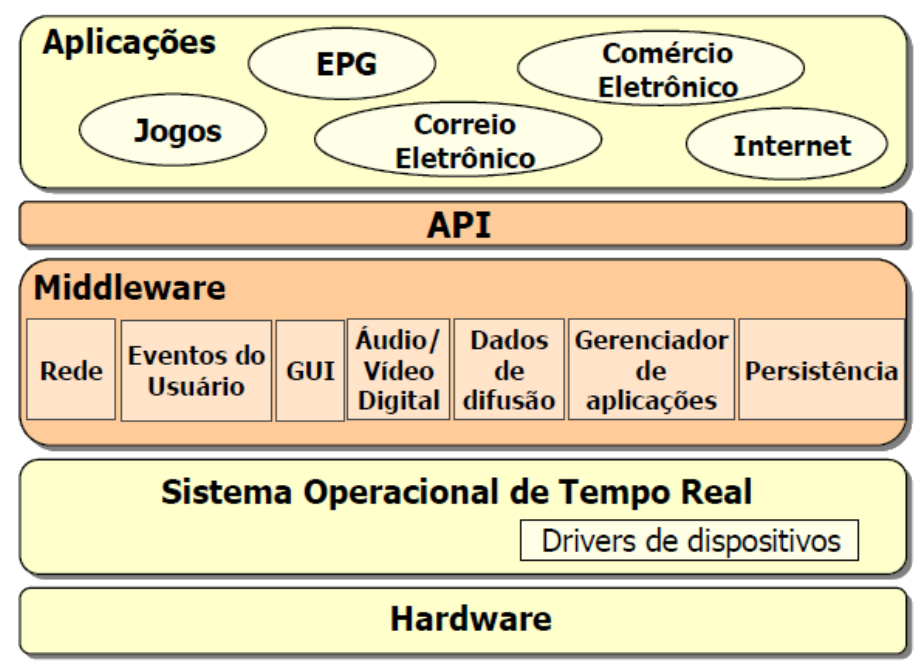

Figura 12 - Camada de aplicações Middleware.

Fonte: Alves (2008).

O Ginga ${ }^{\circledR 33}$ pertence à camada Middleware de software interposta entre as aplicações e outros módulos que compõem o SBTVD, implementados por hardware.

Com o Ginga ${ }^{\circledR}$ é possível desenvolver aplicações interativas que se adapte ao perfil do usuário (localização, tipo de dispositivo, etc.), além de permitir que qualquer dispositivo Bluetooth possa interagir com a televisão, resultando assim em uma interatividade personalizada aumentando as chances de inserção de novos conteúdos.

Para se desenvolver aplicações interativas voltadas para TV Digital precisamos utilizar linguagens de programação voltada para aplicações televisivas. As

33 http://www.ginga.org.br/ 
linguagens do Ginga $^{\circledR}$ são baseadas em dois paradigmas de programação: declarativo e procedural (BECKER,2008)

O Ginga-NCL ${ }^{\circledR}$ (Nexted Context Language) é a linguagem baseada no paradigma declarativo que funciona como um organizador de mídias. O Ginga $J^{\circledR}$ é baseada no paradigma procedural que possue a linguagem Java inclusa. A linguagem LUA é utilizada em aplicações que requerem o uso de complementos procedurais voltadas para aplicações que requerem um maior controle e detalhamento.

\subsubsection{Padrão TV Any-Time}

O TV-Anytime ${ }^{34}$ é uma associação de organizações formada em 1999, responsável por desenvolver um conjunto de especificações abertas para sistemas integrados e interoperáveis possibilitando que provedores de conteúdo, provedores de serviço e consumidores (usuários) sejam capazes de manipular conteúdo digital em dispositivos com capacidade de armazenamento digital. (ALVES, et al, 2008)

Este padrão utiliza atualmente a sua parte procedural utiliza o Java DTV $^{35}$ da Sun Oracle e apresenta alguns objetivos, dentre eles possibilitarem à tecnologia de TV Digital interativa o tratamento no processo de busca, seleção, aquisição, e distribuição do conteúdo digital, bem como o seu compartilhamento para outras redes e ambientes digitais.

Conforme estabeleceu o TV-Anytime Fórum, este processo divide-se em duas etapas: a primeira que está relacionada com a ausência do canal de retorno, quando os serviços são entregues; e a segunda é quando existe este canal de retorno, podendo assim ser mostradas outras funcionalidades (como personalizar o perfil do usuário).

Este padrão contempla alguns objetivos, são eles: assegurar aos usuários um acesso personalizado, agregar valor ao conteúdo, ser independente de tecnologia,

\footnotetext{
${ }^{34} \mathrm{http}: / / w w w . t v-a n y t i m e . o r g /$

${ }^{35} \mathrm{http}: / /$ www.oracle.com/br/sunnews/press/2009/20090417.jsp
} 
possibilitar o desenvolvimento de especificações que contemplem a integração e a interoperabilidade entre os sistemas e especificar as estruturas de segurança.

Visando um melhor tratamento desses objetivos o TV-Anytime é dividido em quatro grupos de trabalho (TV-ANYTIME, 1999): modelo de negócios; sistema, interface de transporte e referência ao conteúdo; metadados; e gerenciamento de direitos autorais.

\subsubsection{T-Learning}

Conforme Bates (2003), T-Learning é o acesso a materiais de aprendizagem ricos em vídeo, através de uma TV ou de um dispositivo mais parecido com a TV.

Existem razões para considerar este conceito, tais como:

1. O acesso das pessoas à TV que é um dispositivo de fácil acesso;

2. A dificuldade que uma família atualmente tem de possuir um computador em sua casa, principalmente conectada à Internet;

3. A TV atinge um número elevado de pessoas;

4. Pela televisão é possível oferecer um número considerado de oportunidades de aprendizagem.

Alguns fatores podem ser citados, pois fortalecem a utilização da TV no cenário de educação à distância, dentre eles: a usabilidade, a qualidade na transmissão, o veículo de informação e a colaboração.

Os mais variados recursos utilizados em um serviço de t-learning, compreendem a disponibilização de ferramentas colaborativas (correio eletrônico, bate-papo e outras), e a apresentação de conteúdos personalizados dependem das tecnologias disponíveis num Sistema de Televisão Interativa. Isso implica que um serviço de $t$ learning deve ser desenvolvido de acordo com os recursos e as limitações tecnológicas do Sistema de Televisão Interativa (BATES, 2003). 
As novas plataformas digitais destacam-se e contribuem para uma futura diversidade dos meios de difusão social.

\subsubsection{Internet e Web}

A Internet surgiu originalmente nos Estados Unidos em 1969 com a necessidade do Departamento de Defesa de integrar suas bases militares durante a Guerra Fria, de modo que se estabelecesse uma rede de comunicação segura e resistente, que não fosse destruída pelos bombardeios e que os inimigos não fossem capazes de acessar. (ARAÚJO, 2008)

À medida que a Internet vai se difundindo, o vocabulário universal vai sendo acrescido de diversos neologismos. A Internet é a rede mundial de computadores, uma rede física baseada no protocolo TCP/P. (MOURÃO, et al, 2010)

A World Wide Web - WWW, ou "rede de alcance mundial" nasceu em 1991 no laboratório CERN (Conseil Europeen pour la Recherche Nucleaire), em Genebra na Suíça. (ARAUJO, 2008)

A Web é apenas um dos muitos serviços disponíveis na Internet, por exemplo: serviços de e-mail, chat, www, ftp, telnet entre outros.

Entende-se o termo Web como sendo a plataforma criada para designar comunidades e serviços, constituída por uma vasta coleção de documentos (denominados páginas no meio virtual) que se referem a arquivos HTML, armazenados em computadores (conhecidos como servidores) e espalhados pela rede que podem conter fotos, animações, textos, vídeos, sons e programas.

O termo WebService se popularizou, sendo padronizada pelo $W 3 C^{36}$ em 2001. A Web é um sistema de hipermídia distribuído, em que os documentos podem apresentar, além de sons e imagens, diversos links que referenciam outros documentos similares.

${ }^{36}$ http://www.w3.org/TR/wsdl 
A Web atualmente permite descobrir, realizar, promover, participar e evidenciar uma gama de variedades de informações. Através dela, é possível usufruir dos seguintes serviços: realizar compras, vendas, anúncios, notícias, cadastros, previsão do tempo, ação da bolsa de valores, horóscopo, jogos, música, filmes, contatos (profissionais ou não), trabalhos de escola ou não, educação, conhecimento. Sendo possível encontrar e fazer amigos, mas através dela também se encontram assuntos que abordam pornografia, violência, prostituição, pedofilia, roubos; e pessoas que praticam atos cruéis por meio desta vasta rede.

Em termos tecnológicos evidencia-se o grande sucesso da tecnologia de Cloud Computing (computação nas nuvens), a tendência vem crescendo internacionalmente e foi destaque em 2010 no evento da CES $^{37}$ (Consumer Electronics Show), como uma das tendências tecnológicas em destaque no mercado mundial. A Computação em nuvens é a descentralização dos bancos de dados e aplicações (programas) dos desktops e servidores das empresas para a Internet, resultando no processamento e armazenamento de dados, através de uma rede de computadores distribuídos (MOURÃO, et al, 2010).

Destacaram-se também o P2P Payment (Pagamentos móveis), os Dispositivos Móveis, os Tablet's, os Televisores com tecnologia $3 D$ (tridimensional), os EReaders, o Blue-Ray, o Blio e as máquinas de vender (refrigerante, café, livros, etc.).

\subsubsection{Ambientes Móveis}

Os ambientes móveis surgiram com o intuito de suprir a expansão do aprendizado eletrônico, facilitando a expansão educacional e a fronteira do conhecimento, onde o aprendizado pode ocorrer em diversos locais e horários. Na literatura encontram-se propostas de novas teorias de aprendizagem, sistemas tecnológicos inovadores e novas ações práticas em formas de aferição do aprendizado. (LITTO, 2009)

37 http://www.cesweb.org/ 
Estes ambientes possibilitam o aprendizado móvel, segundo Litto (2009) o aprendizado acontece por intermédio da utilização dos equipamentos móveis como telefones celulares, pequenos computadores pessoais (PDAs) e eventualmente laptops em redes sem fio.

A mobilidade móvel tem suas vantagens a principal é o acesso aos dados em qualquer lugar e a qualquer hora. Pode-se destacar outras como a entrada e processamento de dados, a otimização de tempo e o envio e recebimento de dados e informações.

Algumas limitações podem ser evidenciadas e caracterizadas como sendo as desvantagens apresentadas pelos ambientes móveis, tais como o alto custo de hardware, o baixo poder de processamento, a pouca infraestrutura de comunicação de dados, interoperabilidade e a cultura (os usuários não têm o costume de acessar informações por meio desses tipos de dispositivos, por falta de conhecimento).

\subsubsection{Padrão M-Learning}

É uma das modalidades de EAD, refere-se ao aprendizado móvel também conhecido como Mobile Learning. O termo se deve ao crescimento e surgimento da modalidade à distância integrada a tecnologias e ao surgimento, evolução e utilização de dispositivos móveis que vieram potencializar essa área.

O termo Mobile Learning, segundo Oliveira (2007), refere-se basicamente ao fato de se utilizar tecnologias de rede sem fio para difundir o ensino e a aprendizagem, facilitando ainda mais o acesso a informações, visto que agora se trabalha sobre o conceito de mobilidade e/ou liberdade geográfica.

O Aprendizado móvel emerge como uma tecnologia inovadora voltada para área educacional. Conforme Litto (2009) o conceito é oriundo de dois conceitos, onde o primeiro refere-se à necessidade de se estabelecer critérios e parâmetros para que os sistemas educacionais dos países das comunidades européias permitissem a mobilidade dos cidadãos facilitando o reconhecimento de seus diplomas em todo o 
território europeu, e o próximo conceito seria permitir o deslocamento de estudantes, professores e burocratas para aprendizagem e treinamento.

O crescimento explosivo de dispositivos móveis está estimulando os esforços para o desenvolvimento idêntico das tecnologias desenvolvidas de computadores desktop para dispositivos móveis. (MAHMOUD, 2007)

O Learning Object - LO ou Objeto de Aprendizagem é conceituado como sendo qualquer entidade com objetivos educacionais, podendo ser utilizado, reusado ou referenciado por uma tecnologia voltada ao suporte à aprendizagem sendo descrito por um Learning Object Metadata - LOM, que permite a sua categorização, indexação e recuperação (LSTC, 2002)

Os objetos de aprendizagem surgem de um novo pensamento e de uma nova proposta a ser implementada, de um conceito novo ou já existente que permita construir uma nova abordagem para a transmissão do conhecimento agregada à tecnologia.

A contribuição e principal característica dos objetos de aprendizagem hoje é serem construídos para serem executados em dispositivos móveis, com o objetivo de transmitir conhecimento e aprendizado agregados com tecnologia e mobilidade (visto na secção 3.3.6). Segundo B'Far (2005) os sistemas computacionais móveis são aqueles capazes de serem movidos e que possam processar informação enquanto se movem.

Conforme Oliveira (2007), professores e equipes desenvolvedoras de objetos educacionais deparam-se agora com uma nova plataforma de desenvolvimento que está em plena expansão e é objeto de estudos e pesquisas incluindo os fabricantes de dispositivos móveis.

Atualmente os professores compartilham, aprendem, disponibilizam, reutilizam conhecimento por meio da tecnologia, e vem descobrindo por meio dela, novas formas de transmissão, assimilação e um diferencial para aplicar em seu modelo pedagógico. É uma nova visão, um novo paradigma que se constrói em função de um objetivo comum, o aprendizado. 
Em virtude da grande quantidade de dispositivos móveis disponíveis no mercado, cada um apresenta funcionalidades particulares e muitas vezes distintas, tanto em software quanto em hardware, isso ocasiona a incompatibilidade dos objetos com os dispositivos, em alguns casos.

Os ambientes móveis na educação proporcionam benefícios tanto aos alunos quanto aos professores. Aos alunos é oferecida uma maior flexibilidade na aprendizagem, pois o material pode estar acessível através de seus dispositivos móveis. Aos educadores the é proporcionado uma nova forma de disponibilizar o material pedagógico e um novo meio de interação com o aluno.

\subsubsection{Computação Ubíqua}

A Computação Ubíqua é um termo utilizado para evidenciar a presença da informática em todos os lugares e no cotidiano das pessoas. É o paradigma de computação que explora a integração crescente de dispositivos de computação com o nosso mundo físico do dia-a-dia. Conforme Magnoni et al (2007) a computação ubíqua manifesta nas características que moldam o ambiente com o intuito de tornálos compatíveis com as necessidades, habilidades e limitações das pessoas.

A computação ubíqua está relacionada com o desenvolvimento de aplicações que não utilizam o desktop, podendo ser utilizadas como estações bases (servidores), onde a interação física entre humano e computadores é distinta, tendo mais similaridade com a forma que os humanos interagem com o mundo físico.

As Interfaces que suportam formas de computação humanas mais naturais (fala, escrita e gestos) começam a substituir os dispositivos tradicionais, ocasionado pela facilidade de aprendizado e de uso.

As aplicações voltadas para a computação ubíqua precisam ser sensíveis ao contexto, adaptando o seu comportamento com base na informação adquirida do ambiente físico e computacional. Pode-se citar como exemplos: aplicações de 
navegação baseada em sistema GPS para carros e dispositivos portáteis; e o reconhecimento de objetos pessoais.

Porém, um número expressivo de aplicações na computação ubíqua, depende da captura automática de experiências reais, para posteriormente prover acesso flexível e universal a estas experiências.

É importante para os educadores terem os seus conteúdos armazenados em servidores na Internet que possam ser acessados em qualquer local, e a qualquer momento. A facilidade de busca, atualizações e integridade de conteúdos de qualquer lugar tornam mais evidente à presença da computação ubíqua, que evidencia um novo avanço tecnológico, por meio do uso de equipamentos e dispositivos tecnológicos. 


\section{TRABALHOS RELACIONADOS}

A revisão bibliográfica realizada para o embasamento teórico necessário para a elaboração da proposta apresentada está resumida a seguir, embora outras referências tenham sido selecionadas e navegadas. Abaixo estão listados alguns dos mais relevantes trabalhos relacionados que serviram para evidenciar o estado da arte e contribuir satisfatoriamente para a ampliação do conhecimento aplicado neste trabalho.

\subsection{METODOLOGIA FRANTZI DE INTEGRAÇÃO DO SCORM COM TV ANYTIME}

Em (FRANTZI, et al, 2004) os autores propõem uma metodologia que visa integrar o padrão SCORM voltado para conteúdos Web com TV Anytime para alcançar interoperabilidade em TV digital e aplicações de aprendizado eletrônico, assim como associar metadados educacionais com programas de TV digital.

A metodologia permite também a interoperabilidade entre aplicações educativas em ambientes de TV digital e facilita a criação de metadados educativos voltados para programas de TV Digital. É possível visualizar por meio de um diagrama de objetos - relacionamento que descreve uma aplicação desenvolvida relativa ao mapeamento entre dois padrões: SCORM e TV-Anytime, que permite a transformação dos metadados da TV-Anytime para a criação de objetos de aprendizagem compatível com SCORM para cursos que utilizem material educacional de programas televisivos. 


\subsection{PROPOSTAS DE LÓPES PARA T-LEARNING}

Em (LÓPES-NORES, et al, 2004) os autores descrevem em seu primeiro artigo o fornecimento de serviços educacionais sobre TV Digital interativa, como sendo um complemento para soluções de aprendizado eletrônico. Tal solução está baseada na plataforma padrão Multimedia Home Plataform - DVB-MHP ${ }^{38}$ que provê o suporte para serviços de aprendizado colaborativo, neste trabalho foi descrito uma arquitetura e avaliada algumas tecnologias para serem implementadas neste processo de aprendizagem colaborativa.

Em seu segundo trabalho (LÓPES-NORES, et al, 2006) é possível visualizar a implementação de um módulo de software que habilita e provê serviços educacionais sobre TV Digital Interativa, onde este módulo foi projetado de acordo com as peculiaridades tecnológicas de receptor de TVDi, assim como recursos para padrões que favorecem a convergência de um nível médio de aprendizado à distância.

O padrão SCORM para T-Learning é o descrito, e mostra a execução dos serviços, o gerenciamento das informações sobre o serviço, assim como uma avaliação e monitoramento. E, finalizando apresenta a arquitetura de uma plataforma de aprendizado para TV, que mostra o SCORM como o módulo central.

\subsection{PROPOSTA DE OLIVEIRA SOBRE T-LEARNING NA AMAZÔNIA}

Em (OLIVEIRA, et al, 2006) os autores descrevem um projeto que aborda educação interativa, englobando EAD e serviços para o cidadão como forma de minimizar uma distância considerável entre eles e as tecnologias digitais utilizando TVD como infraestrutura, com transmissão via satélite.

\footnotetext{
38 É um projeto de middleware aberto do sistema padrão desenhado pelo DVB voltado para TV
} Digital Interativa. 
O projeto evidencia e descreve a possibilidade de prover educação utilizando recursos tecnológicos e uma infra-estrutura de TV Digital ( $T$-Learning) o aprendizado pela TV, abordando a comunicação via satélite em uso na região Amazônica, conseqüente das distâncias de localidades geograficamente dispersas.

\subsection{PROPOSTA DE GOMES DE UM OBJETO DE APRENDIZAGEM CONSTRUTIVISTA}

Em (GOMES, et al, 2007) os autores propõem o desenvolvimento de um objeto de aprendizagem $(\mathrm{OA})$, baseado na teoria construtivista de Piaget.

O OA consiste de um simulador de circuitos digitais, utilizado como reforço de ensino, onde os alunos podem construir seus próprios circuitos digitais com as portas lógicas e, em seguida realizar os testes desses circuitos. O projeto foi desenvolvido para utilizar a tecnologia de TV Digital.

\subsection{PROPOSTA DE BORGES ENGLOBANDO EDUCAÇÃO ATRAVÉS DA TV DIGITAL}

Em (BORGES, et al, 2008) os autores apresentam um estudo de caso sobre a viabilidade da utilização de metadados para agregar informações a uma programação tradicional dando impulso ao aprendizado da população.

Aborda o estudo dos padrões de metadados utilizados em TV digital, e foi aplicado em um cenário que aborda uma campanha de combate a dengue explorando as diversas formas de interatividade possíveis atendendo o padrão de TVD. É simplesmente uma integração de educação com TVD e mostra resultados positivos mensurando a potencialidade dos metadados com TVD como ferramenta educacional. 


\subsection{PROPOSTA DE RIBEIRO FILHO SOBRE A AVALIAÇÃO DE APRENDIZAGEM POR MEIO DA TV DIGITAL INTERATIVA}

Em (RIBEIRO FILHO, et al, 2009) os autores relatam o desenvolvimento de uma aplicação desenvolvida para TV Digital, onde a aplicação auxiliará no processo de avaliação dos alunos. O sistema tem como objetivo permitir uma interatividade entre alunos e professores, onde a validação do aluno no sistema ocorrerá por meio do seu login e senha de acesso.

O software desenvolvido permite a criação de questionários para serem aplicados na TV Digital. E o aplicativo faz o uso do canal de interatividade para realizar a comunicação da aplicação com um servidor remoto, fornecendo recursos de interatividade para que o aluno seja avaliado utilizando os recursos do SBTVD.

\subsection{PROPOSTA DE LEITE PARA O PROCESSO PEDAGÓGICO DE ADAPTAÇÃO} AO AMBIENTE VIRTUAL: CONTRIBUIÇÕES PARA TUTORES E ALUNOS.

Em (LEITE, 2009), o autor propõe um artigo que relata um estudo de caso, sobre a aplicação de uma técnica para obtenção de resultados referentes à adaptação ao ambiente virtual dos alunos de um curso de EAD.

O ambiente virtual utilizado para a avaliação da adaptação do processo pedagógico foi o MOODLE. Todo o processo permitiu a interatividade entre professores e alunos com a modalidade de EAD, articulando os saberes pedagógicos e tecnológicos oferecendo subsídios necessários para validar a interação de conteúdos e ferramentas utilizadas no processo. 


\subsection{ANÁLISE COMPARATIVA DOS ARTIGOS}

Os resumos descritos e mencionados nesta seção foram artigos que englobam padrões e técnicas para se trabalhar com conteúdos de TV Digital Interativa. E principalmente relacionados com Educação à Distância, constituindo desta forma uma fonte rica de extração de conhecimento.

Um trabalho bem interessante de ser visualizado é o proposto por Frantzi (2004) em relação à integração de TV-Anytime e SCORM visando permitir a interoperabilidade entre aplicações educacionais em ambientes de e-learning e TV Digital.

Nos artigos de LÓPES é possível perceber a continuação do seu trabalho de pesquisa, onde num primeiro momento ocorreu a fase de levantamento de tecnologias voltadas para o processo de aprendizagem colaborativa para a tecnologia de TV Digital Interativa e em um segundo momento a implementação de um módulo utilizando o padrão SCORM.

Observa-se a importância do uso de objetos de aprendizagem neste contexto, assim como a possibilidade de reutilizar e aplicar padrões, específicos para os conteúdos educacionais utilizados em programas de TV.

Percebe-se também o uso do SCORM, como um modelo de referência utilizado em aplicações de T-Learning. Assim como a sua viabilidade, uma vez que foi possível constatar uma aplicação real onde o SCORM é o módulo central da arquitetura de uma plataforma de aprendizado para TV, descrevendo a execução e o gerenciamento dos serviços realizados.

A potencialidade dos metadados com TV Digital é transcrito e observado na maioria dos trabalhos apresentados, sendo uma combinação que traz resultados positivos quando se trata dos conteúdos referentes à ambientes educacionais aplicados em programas televisivos.

Os conteúdos educacionais precisam ser tratados, para isso pode-se utilizar mecanismos para a realização da localização das cenas ou conteúdo de vídeo e obter informações pertinentes à produção do respectivo material. Para compor e 
trabalhar com todo este material é necessário a utilização de um padrão adequado de metadados para possibilitar tais manipulações.

Através destas pesquisas foi possível observar um grande número de aplicações voltadas para o aprendizado por meio das mais variadas tecnologias que permitem a interatividade entre professores e alunos, dentre elas podemos destacar: a TVD, os ambientes Web, tipos e formas de interatividade e dispositivos móveis.

Os ambientes virtuais de aprendizagem e os sistemas gerenciadores de aprendizado trazem grandes contribuições para a melhoria do processo pedagógico, e como alternativas de avaliação do conteúdo adquirido pelos alunos.

A EAD vem destacando-se e os ambientes/plataformas onde os objetos de aprendizagem são executados para serem difundidos, permitem alcançar localidades remotas e um público alvo diversificado. 


\section{MODELO DE INTERATIVIDADE}

Esta etapa é responsável por apresentar a especificação de requisitos do modelo de interatividade, das ferramentas interativas e do estudo de caso (descrito no contexto capitulo1) construído baseado no Template Volere, para a melhor compreensão e definição dos requisitos funcionais e não-funcionais, assim como questões de projeto.

Os dados foram coletados por meio da aplicação das técnicas de entrevistas, questionários (apêndice A) e levantamento orientado a ponto de vistas com os especialistas da área os quais permitiram compor os requisitos, através da descrição das necessidades apresentadas.

Para melhor compreender o processo como um todo, de adaptações e integrações de tecnologias, contou-se com a aplicação de técnicas de análise como a de entrevista, questionário, e levantamento orientado a ponto de vistas.

As entrevistas e questionários (modelo no apêndice A) foram aplicados com os atores do processo, dentre eles podemos citar, os professores titulares, os assistentes, alunos e coordenadores de curso.

É importante ressaltar que o modelo pretendido visa auxiliar no processo de ensino e aprendizado dos cursos do SPMT-UEA, através de um modelo interativo que permita professores e alunos interagirem por intermédio de uma solução baseada em um modelo de aprendizagem eletrônica, conforme visto no capitulo 3 , seção 3.2.1.1.

No escopo deste trabalho, a interatividade é o fator principal, sabe-se que esta pode acontecer por diversas formas, formatos e meios e está diretamente relacionada ao modo como um usuário pode influenciar na modificação da forma como pode ser transmitido e desenvolvido um determinado conteúdo voltado para um ambiente computacional. Os tipos de interatividade variam de acordo com a aplicação desejada. 
Os modelos presenciais mediados por TV, analisados e observados para o desenvolvimento desta proposta são os cursos presenciais mediados por tecnologia que ocorrem na UEA.

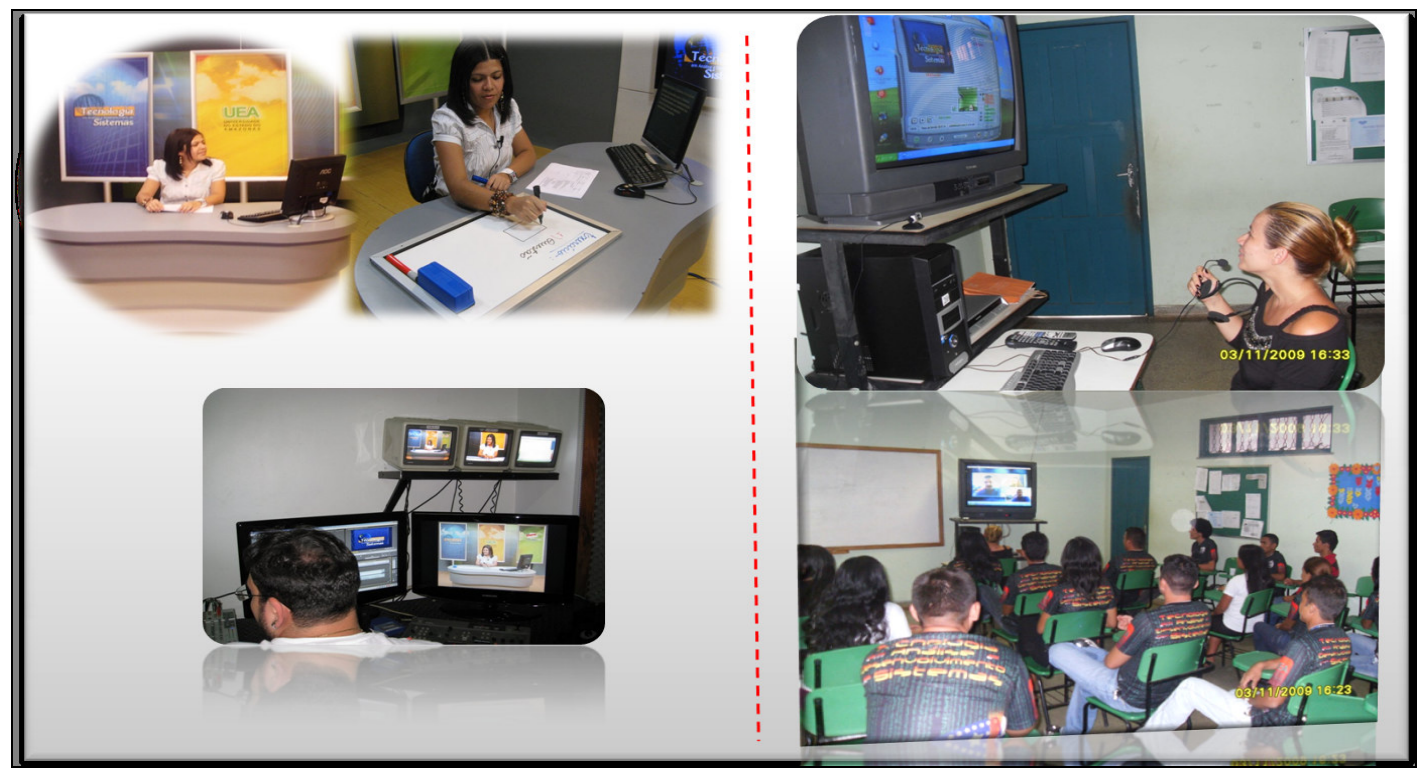

Figura 13 - Transmissão de Aula do Curso TADS do SPMT - UEA

A figura 13 mostra uma aula em tempo real sendo ministrada neste modelo do curso de tecnologia em análise e desenvolvimento de sistemas, onde o professor ministra as suas aulas, supervisionado pelo administrador de conteúdo televisivo responsável pelo controle das câmeras e do conteúdo lançado na tela da TV; e do outro lado nos municípios estão o professor assistente e os alunos assistindo a aula e interagindo por meio do kit tecnológico (detalhado no capitulo 2, seção 2.2.1).

A aula é transmitida ao vivo do estúdio da universidade na capital, e os alunos tem a possibilidade de interagir com o professor, apenas em um horário especifico definido pelo mesmo, onde existem algumas restrições de interação em virtude da quantidade de alunos, de municípios e do tempo disponível para a realização desta dinâmica. 
Atualmente nos cursos do SPMT a interatividade acontece por meio de um software proprietário, porém não é ainda uma solução satisfatória para os professores. Durante o processo os professores titulares disponibilizam um horário (préestabelecido) para realizar esta dinâmica de interatividade, por município, escolhendo-se um ou dois alunos no máximo que realizam perguntas ou algum tipo de questionamento.

A necessidade existente de uma retroalimentação em tempo real do aprendizado dos alunos desencadeou a motivação pela busca de uma solução de interatividade em tempo real.

Obter informações referentes ao aprendizado dos alunos no instante em que um conteúdo for ministrado é um retorno importante que o professor necessita para trabalhar com uma metodologia mais adequada.

\subsection{OBJETIVO DO PROJETO}

O objetivo deste trabalho é propor um modelo de ensino interativo aplicáveis ao cenário do SPMT da UEA.

\subsection{METAS DO PROJETO}

A busca por um modelo que possa prover uma realimentação imediata ao professor que ministra aulas neste modelo educacional contribuirá academicamente para os cursos atuantes desta universidade e posteriormente para outras universidades que utilizem o canal televisivo como meio de transmissão de conteúdos educacionais.

Algumas das metas de projeto pretendidas podem ser citadas a seguir:

- Proporcionar uma realimentação imediata da aula do professor neste sistema educacional. 
- Permitir ao aluno interagir com o conteúdo ministrado, resolvendo questões e obtendo os resultados imediatamente.

- Possibilitar a satisfação dos professores em relação ao aprendizado do aluno;

- Possibilitar a satisfação dos alunos ao obterem uma retroalimentação imediata do aprendizado do conteúdo.

- Contribuir para o processo interativo dos cursos do SPMT da UEA.

Ao adotar este modelo a universidade contará com mais um recurso tecnológico interativo que pode ser implementado em seus cursos, resultando em ganho do ponto de vista pedagógico.

A universidade poderá ser mais adiante uma referência ao adotar para o SPMT recursos de uma ferramenta migrada de um $L M S$ de referência que é o TIDIA Ae, e cuja integração está relacionada com a tecnologia de TV Digital.

\subsection{AS PARTES INTERESSADAS}

A UEA é a principal interessada na implantação do modelo. Outros interessados são os especialistas do processo educacional do SPMT (Coordenação, professores e assistentes pedagógicos), sendo os professores e os alunos do curso serão os principais usuários do sistema.

\subsection{RESTRIÇÕES DE PROJETO}

As restrições referem-se a um limite que pode ser produzido ou realizado conforme as especificações listadas por um cliente referente às atividades ou necessidades apresentadas relacionadas ao projeto. 
A seguir estão listadas, as restrições identificadas para o cumprimento do projeto.

- Integrar tecnologias E-learning ao T-learning, sendo que o sistema de gerenciamento de aprendizagem escolhido foi o TIDIA Ae;

- Utilizar plataforma de software livre;

- Utilizar ferramentas voltadas para aplicações com TV Digital;

- O exercício deve ser visualizado na tela da TV;

- A resposta dos exercícios deve ocorrer por meio de um dispositivo móvel (celular).

\subsection{ESCOPO DO TRABALHO}

No capítulo 2 seção 2.3, é possível obter uma visão macro do cenário do SPMT da UEA (escopo do trabalho). Dependendo do curso e das disciplinas ministradas, metodologias e recursos são utilizados com o objetivo de facilitar o aprendizado dos alunos.

$\mathrm{Na}$ figura 13 apresentada no capítulo 5 seção 5.1 .1 , observa-se o professor titular ministrando a sua disciplina pela televisão, e sendo transmitida via satélite em tempo real para os municípios, onde se encontram o professor assistente e os alunos. Sendo o professor assistente responsável pela mediação do aprendizado dos alunos e interagindo com o professor titular por meio do chat disponível pelo software IP.TV ${ }^{\circledR}$. 


\subsection{ESCOPO DO SISTEMA}

A proposta é explorar e utilizar a interatividade proporcionada pelos ambientes de gerenciamento de aprendizagem e aplicar no aprendizado pela TV contribuindo para a construção de um conhecimento construtivista baseado em uma interatividade em tempo real, transformando o papel passivo de um aluno (em sala de aula) "ouvindo o que lhe dizem", num papel ativo onde os alunos interagem através de dispositivos tecnológicos por intermédio do meio que lhe transmite o conhecimento, a TV.

Porém, o conceito assimilado de TV Interativa (visto no capitulo3, seção 3.3.2) desde a sua concepção permite atender um público-alvo bem maior quando comparado com a Internet, uma vez que permite que informações multimídias possam ser manipuladas e permitindo uma interatividade maior com o usuário.

Após a descrição de todo cenário apresentado da modalidade presencial mediada por tecnologia é possível observar a sua importância em relação ao ensino a distância. A TV Interativa é mais uma alternativa positiva para a melhoria do processo, em virtude da padronização de metodologias, linguagens, recursos multimídias dentre outros aspectos que tendem a possibilitar uma interatividade e oferecer recursos de hipermídia com um baixo custo e com qualidade.

O TIDIA Ae (definido no capitulo 3 na seção 3.2.1.1) é composto de uma gama de ferramentas que possibilitam uma interatividade em tempo real entre tutores e alunos. A princípio a idéia é explorar a ferramenta de exercícios existente no ambiente.

Com essa migração será possível que o professor titular possa ministrar suas aulas lançando dinâmicas e obtendo um retorno imediato das respostas dos alunos (quantos acertaram/erraram por Município). O Professor titular terá a possibilidade de realizar comentários, assim como monitorar e gerenciar as respostas/resultados imediatamente.

Esta interatividade poderá ocorrer a partir de qualquer um dos dispositivos sugeridos a seguir: controle remoto, telefone celular, "pda", "smartphone", "netbook" ou até mesmo de um computador. A opção de ser um "netbook" permitirá que os conteúdos 
de aula lançados na TV, possam ser armazenados e acessados pelos alunos facilitando não apenas a interatividade como também o seu aprendizado. Por outro lado um celular seria um dispositivo de fácil manuseio e significativamente relevante para a aplicação.

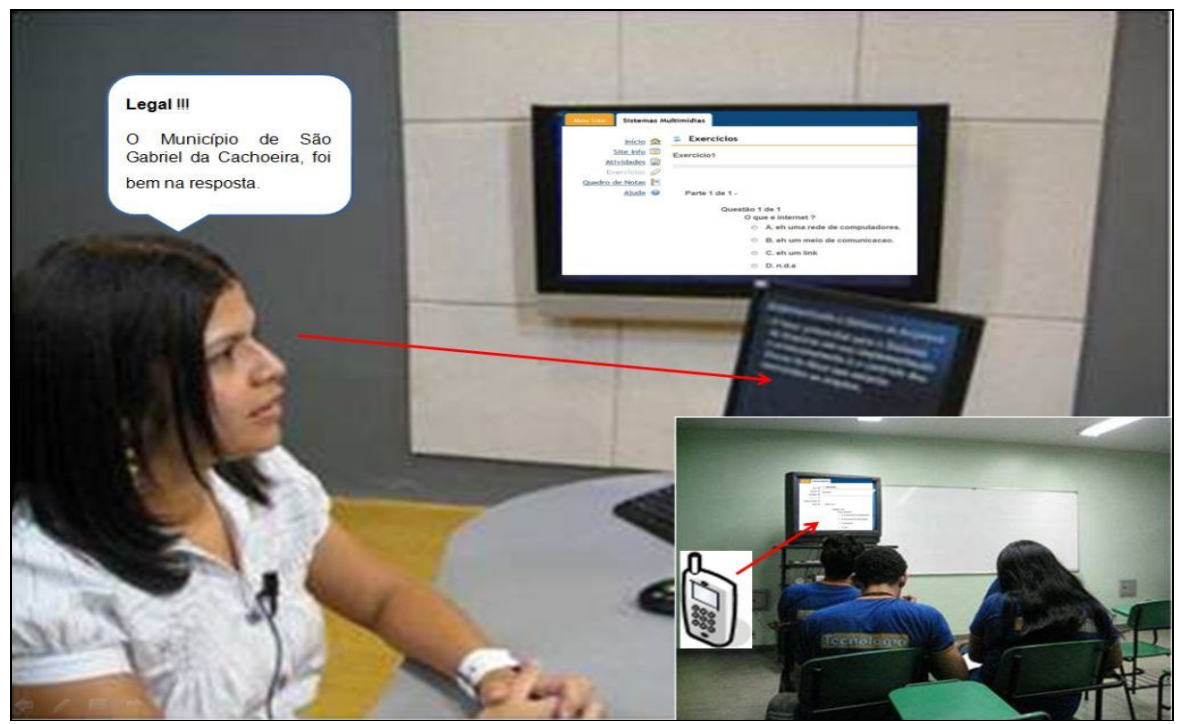

Figura 14 - Representação da proposta.

$\mathrm{Na}$ figura 14 pode-se visualizar uma possível simulação do cenário desejado de interatividade que se deseja alcançar, onde o professor titular no estúdio de TV transmitindo a sua aula e lançando uma questão na tela, no outro lado (nos municípios) estão os alunos interagindo com o professor, respondendo a questão a partir de um dispositivo móvel. No instante em que os resultados são obtidos o professor consegue visualizar na tela do seu computador e obter uma realimentação imediata do aprendizado, podendo então a seu critério mostrar na tela da TV os resultados obtidos com o lançamento da questão.

O cenário acima proposto é significativamente relevante, e pode claramente se tornar viável e funcional, e atenderá expressivamente as necessidades dos professores titulares que ministram aulas neste modelo educacional. Deve-se levar em consideração a quantidade de alunos que devem interagir simultaneamente, e a 
quantidade de municípios, o que dificulta consideravelmente uma proposta interativa por meio apenas da televisão, sem contar com a transmissão via satélite que depende de fatores ambientais e de uma transmissão de alta qualidade para permitir a interação, o que não ocorre atualmente.

Existem vários meios que podem ser seguidos para sua realização, porém alguns obstáculos podem impedir a validação por estes caminhos.

Para validar a proposta foram levantados os seguintes cenários:

1. Simulação em Laboratório;

2. Simulação em um dos Cursos do Modelo;

3. Simulação por intermédio de emuladores de TV Digital.

Tais cenários supracitados, foram estudados para validar a proposta, mais a sua realização envolverá fatores como: financeiro; tempo (considerado mínimo para o cumprimento total do modelo); burocráticos; tecnológicos (linguagem nova, ambiente novo, tecnologias distintas, etc); entre outros que serão visualizados no decorrer da finalização do estudo.

Pode-se assim concluir que se deseja como resultado desta proposta 0 desenvolvimento de uma solução que permita a integração de conteúdos interativos de ambiente Web para TV Digital, capaz de garantir a interoperabilidade entre estas plataformas.

A idéia é permitir que os professores possam ter acesso em tempo real, às informações geradas pelas atividades de aprendizagem dos alunos. Exemplo: acesso às respostas de exercícios e avaliações em tempo real, realizadas por meio da TV. 


\subsubsection{Diagrama de Caso de Uso}

Neste contexto foram identificados os seguintes atores, mostrados na tabela 6 a seguir.

Tabela 6 - Descrição dos atores do Diagrama de Caso de Uso.

\begin{tabular}{l|l}
\hline ATORES & DESCRIÇÃO \\
\hline PROFESSOR TITULAR & $\begin{array}{l}\text { Responsável pela elaboração e exportação dos exercícios no } \\
\text { Ambiente de Aprendizagem Eletrônica TIDIA Ae. }\end{array}$ \\
\hline PROFESSOR ASSISTENTE & $\begin{array}{l}\text { Responsável pelo lançamento no SCRI da quantidade de } \\
\text { alunos em sala de aula no momento da interatividade. }\end{array}$ \\
\hline ALUNOS & $\begin{array}{l}\text { Responsáveis pela realização das respostas dos exercícios } \\
\text { mostrados na TV, por meio de um dispositivo móvel. }\end{array}$ \\
\hline ADMINISTRADOR TELEVISIVO & $\begin{array}{l}\text { Responsável pela busca, apresentação e transmissão do } \\
\text { exercício na tela da TV. }\end{array}$ \\
\hline $\begin{array}{l}\text { SISTEMA TIDIA AE } \\
\text { SISTEMA DE QUESTÕES }\end{array}$ & $\begin{array}{l}\text { Sistema responsável por importar e apresentar os exercícios } \\
\text { elaborados no TIDIA Ae e o resultado de acertos e erros das } \\
\text { questões por município. }\end{array}$ \\
\hline DISPOSITIVO MÓVEL & $\begin{array}{l}\text { Sistema responsável por importar, calcular e exportar o } \\
\text { percentual de acertos e erros das questões por município. }\end{array}$ \\
\hline e exportação dos exercícios.
\end{tabular}


A figura 15 apresenta o diagrama de casos de uso proposto para o projeto de TV interativa e a seguir a descrição detalhada dos casos de uso.

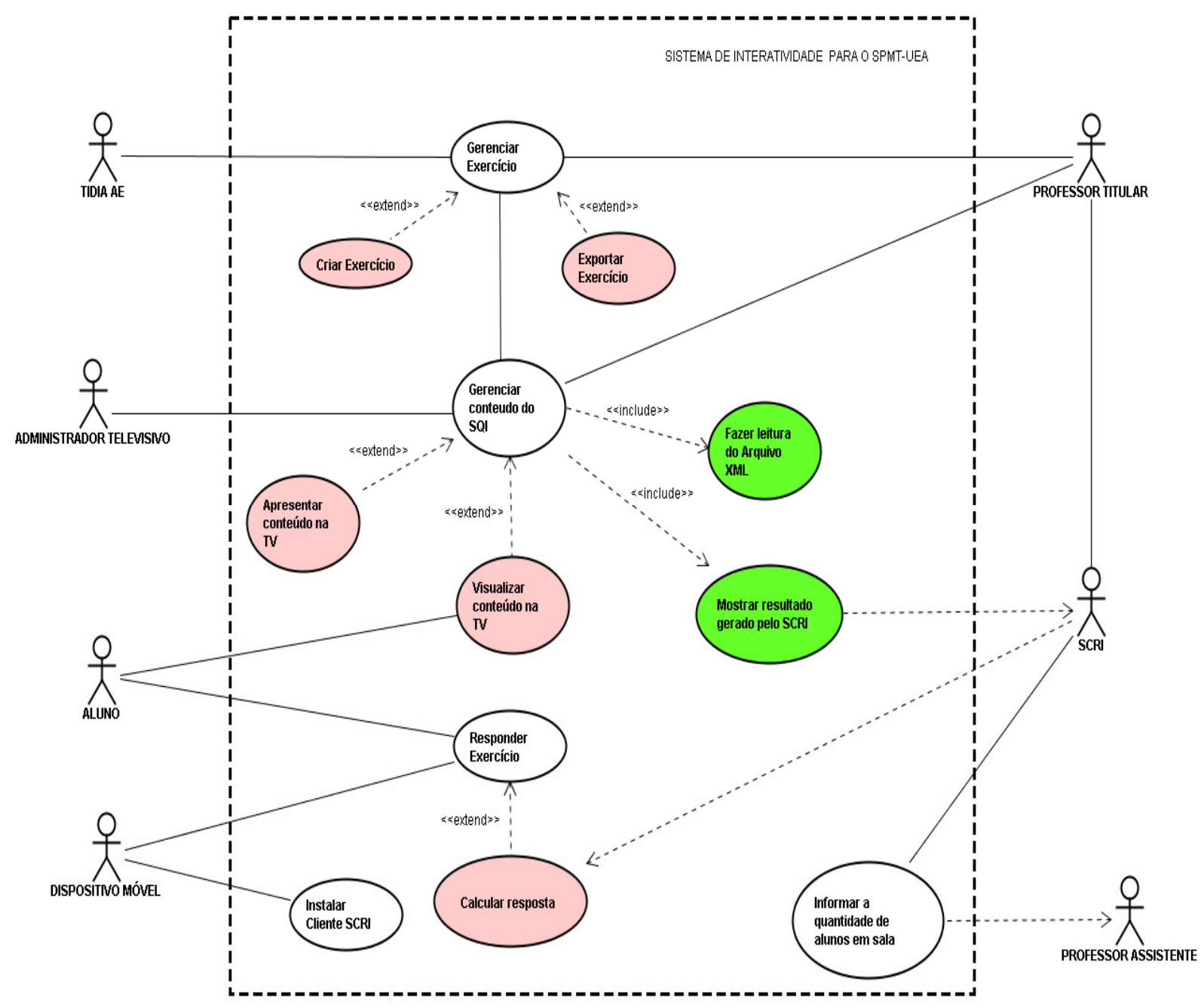

Figura 15 - Diagrama de Caso de Uso da Aplicação. 


\section{Descrição dos Casos de Uso}

\begin{tabular}{|l|l|}
\hline UC-01: Caso de Uso 01 & \multicolumn{1}{|c|}{ Gerenciar Exercício } \\
\hline Atores & TIDIA Ae, Professor \\
\hline Descrição & $\begin{array}{l}\text { O professor titular deverá criar um login e senha } \\
\text { no sistema TIDIA Ae; Criar o site da disciplina, } \\
\text { disponibilizando informações; Criar um projeto } \\
\text { com o nome da disciplina e escolher as } \\
\text { ferramentas que inicialmente serão utilizadas } \\
\text { (ex: exercício e quadro de notas); Adicionar } \\
\text { alunos da disciplina; Exportar o exercício em } \\
\text { formato XML. }\end{array}$ \\
\hline Evento Iniciador & Logar no sistema TIDIA Ae. \\
\hline Pré-condição & Sistema TIDIA Ae em execução. \\
\hline Pós-condição & Registro criação e exportação de exercício. \\
\hline Extensões & $\begin{array}{l}\text { Casos de Uso “Criar exercício" e “Exportar } \\
\text { Exercício". }\end{array}$ \\
\hline Inclusões & Não há inclusões. \\
\hline
\end{tabular}

\begin{tabular}{|l|l|}
\hline UC-02: Caso de Uso 02 & Gerenciar conteúdo do SQI \\
\hline Atores & $\begin{array}{l}\text { Administrador televisivo, SQI, Professor Titular, } \\
\text { Aluno. }\end{array}$ \\
\hline Descrição & $\begin{array}{l}\text { O administrador televisivo visualiza e coordena a } \\
\text { apresentação das questões na TV selecionadas } \\
\text { pelo professor titular. }\end{array}$ \\
\hline Evento Iniciador & Receber os arquivos no formato XML. \\
\hline Pré-condição & Durante a realização das aulas. \\
\hline Pós-condição & $\begin{array}{l}\text { Registro de apresentação e transmissão do } \\
\text { conteúdo. }\end{array}$ \\
\hline
\end{tabular}




\begin{tabular}{|l|l|}
\hline Extensões & $\begin{array}{l}\text { Casos de Uso “Visualizar conteúdo na TV" e } \\
\text { "Apresentar conteúdo na TV". }\end{array}$ \\
\hline Inclusões & Caso de Uso "Fazer leitura do arquivo XML". \\
\hline
\end{tabular}

\begin{tabular}{|l|l|}
\hline UC-03: Caso de Uso 03 & \multicolumn{1}{|c|}{ Apresentar resultado gerado pelo SCRI } \\
\hline Atores & SCRI. \\
\hline Descrição & $\begin{array}{l}\text { O SCRI exporta um arquivo XML por município } \\
\text { com o resultado de erros e acertos dos alunos } \\
\text { para o servidor de conteúdo localizado no } \\
\text { estúdio, para que o administrador de conteúdo } \\
\text { televisivo possa apresentar na TV. }\end{array}$ \\
\hline Evento Iniciador & $\begin{array}{l}\text { O arquivo é enviado automaticamente após o } \\
\text { cálculo das respostas. }\end{array}$ \\
\hline Pré-condição & $\begin{array}{l}\text { Existência de todos os arquivos de respostas dos } \\
\text { alunos presentes em sala. }\end{array}$ \\
\hline Pós-condição & $\begin{array}{l}\text { Informações agregadas enviadas ao servidor de } \\
\text { conteúdo. }\end{array}$ \\
\hline Extensões & $\begin{array}{l}\text { Não há extensões. } \\
\text { Não há inclusões. }\end{array}$ \\
\hline Inclusões & $\begin{array}{l}\text { O sistema pode não estar apto para transmitir os } \\
\text { resultados em virtude de problemas de } \\
\text { estabelecimento de conexão (físico, intermitência } \\
\text { do canal, entre outros.), neste caso um limite de } \\
5 \text { tentativas são realizadas. Caso contrário a } \\
\text { solicitação deverá acontecer diretamente pelo } \\
\text { sistema. }\end{array}$ \\
\hline Histórico & \\
\hline
\end{tabular}




\begin{tabular}{|l|l|}
\hline UC-04: Caso de Uso 04 & \multicolumn{1}{|c|}{ Responder Exercício } \\
\hline Atores & Aluno, Dispositivo Móvel, SCRI. \\
\hline Descrição & $\begin{array}{l}\text { Os alunos devem responder as questões por } \\
\text { meio de um dispositivo móvel. }\end{array}$ \\
\hline Evento Iniciador & $\begin{array}{l}\text { Invocação feita por um subsistema do dispositivo } \\
\text { do usuário para recepção de informações. }\end{array}$ \\
\hline Pré-condição & $\begin{array}{l}\text { Serviço de obtenção disponível para ser } \\
\text { executado. }\end{array}$ \\
\hline Pós-condição & Informações persistidas. \\
\hline Extensões & Caso de Uso "Calcular resposta". \\
\hline Inclusões & Não há inclusões \\
\hline Histórico & $\begin{array}{l}\text { O dispositivo pode não estar apto para transmitir } \\
\text { os resultados em virtude de problemas de } \\
\text { estabelecimento de conexão (físico, intermitência } \\
\text { do canal, entre outros.), neste caso uma nova } \\
\text { tentativa deve ser realizada, caso contrário emite- } \\
\text { se uma mensagem de <<erro>>. }\end{array}$ \\
\hline
\end{tabular}

\begin{tabular}{|l|l|}
\hline UC-05: Caso de Uso 05 & \multicolumn{1}{|c|}{ Informar a quantidade de alunos em sala. } \\
\hline Atores & SCRI, Professor Assistente. \\
\hline Descrição & $\begin{array}{l}\text { O professor assistente do Município deverá } \\
\text { informar no sistema SCRI no dia da aplicação } \\
\text { dos Exercícios interativos a quantidade de alunos } \\
\text { presentes em sala de aula. }\end{array}$ \\
\hline Evento Iniciador & $\begin{array}{l}\text { O sistema SCRI deverá estar alimentado } \\
\text { corretamente com todas as informações dos } \\
\text { Municípios. }\end{array}$ \\
\hline Pré-condição & Sistema SCRI atualizado. \\
\hline Pós-condição & Status ok. \\
\hline Extensões & Não há extensões. \\
\hline Inclusões & Não há inclusões. \\
\hline
\end{tabular}




\begin{tabular}{|l|l|}
\hline UC-06: Caso de Uso 06 & \multicolumn{1}{|c|}{ Instalar cliente SCRI } \\
\hline Atores & Dispositivo Móvel, Professor Assistente. \\
\hline Descrição & $\begin{array}{l}\text { O software cliente SCRI deve ser instalado no } \\
\text { dispositivo móvel para prover a comunicação } \\
\text { com o sistema SCRI. }\end{array}$ \\
\hline Evento Iniciador & Enviar arquivo para o dispositivo móvel. \\
\hline Pré-condição & Compilador gerado pela aplicação. \\
\hline Pós-condição & Status ok. \\
\hline Extensões & Não há extensões. \\
\hline Inclusões & Não há inclusões. \\
\hline
\end{tabular}

\subsection{REQUISITOS FUNCIONAIS}

Os requisitos funcionais são aqueles que descrevem o comportamento do sistema, ou seja, descrevem o que o sistema deve fazer. Os requisitos funcionais (RFs) podem ser descritos em requisitos de usuário (que especificam as funções que o sistema deve prover ao usuário final) e requisitos de sistema (que especificam as funções e restrições para que o sistema seja capaz de atender).

Esta seção apresenta amplamente os requisitos funcionais (RFs) aplicáveis ao projeto descritos abaixo na tabela 7 .

Tabela 7 - Descrição dos requisitos funcionais do sistema.

\begin{tabular}{l|l}
\hline REQUISITOS & DESCRIÇÃO \\
\hline RF-01 & $\begin{array}{l}\text { A Coordenação dos cursos do SPMT deve solicitar } \\
\text { aos professores titulares da disciplina se cadastrar } \\
\text { no sistema TIDIA Ae. }\end{array}$ \\
\hline
\end{tabular}




\begin{tabular}{|c|c|}
\hline RF-02 & $\begin{array}{l}\text { A Coordenação dos cursos do SPMT deve solicitar } \\
\text { aos professores titulares da disciplina criar e } \\
\text { exportar os exercícios no sistema TIDIA Ae. }\end{array}$ \\
\hline RF-03 & $\begin{array}{l}\text { O Administrador do sistema deve permitir ao aluno, } \\
\text { professor titular e assistente, visualizar as } \\
\text { questões criadas no TIDIA Ae na TV. }\end{array}$ \\
\hline RF-04 & $\begin{array}{l}\text { O Administrador de TV deve atualizar (importar) os } \\
\text { arquivos de conteúdo (exercícios) no terminal de } \\
\text { acesso. }\end{array}$ \\
\hline RF-05 & $\begin{array}{l}\text { O Administrador do sistema de TV deve permitir o } \\
\text { acesso do professor titular, ao sistema SQI para } \\
\text { selecionar as respostas dos alunos. }\end{array}$ \\
\hline RF-06 & $\begin{array}{l}\text { O professor deve monitorar as questões } \\
\text { disponíveis no sistema SQI, selecionando as mais } \\
\text { adequadas a serem apresentadas. }\end{array}$ \\
\hline RF-07 & $\begin{array}{l}\text { O Administrador de TV ou professor titular devem } \\
\text { atualizar (importar) o banco de questões do SQI } \\
\text { com exercícios criados e exportados pelo TIDIA } \\
\text { Ae. }\end{array}$ \\
\hline RF-08 & $\begin{array}{l}\text { Os Coordenadores de Curso do SPMT tem a } \\
\text { função de alimentar o sistema SCRI. }\end{array}$ \\
\hline RF-09 & $\begin{array}{l}\text { Os professores assistentes devem lançar no SCRI } \\
\text { a quantidade de alunos presentes em sala de aula } \\
\text { para a realização da interatividade. }\end{array}$ \\
\hline RF-10 & $\begin{array}{l}\text { Permitir ao professor titular acessar o sistema } \\
\text { SCRI para visualizar as respostas dos alunos por } \\
\text { Município(s). }\end{array}$ \\
\hline RF-11 & $\begin{array}{l}\text { Os professores titulares devem acessar o sistema } \\
\text { SCRI para selecionar as respostas dos alunos por } \\
\text { Município(s) e apresentar na TV por meio do SQI. }\end{array}$ \\
\hline RF-12 & $\begin{array}{l}\text { Os professores titulares podem monitorar o } \\
\text { aprendizado dos alunos na referida disciplina } \\
\text { através do sistema SCRI. }\end{array}$ \\
\hline
\end{tabular}




\begin{tabular}{l|l}
\hline RF-13 & $\begin{array}{l}\text { Os coordenadores de Curso do SPMT devem } \\
\text { solicitar aos professores assistentes inserir no } \\
\text { SCRI a quantidade de alunos presentes em sala } \\
\text { de aula para realizar a interatividade. }\end{array}$ \\
\hline RF-14 & $\begin{array}{l}\text { Os professores assistentes e os alunos devem } \\
\text { instalar o aplicativo cliente SCRI no dispositivo } \\
\text { móvel do aluno que permite a interação. }\end{array}$ \\
\hline RF-15 & $\begin{array}{l}\text { Os professores assistentes devem orientar e } \\
\text { permitir o acesso do aluno do SPMT para } \\
\text { responder e enviar a sua resposta pelo cliente } \\
\text { SCRI embutido no dispositivo móvel. }\end{array}$ \\
\hline
\end{tabular}

\subsection{REQUISITOS NÃO FUNCIONAIS}

\subsubsection{Requisitos Sensoriais}

Os requisitos sensoriais dão ênfase à aparência da aplicação e esta deve ser personalizada obedecendo às seguintes configurações:

Tela Principal (Aplicação na TV)

- Logomarca de Interatividade (canto inferior esquerdo da tela);

- Utilizar Fonte adequada para ser visualizada na TV;

- Utilizar como fundo uma imagem escolhida pelo especialista do sistema;

- Usar cores que não interfiram na qualidade da imagem. 


\subsubsection{Requisitos de Interatividade}

A interface deverá ser amigável e de fácil manuseio, simples e que permita uma visualização adequada das questões, obedecendo ao tamanho padrão utilizado pela produção de conteúdos televisivos da universidade.

A correta utilização do dispositivo móvel, a aplicação voltada para o dispositivo deve ser de baixa complexidade considerando usuários que possuem uma média alfabetização digital.

O sistema deve apresentar uma realimentação para todas as ações do usuário, indicando a realização ou conclusão de uma operação.

\subsubsection{Requisitos de Usabilidade e Humanidade}

Os administradores de conteúdo televisivo possuem um conhecimento técnico, são especialistas na área, o que facilita a sua navegação e apresentação do conteúdo na tela da TV. Pode-se destacar os seguintes requisitos:

- A facilidade ao acesso às informações mostradas na televisão precisa seguir um padrão considerando itens como tamanho, formato, resolução de tela e elementos gráficos. Portanto as interfaces das aplicações deverão ser geradas seguindo os seguintes princípios de usabilidade: (i) simples, para total compreensão do conteúdo pelos usuários não acostumados aos layouts da TV Digital, tornando fácil o seu acesso, (ii) de fácil compreensão para que os usuários não percam muito tempo para encontrar o que deseja, (iii) os textos e conteúdos exibidos devem ser objetivos e não muito extensos.

- O sistema de TV, o SQI e o SCRI devem ser de fácil uso para os professores e alunos utilizarem respectivamente. 
- Não há necessidade atualmente de estar em outras línguas, por ser um sistema inicial e de foco definido.

\subsubsection{Requisitos de Desempenho}

São requisitos responsáveis pela especificação da quantidade de tempo disponível para a realização de determinadas tarefas, ou seja, referem-se ao tempo de resposta e também a capacidade do produto para funcionar a uma velocidade adequada no ambiente pretendido. Dentre eles podemos destacar:

- A interface principal do sistema ao usuário deve apresentar um tempo de resposta máximo (a ser definido pelo professor titular).

- A resposta deve ser rápida o suficiente para evitar a interrupção do fluxo de pensamento do usuário.

- O sistema deve consultar o servidor de conteúdo, para gerar as questões dos exercícios dos alunos na tela.

- O sistema de SCRI deve consultar o servidor de conteúdo para atualizar as respostas dos alunos na tela do computador do professor.

- O sistema SCRI deve realizar a leitura e transmitir os conteúdos atualizados dos municípios no prazo máximo de 3 minutos do lançamento de uma questão.

\subsubsection{Requisitos de Operação e Ambientais}

São requisitos responsáveis por especificar o ambiente físico em que 0 sistema irá operar. Dentre eles podemos destacar os seguintes requisitos: 
- O ambiente pode ser utilizado quando a transmissão estiver com um enlace adequado de banda para não ocasionar perda de informações e de transmissões;

- Em virtude de a transmissão ocorrer via satélite, o tempo chuvoso pode provocar muita perda de sinal;

\subsubsection{Requisitos de Manutenção e Suporte}

Os requisitos de manutenibilidade e de suporte referem-se aos ambientes e plataformas necessárias para que o produto entre em execução. Podemos destacar os seguintes requisitos:

- O sistema pode ser operado em ambientes de plataformas de software livre;

- O sistema cliente SCRI deve ser capaz de ser instalado e utilizado pelos usuários alunos.

- Novas versões do produto podem ser lançadas semestral ou anualmente dependendo do impacto que causar com o seu uso e a demanda obtida.

- O sistema de TV é projetado para funcionar em um estúdio de televisão numa transmissão em tempo real.

- O sistema deverá apresentar a portabilidade e com possibilidade de agregar tecnologias;

\subsubsection{Requisitos de Padrão (Standard)}

Considerando a diversidade de soluções tecnológicas que podem ser adotadas para a implementação de um sistema de televisão digital interativa, diversos órgãos de 
padronização concentraram esforços na especificação de padrões, o padrão adotado pelo Brasil é baseado no padrão ISDB (Padrão Japonês). Segundo Becker (2008) o decreto $n$ \%5.820 de 26.07.2006 definiu as tecnologias do ISDB-TB (International System for Digital Broadcasting - Terrestrial Brazil), nome adotado pelo SBTVD, e também estabeleceu as regras de implementação de TV Digital no Brasil em um prazo de sete anos para a cobertura total do sinal em todo o território brasileiro.

Um sistema de televisão digital interativa deve adotar e integrar um conjunto de diferentes tecnologias de hardware e software para implementar suas funcionalidades.

\subsection{QUESTÕES DE PROJETO}

\subsubsection{Riscos}

Os riscos compreendidos nesta fase referem-se à incompatibilidade de software ou de plataformas, por este motivo deve-se trabalhar com modelos que sejam entendidos e manipulados pelas distintas plataformas e sistemas operacionais. Existe o risco de não ser realizado todas as provas de conceito, porém isso se dará em virtude do prazo estabelecido não ser suficiente para implementar todos os requisitos.

\subsubsection{Custos}

Os projetos a partir do momento que se constituem, automaticamente, geram um ônus para uma organização ou para o desenvolvedor responsável pela sua execução. 
Os custos a serem levantados podem ser descritos a seguir:

- Custos com equipe de desenvolvimento;

- Custos com equipamentos, licenças de software e sistemas de comunicação;

- Custos com riscos;

- Custos com a implantação e treinamento de usuários;

- Custos com fatores não detectados.

\subsubsection{Documentação e Treinamento do Usuário}

A documentação do sistema (manual), assim como o treinamento do usuário será realizada pela equipe pedagógica dos cursos.

\subsubsection{Sala de Espera}

Referem-se a requisitos que podem futuramente serem implementados, mais em virtude do tempo e de prazos anteriormente definidos não podem ser finalizados. Dentre eles pode-se destacar:

- Implementar funcionalidades de outras ferramentas interativas geradas pelo TIDIA Ae.

- Atualizar em novas versões, outras ferramentas interativas do sistema TIDIA Ae. 


\subsubsection{Idéias para Soluções}

Com o decorrer dos estudos e análises levantadas, podem-se encontrar outros possíveis caminhos validos para contribuir positivamente para o sucesso deste modelo de sistema. Dentre eles pode-se destacar a:

- Integração do sistema TIDIA Ae com o sistema acadêmico da UEA, visando importar todos os dados dos alunos automaticamente;

- Integrar outras tecnologias que permitam proporcionar interatividade com outras ferramentas disponíveis no sistema TIDIA Ae. 


\section{MODELAGEM E PROJETO DO MODELO INTERATIVO}

Esta seção aborda a modelagem e o projeto da infraestrutura interativa utilizando os conceitos de UML, para explorar a arquitetura e a troca de informações realizadas. Mostrando de forma clara os padrões, as técnicas e os modelos utilizados para provar a viabilidade da solução técnica proposta.

\subsection{CENÁRIO DA APLICAÇÃO}

O SPMT da UEA é o cenário onde se deseja aplicar o modelo de aprendizagem interativa proposto. Segundo Roderick SIMS (1997) a interatividade é uma atividade entre dois organismos, que provê respostas adequadas às necessidades informativas de ambos, podemos ressaltar a realimentação a ser permitida através da resposta imediata dos alunos, onde permitirá ao professor mensurar o conhecimento obtido dos mesmos, ao ministrar uma disciplina neste contexto educacional. No capítulo 2, na seção 2.3 é abordado todo o cenário do SPMT da UEA, e no capitulo 5, na seção 5.6 que trata do escopo do sistema é possível visualizar a proposta desejada de interatividade em tempo real aplicado no cenário do SPMT da UEA.

\subsection{MODELAGEM DA PROPOSTA}

A figura 16 a seguir representa o contexto da aplicação definido no capitulo 1, seção 1.1. Contexto, na computação, é uma informação relevante usada para caracterizar uma situação de uma entidade (DEY; ABOWD; 1999) e podemos considerar uma entidade como sendo um objeto relevante (uma pessoa, um lugar ou um objeto). 
Neste trabalho existem quatro entidades identificadas, são elas: os usuários do sistema (que são compostos pelo administrador de conteúdo, professor titular/assistente e aluno), o dispositivo móvel, o sistema SCRI e a aplicação televisiva.

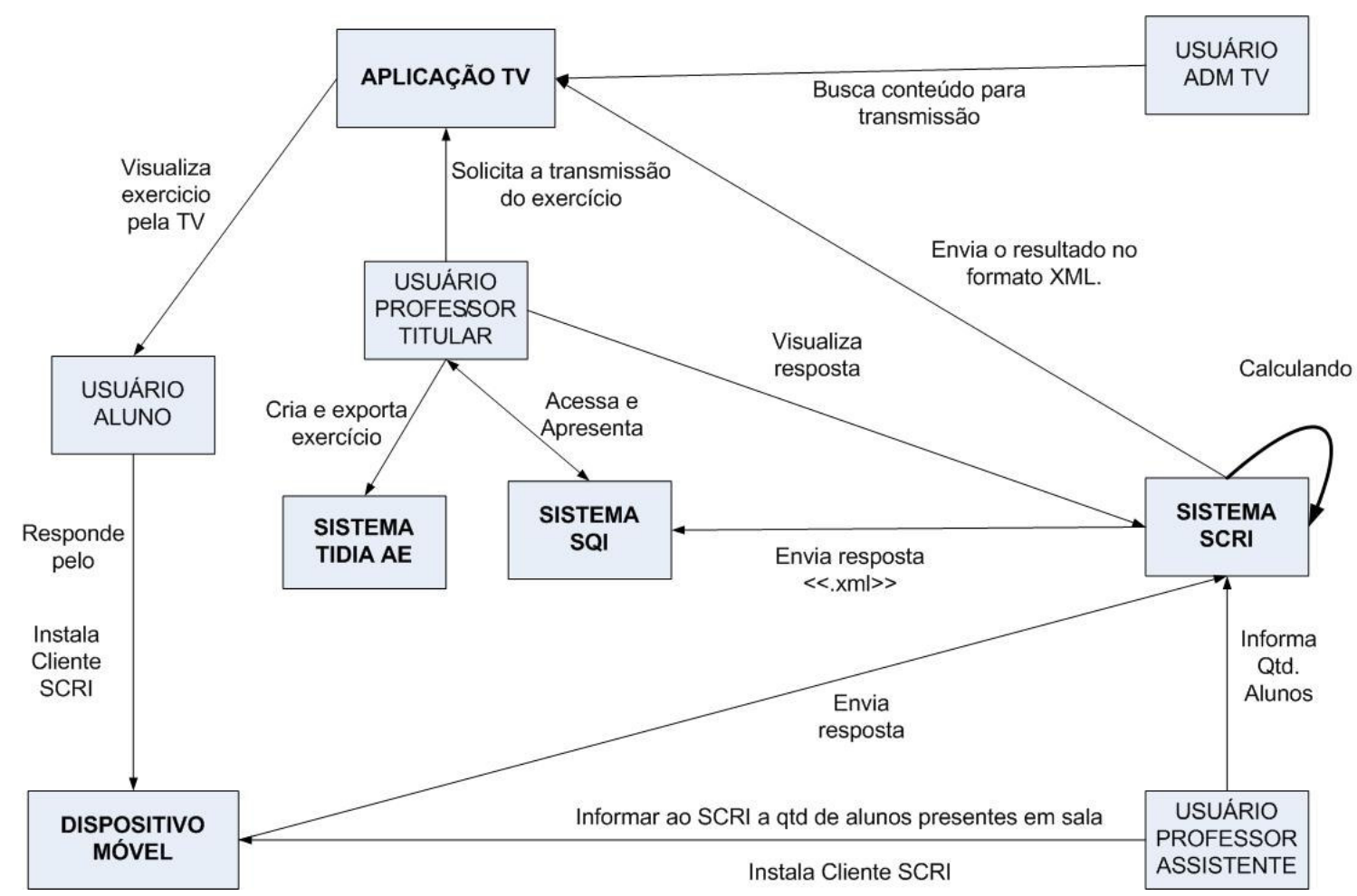

Figura 16 - Modelagem de Contexto da Interação dos Usuários

\subsection{MODELO ARQUITETURAL}

O modelo arquitetural proposto neste trabalho é composto de uma arquitetura híbrida, combinado com objetos específicos, resultado da utilização de diferentes softwares de distintas linguagens de programação e interfaces.

A arquitetura é constituída por módulos que podem ser visualizados na figura 17 que mostra que a interação entre os módulos é representada pelas setas direcionais, 
observando-se assim a dependência existente entre os componentes, sendo descritos a seguir.
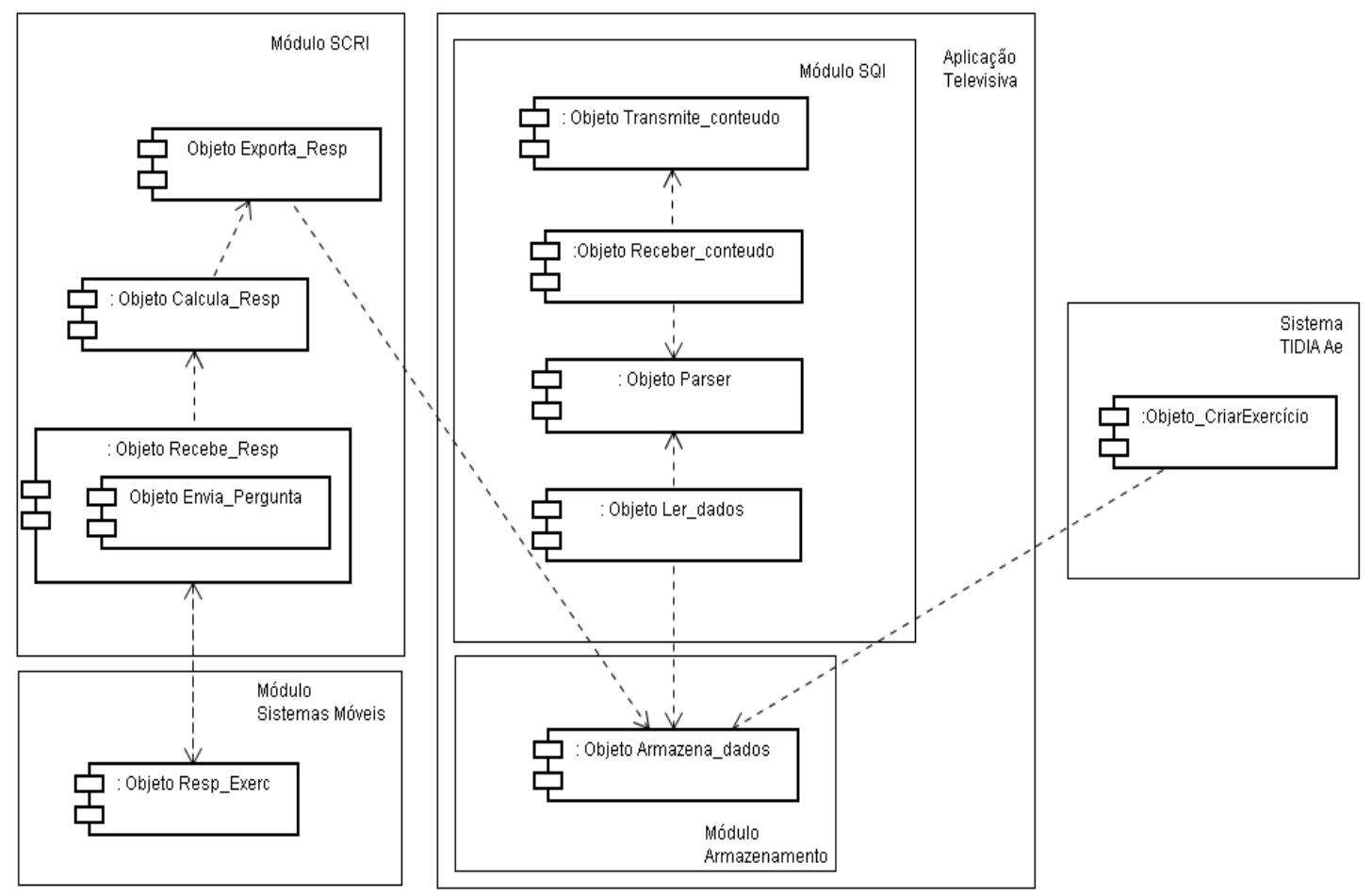

Figura 17 - Modelo arquitetural do sistema interativo.

Descrição dos Módulos e objetos:

- Módulo de Aplicação Televisiva é responsável pela funcionalidade do módulo SQI e pelas informações enviadas e armazenadas pelos módulos SCRI e TIDIA Ae para o módulo de armazenamento, onde as informações são acessadas diretamente pelo módulo SQI.

- Módulo de Sistemas TIDIA Ae refere-se ao sistema de gerenciamento de aprendizagem onde os exercícios são criados e exportados em formato $X M L$ pelo objeto CriarExercício que envia para o objeto Armazena_dados localizado no módulo armazenamento. Na figura 18 é possível visualizar um exemplo do arquivo XML padrão QTI (definido no capítulo 3 seção 3.3.2.3) 
gerado pelo professor titular no sistema TIDIA Ae e armazenado pelo mesmo no objeto Armazena_dados do módulo de armazenamento.

- <response label ident="A" rarea="Ellipse" rrange="Exact" rshuffle="Yes">

$-<$ material $>$

- <mattext charset="ascii-us" texttype="text/plain" xml-space="default">

- <![CDATA[ eh uma rede de computadores. ]]>

$<$ /mattext $>$

$<$ /material>

$-<$ material $>$

<matimage embedded="base64" imagtype="text/html" uri="'" />

$<$ /materials

$</$ response abel $>$

- <response label ident="B" rarea="Ellipse" rrange="Exact" rshuffle="Yes">

$-<$ material $>$

- <mattext charset="ascii-us" texttype="text/plain" xml-space="default" >

- <![CDATA[ eh um meio de comunicacae. ]]>

$<$ /mattext $>$

$<$ /material $>$

- <material>

<matimage embedded="base64" imagtype="text/html" uri="'" />

$<$ /material $>$

$</$ response label $>$

- <response ${ }_{2}$ abel ident="C" rarea="Ellipse" rrange="Exact" rshuffle="Yes">

$-<$ material $>$

- <mattext charset="ascii-us" texttype="text/plain" xml-space="default" >

- <! [CDATA[ eh um link ]]>

$<$ mattext $>$

$<$ /material $>$

- <material $>$

<matimage embedded="base64" imagtype="text/html" uri="'" />

$<$ /material $>$

$</$ response label $>$

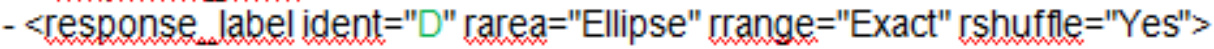

$-<$ material $>$

- <mattext charset="ascii-us" texttype="text/plain" xml-space="default" >

$-<$ CLDATA $[n$ d a $]]>$

$<$ /mattext $>$

$<$ /material $>$

Figura 18 - Exemplo do arquivo XML de exercício gerado pelo sistema TIDIA Ae.

- Módulo do SCRI refere-se a um sistema computacional cujos protótipos de interfaces foram desenvolvido em ambiente Delphi 10 (apresentados no capitulo 6), trabalhando com o banco MySqL e com componentes e pacotes $\mathrm{XML}$ responsáveis pela implementação das funcionalidades desejadas. A 
Extensible Markup Language (XML) é uma linguagem de marcação que tem o propósito de proporcionar a criação de marcadores e atributos conforme as necessidades dos desenvolvedores (W3C, 2009). O sistema tem como objetivo receber através do objeto Recebe_Resp o resultado informado pelo aluno por meio do objeto Resp_Exerc, que por sua vez envia o resultado para o objeto Calcula_Resp responsável pelo cálculo do percentual de acertos e erros dos alunos, e envia para o objeto Exporta_Resp através de um arquivo de resposta padrão XML (que pode ser visualizado na figura 19), que por sua vez envia o arquivo via Internet para o objeto Armazena_dados no Módulo Armazenamento.

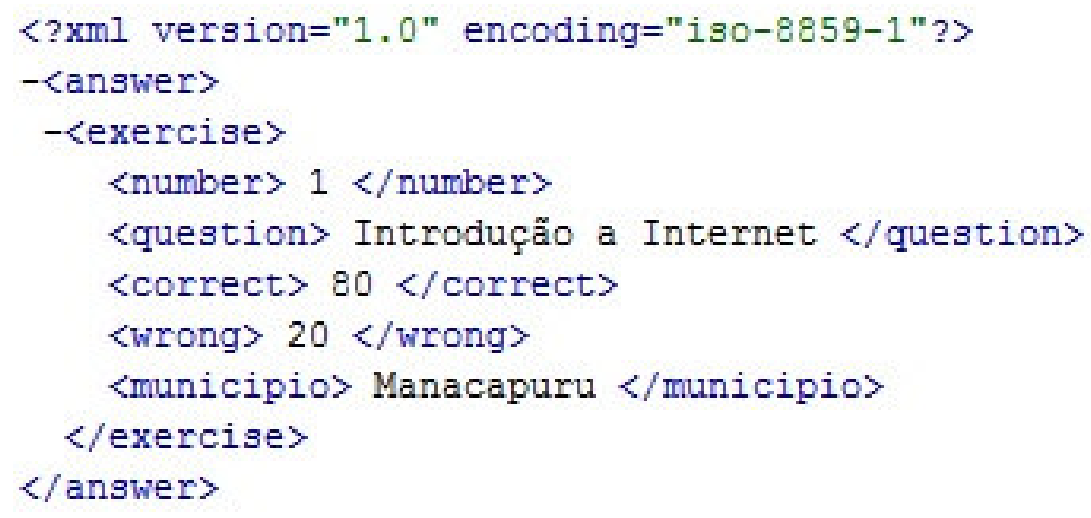

Figura 19 - Exemplo do arquivo XML gerado e exportado pelo sistema SCRI.

- Módulo de Sistemas Móveis refere-se ao sistema cliente SCRI a ser configurado no dispositivo móvel do aluno, sendo desenvolvido para suportar a tecnologia do JME (JAVA Microedition) e conexão Bluetooth para se comunicar com o servidor de conteúdo local (situado no município), o modelo a ser importado pelo dispositivo móvel do sistema SCRI (pode ser visto na figura 20). O sistema SCRI, é responsável pelo recebimento e tratamento dos dados com o intuito de gerar o resultado, o modelo de resposta enviado pelo cliente SCRI (visualizado na figura 21) será exportado para o Módulo SQI via conexão Web ou Bluetooth. Deve-se desenvolver de uma Interface gráfica amigável voltada para aplicações em dispositivos móveis. 


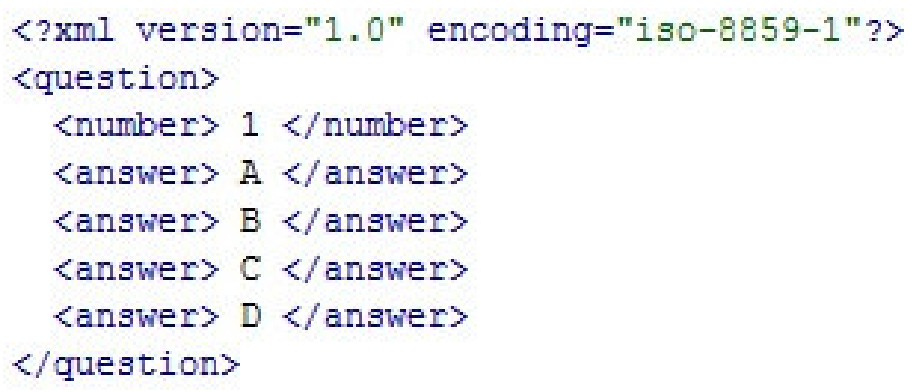

Figura 20 - Exemplo do arquivo XML importado pelo cliente SCRI.

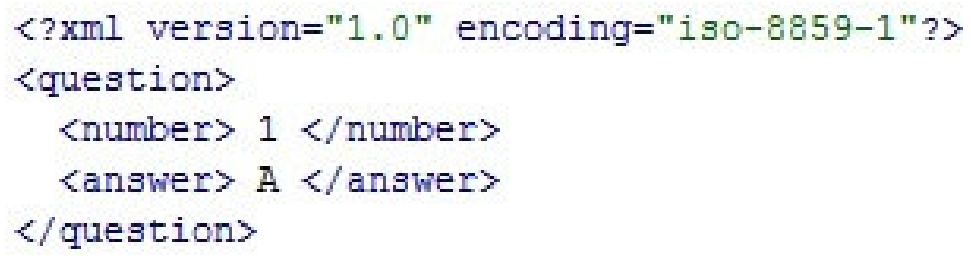

Figura 21 - Exemplo do arquivo XML exportado pelo cliente SCRI.

- Módulo SQI é o responsável pelo lançamento das questões interativas (exercícios construídos no TIDIA Ae) e transmitidas na tela da TV, cujo aplicativo é desenvolvido utilizando a tecnologia de Java TV. Para que este evento de apresentação e transmissão de conteúdos ocorra é necessário inicialmente que o professor titular selecione o arquivo de exercício desejado, o objeto Ler_dados importa o arquivo em formato XML (mostrado na figura 18) e o objeto Parser busca e faz a leitura do conteúdo a ser apresentado, o objeto Receber_conteudo é responsável pela apresentação do conteúdo na tela da TV e o objeto Transmite_conteudo fica responsável pela transmissão dos exercícios na tela da TV.

- Módulo de Armazenamento é o responsável pelo armazenamento de todos os arquivos XML gerado pelos módulos que integram o modelo da aplicação televisiva (Tidia Ae e SCRI). 
Para armazenar os dados gerados tanto pelo TIDIA Ae como pelo SCRI, foram utilizados arquivos XML que possibilitam ao desenvolvedor adicionar estruturas a seus documentos (sintaxe).

Neste contexto, a interpretação e validação, dos arquivos XML gerados e transmitidos para TV Digital é realizada por meio de um interpretador Parser. Existem dois tipos de Parser o primeiro que utiliza a interface Document Object Model - DOM, que é baseada na construção de estruturas em árvores na memória compostas pelos dados do arquivo permitindo assim a sua manipulação, onde é possível criar, excluir, pesquisar e escrever dados em um documento XML, porém o DOM utiliza muito recurso de memória. E o outro tipo é o Simple API for XML - SAX que permite somente a leitura dos dados contidos em um documento $X M L$, é simples de usar, realiza a leitura de arquivos XML de qualquer tamanho e em relação ao acesso de informações de um documento XML, o SAX é mais rápido quando comparado ao DOM (W3SCHOOLS, 2008).

O Parser XML SAX é a tecnologia mais indicada para realizar a leitura dos arquivos XML exportados do TIDIA Ae, e o Parser XML DOM é mais indicado para permitir a escrita no XML SCRI cliente no momento em que o aluno interage com a aplicação selecionando a opção correta. Para implementação do objeto parser a tecnologia escolhida e utilizada por oferecer um conjunto reduzido de componentes para formatação de dados em XML foi o nanoXML ${ }^{39}$, definido pela Multimedia Home Platform - MHP do padrão Digital Video Broadcasting - DVB para o tratamento de conteúdo XML em TV Digital (NANOXML, 2008).

\subsection{PROJETO}

Esta seção consiste em apresentar a infra-estrutura que permitirá o suporte tecnológico para que ocorram o trafego das informações que compõem o modelo interativo proposto.

39 http://devkix.com/nanoxml.php 
Esta infra-estrutura foi desenhada levando em consideração todos os requisitos, tecnologias, meio de comunicação via satélite atuante no SPMT da UEA. A figura 22 retrata a disponibilização dos elementos, sendo possível visualizar o resultado esperado com a implementação deste modelo interativo educacional.

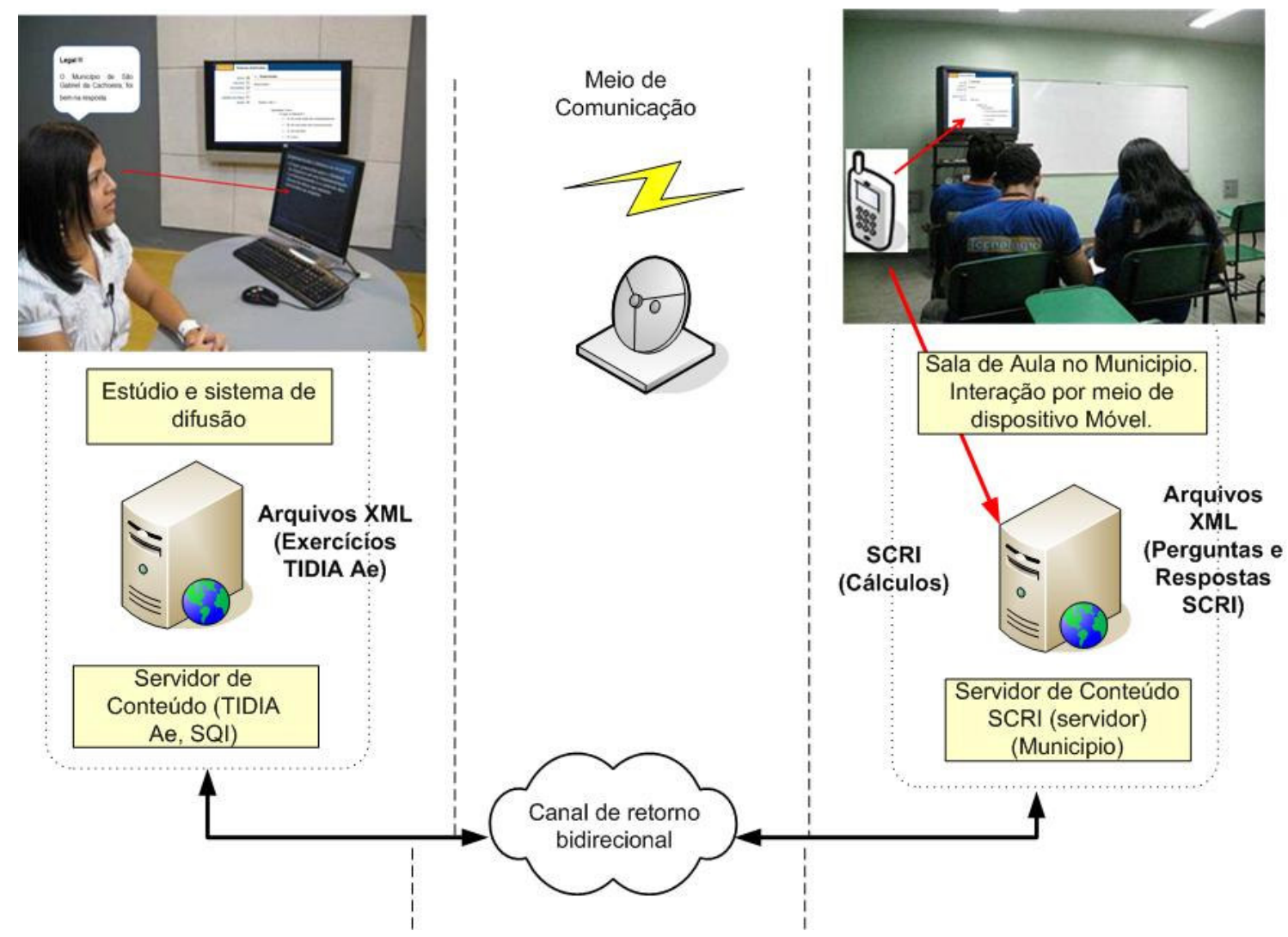

Figura 22 - Modelo de infra-estrutura interativa proposta.

Na figura 22 está o professor titular (lado esquerdo) no estúdio de TV apresentado a sua aula em tempo real, onde o sistema difusor vai prover a transmissão do conteúdo e suportar as interações com os alunos (lado direito) que se encontram nos municípios da região. Por meio da TV (receptor de conteúdo) serão recebidos e apresentados os conteúdos para os alunos possibilitando a sua interação. O meio de difusão que permitirá a habilitação da comunicação entre difusor e receptor é via satélite. 
$\mathrm{Na}$ figura 23, é possível observar o cenário proposto com base nos requisitos especificados e na modelagem realizada, atendendo as necessidades dos atores envolvidos no processo e do contexto apresentado no capítulo 1 seção 1.1 .

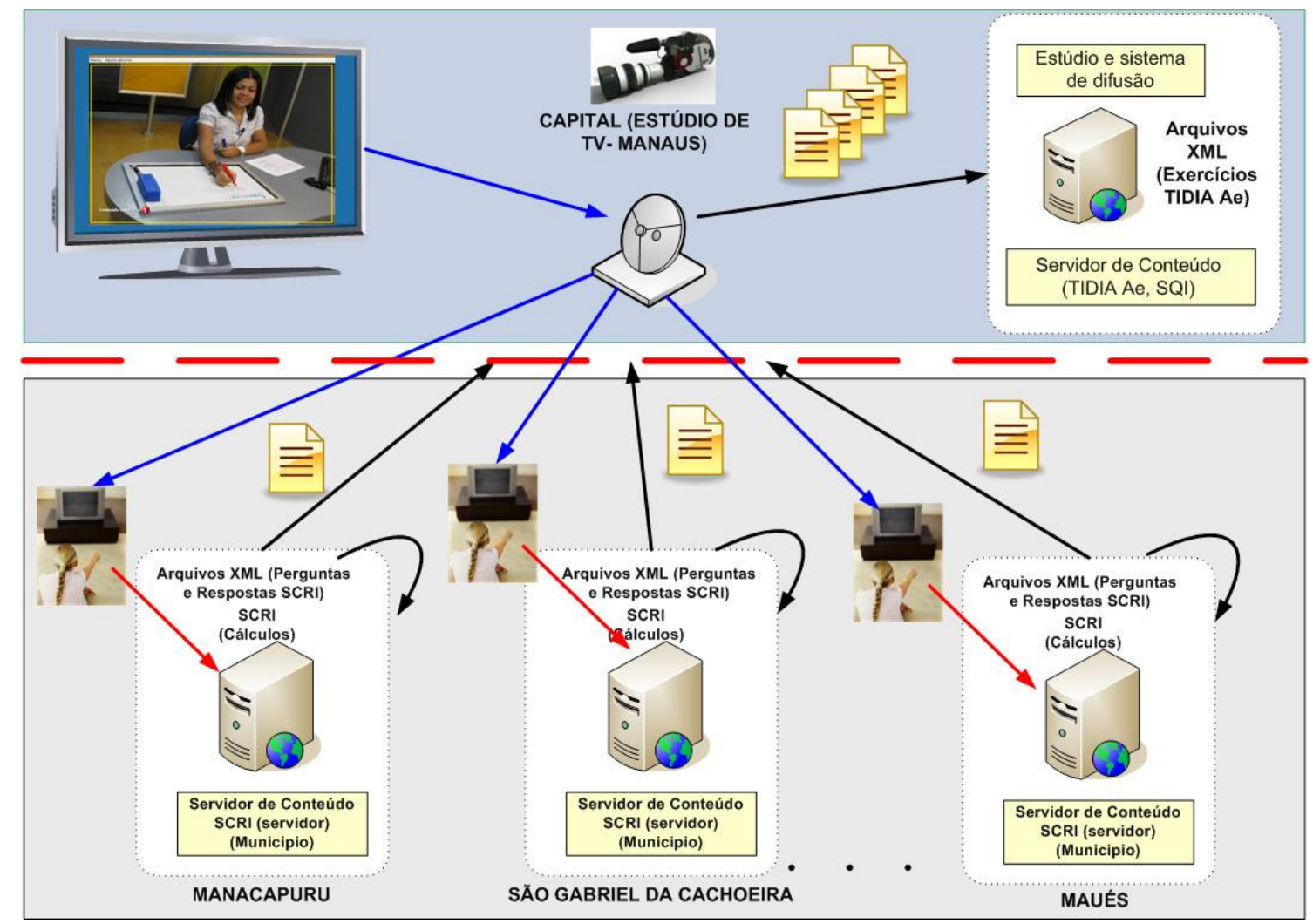

Figura 23 - Esquema de cenário proposto do modelo interativo.

Neste esquema é possível visualizar a existência de servidores locais em cada município onde ocorrem os cursos do SPMT, responsáveis pela realização do tratamento das informações antes delas serem enviadas para o servidor central na capital. Em cada Municipio, há um servidor de conteúdo local responsável pelo tratamento dos dados e pela geração dos resultados por meio do SCRI que por sua vez realiza a exportação do(s) arquivo(s) em formato XML para o servidor central localizado no estúdio da UEA na capital. 
Os alunos interagem por meio de um celular que é configurado para receber e executar o cliente do SCRI responsável pelo envio dos arquivos de resposta para o servidor local.

As respostas são tratadas e um resultado final é enviado para o servidor central. O professor titular então acessa o conteúdo por meio do SQI e poderá realizar a apresentação do conteúdo na tela da televisão o qual será transmitido para todos os demais municípios.

O fluxo de dados da rede desta forma não será tão intenso (evitando assim um possível congestionamento na rede), não ocorrendo gargalos na comunicação, perda de dados, e retardos em relação ao tempo de comunicação prevista entre os servidores, ressaltando que todo o modelo interativo foi pensado, modelado e projetado considerando o cenário apresentado.

Neste modelo é possível observar como a proposta do modelo interativo descrita no capítulo 5 seção 5.6 , foi projetada considerando os requisitos elicitados ao decorrer do mesmo capitulo.

O professor titular desta forma poderá lançar uma questão na tela da TV, iniciar a interação em tempo real, solicitar que os alunos interajam com a aplicação e posteriormente evidenciar os resultados, realizando comentários, elogios, ou realizando tomadas de decisões pertinentes considerando dados concretos.

O capítulo apresenta detalhes de projeto representado por meio das classes associadas através do diagrama de classes relacionado com o cenário de caso de uso (visto o capitulo 4), visando detalhar e mostrar a interação existentes entre os objetos. O diagrama de sequência mostrará a sequência de mensagens que são trocadas entre as interações principais do sistema. 

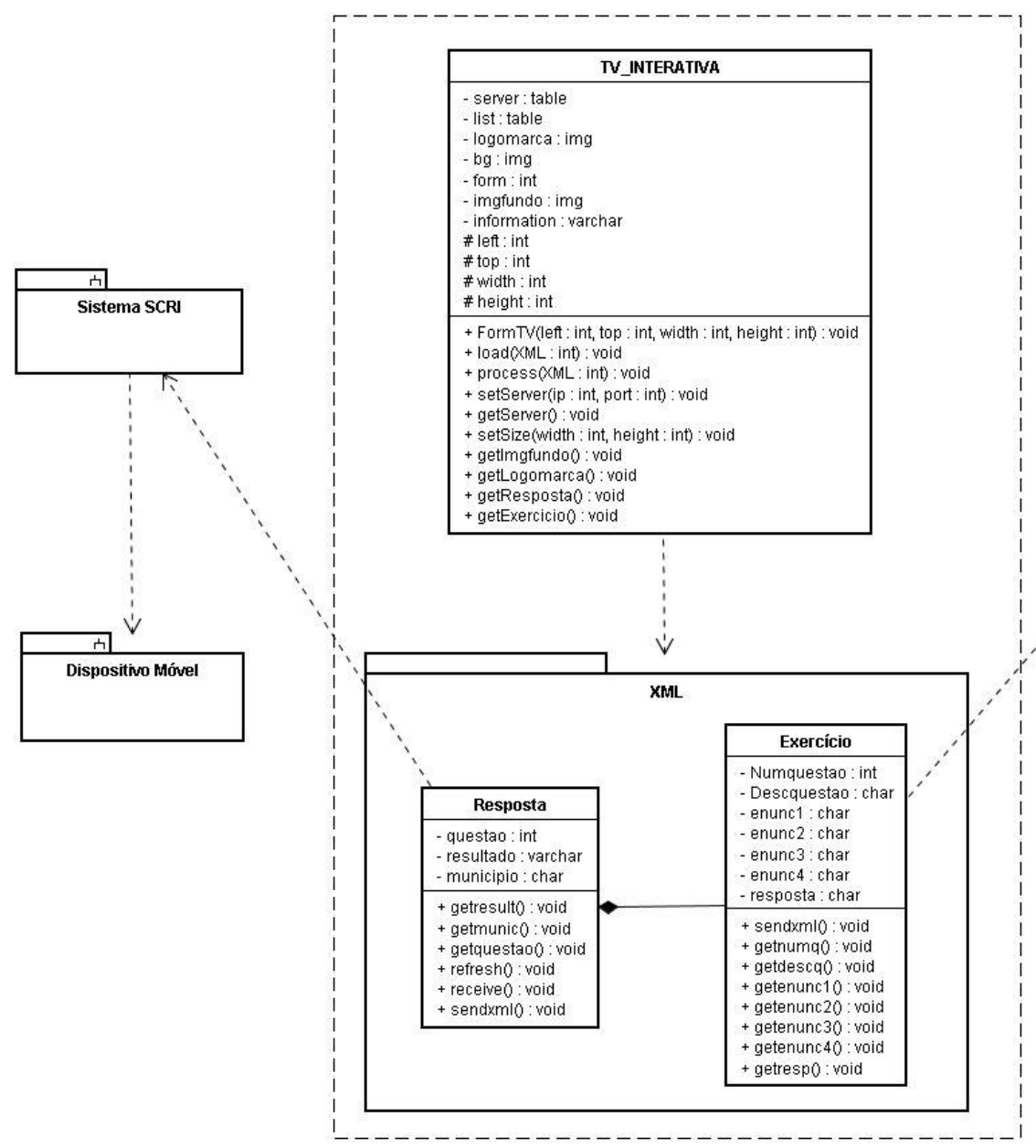

Figura 24 - Diagrama de classes do modelo televisivo.

A figura 24 mostra as dependências existentes entre a classe principal e as demais classes do pacote XML com os outros subsistemas. A classe TV_INTERATIVA depende dos arquivos de resposta e exercícios gerados e armazenados no pacote denominado XML, que por sua vez dependem de informações oriundas de outros subsistemas, por exemplo, a classe resposta depende do subsistema SCRI que por sua vez depende da informação oriunda do subsistema dispositivo móvel. A classe exercício possui um relacionamento de agregação forte com a classe resposta, em virtude de a classe ser composta por uma quantidade de resposta, relacionada com cada objeto exercício criada. 
O diagrama de sequência deste cenário ilustra a troca de mensagens entre professores e alunos dentro do contexto de interatividade como se pode observar na figura 25 a seguir.

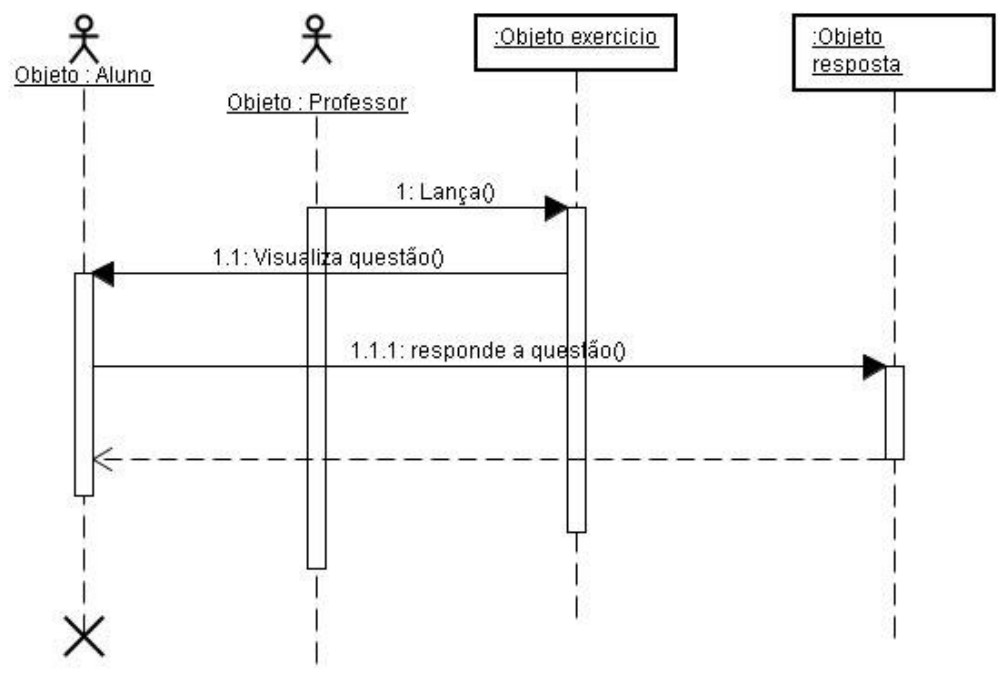

Figura 25 - Cenário da interatividade realizada entre professor e alunos.

O diagrama de sequência deste cenário ilustra a realização do exercício no sistema TIDIA Ae pelo professor que em seguida exporta o arquivo em formato XML para o servidor de conteúdo (representado pelo objeto armazena_dados) localizado no estúdio da UEA, como se pode observar na figura 26. 


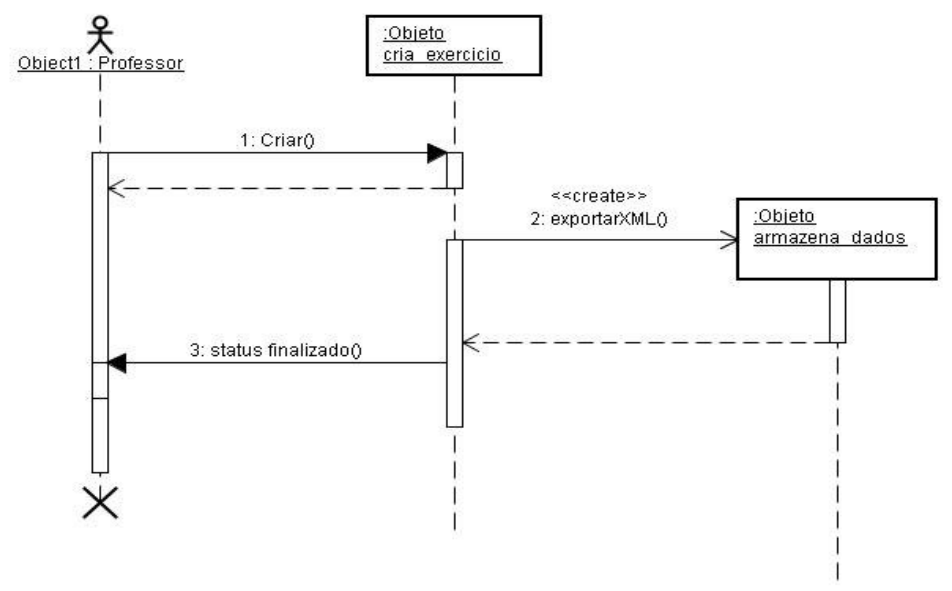

Figura 26 - Cenário representativo da criação do exercício no TIDIA Ae.

O diagrama de sequência deste cenário ilustra a realização do exercício no sistema TIDIA Ae pelo professor que em seguida exporta o arquivo em formato XML para 0 servidor de conteúdo (representado pelo objeto armazena_dados) localizado no estúdio da UEA, como se pode observar na figura 27 a seguir.

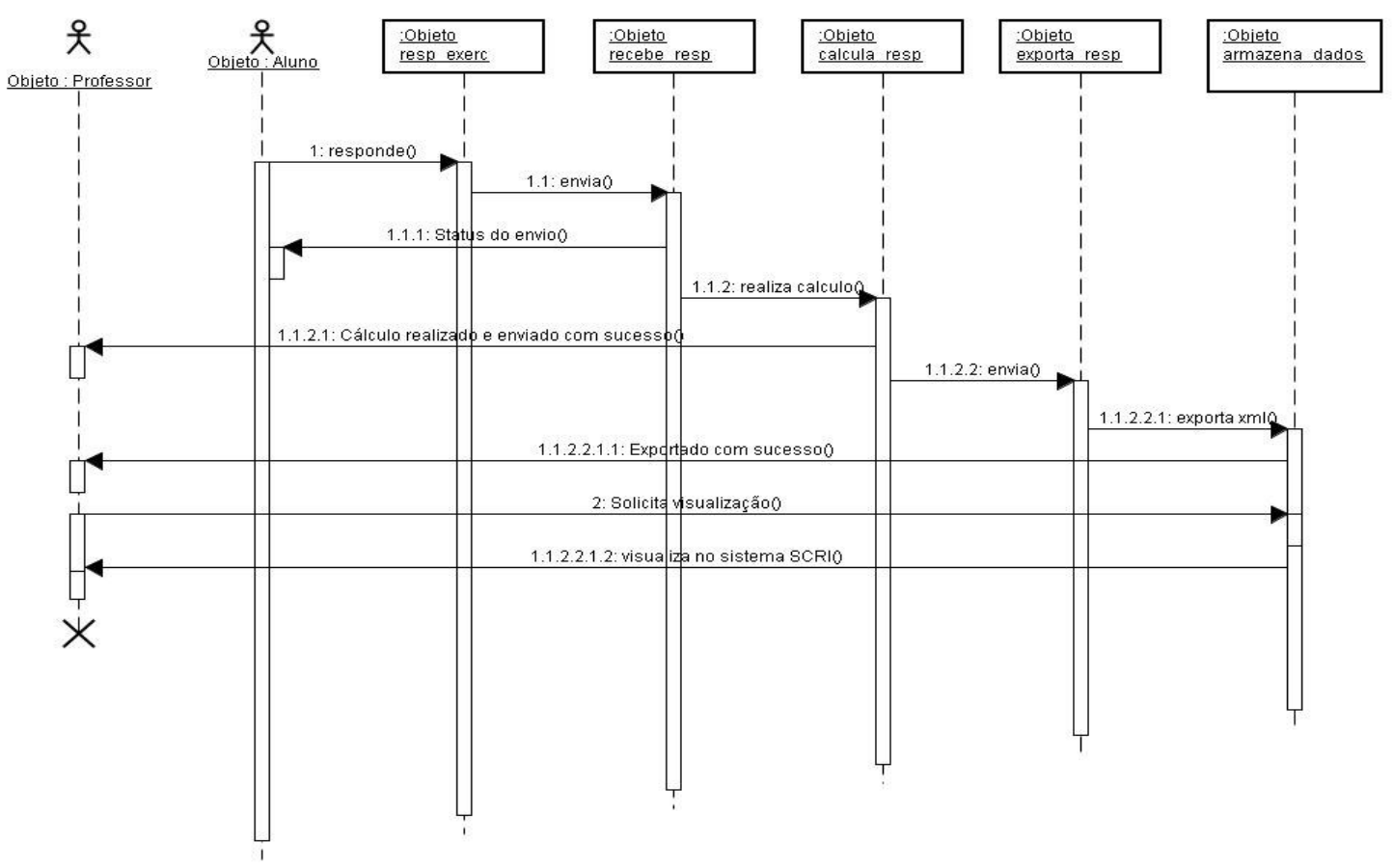

Figura 27 - Cenário representativo da transmissão da resposta e leitura no sistema SCRI. 
O diagrama de sequência deste cenário ilustra o processo de busca do arquivo de exercício ou de resposta no servidor de conteúdo, sua leitura a partir do parser e sua chamada e transmissão de conteúdo na tela da TV, como se pode observar na figura 28 a seguir.

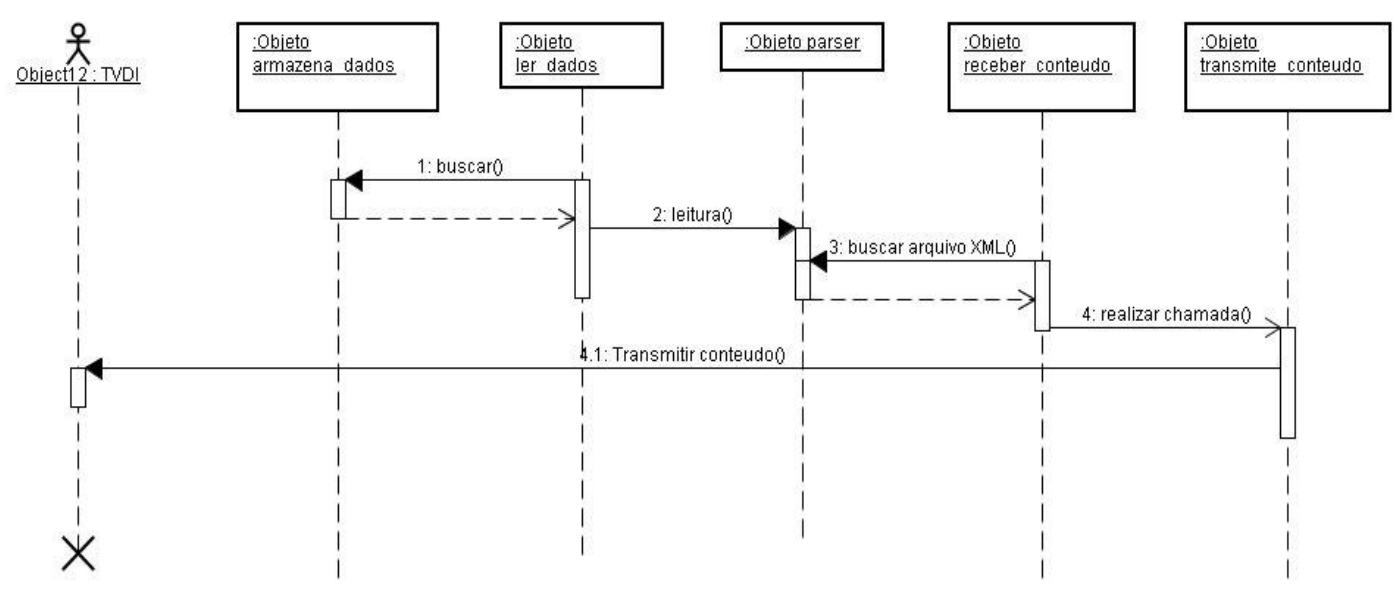

Figura 28 - Cenário representativo da recepção e transmissão de conteúdo interativo.

\subsection{TECNOLOGIAS PARA O DESENVOLVIMENTO DO CENÁRIO}

A escolha de distintas tecnologias consiste no desenvolvimento de uma solução viável. As tecnologias necessárias são de software, comunicação e hardware.

Para compor esta solução, utilizou-se a tecnologia de TV Digital, de um ambiente de aprendizado eletrônico, de um sistema computacional, de um banco de dados, e com a utilização de tecnologias de dispositivos móveis, XML e demais recursos tecnológicos voltados para a aplicação.

Na tabela 8 a seguir é possível visualizarmos os ambientes e tecnologias utilizadas. 
Tabela 8 - Descrição de tecnologias propostas.

\begin{tabular}{|c|c|}
\hline TECNOLOGIAS & DESCRIÇÃO \\
\hline TV Digital & $\begin{array}{l}\text { Ambiente de desenvolvimento Eclipse Galileo; } \\
\text { Linguagem Java para TV. } \\
\text { Emulador de TV Digital XleTView. }\end{array}$ \\
\hline $\begin{array}{l}\text { Ferramenta Educacional do } \\
\text { Ambiente Web }\end{array}$ & TIDIA Ae \\
\hline Sistema Computacional & $\begin{array}{l}\text { SCRI - Ambiente Delphi 10, utilizando recursos da } \\
\text { linguagem XML; } \\
\text { Banco de dados MySql. }\end{array}$ \\
\hline Interatividade & $\begin{array}{l}\text { Dispositivo móvel: celular. } \\
\text { Linguagem Java para aplicativos móveis (JME). } \\
\text { A aplicação pode ser desenvolvida utilizando o } \\
\text { software Netbeans } 6.8 \text { que já vem um emulador } \\
\text { integrado que permite a realização dos testes } \\
\text { simulando uma aplicação. }\end{array}$ \\
\hline
\end{tabular}

O processo que resulta na interatividade em tempo real pela televisão, é constituído pelas seguintes etapas:

1. Criação pelo professor da disciplina, do exercício, inclusão dos alunos e exportação do exercício em formato XML, através do sistema TIDIA Ae.

2. Para a realização de uma aplicação real, a aplicação Xlet em Java DTV deve ser transmitida ao terminal de acesso do receptor de TV, onde será executado. Em virtude de não se ter acesso ao sistema a aplicação deve ser simulada através do emulador de TV Digital XleTView, que realiza a chamada do código 
desenvolvido em linguagem Java, composto pelas bibliotecas, imagens e metadados gerando a simulação da aplicação.

3. Os alunos irão interagir com o sistema por meio de um dispositivo móvel, podendo a principio ser um celular. A resposta do aluno será armazenada em um arquivo de resposta desenvolvido em formato $X M L$ que será armazenado no servidor local de cada município.

4. O sistema SCRI irá realizar a leitura dos arquivos de resposta em formato $X M L$ e irá tratar o conteúdo por meio de um parser, fornecendo ao professor titular a quantidade (ou o percentual) de acertos e erros dos alunos em relação ao exercício lançado. Sendo que a comunicação pode ser Wi-fi ou por meio da rede de Internet.

5. O professor titular realiza a chamada da aplicação na tela da televisão.

Todas as etapas anteriores constituem o processo necessário que permitirá aos professores titulares dos cursos do SPMT da UEA, criar exercícios no sistema TIDIA Ae (que oferece várias ferramentas) e lançarem esses exercícios na TV. Constituindo um processo interativo e síncrono, possibilitando ao professor visualizar de forma macro o conhecimento obtido pelos alunos na disciplina ministrada.

Pontos importantes:

- O professor deverá desenvolver as questões (exercícios) apenas no TIDIA Ae que gera uma interface XML-QTI padrão (lido pelo parser codificado) a ser enviada para o módulo de armazenamento.

- As perguntas lançadas nos dispositivos móveis dos alunos assim como as respostas enviadas, são transmitidas em um modelo $X M L$ padrão, apresentadas nas figuras 20 e 21 .

- Consequente da demanda de alunos que irão interagir com a aplicação tornase inicialmente inviável a realização de uma avaliação individual, levando em consideração o contexto apresentado. A avaliação refere-se ao grupo de alunos de um determinado município que faz parte do curso. 


\section{DESENVOLVIMENTO DO PROTÓTIPO}

A proposta apresentada tem como propósito fornecer uma interatividade em tempo real entre professores e alunos do SPMT da UEA.

Visando cumprir este objetivo muitas tecnologias foram estudadas, assim como padrões, técnicas e modelos foram analisados, para fornecer como resultado soluções que possam futuramente entrar em funcionamento, a partir do advento da tecnologia de TV Digital.

A princípio não seria possível aplicá-la na região Amazônica, pois esta tecnologia ainda não está totalmente em uso. Em virtude deste obstáculo, a simulação do protótipo contou com o apoio de um simulador de TV Digital.

O protótipo é constituído de várias etapas, divididas que constituem a solução de interatividade desejada.

\subsection{SISTEMA TIDIA Ae}

O SISTEMA TIDIA Ae deverá estar disponível no servidor central localizado no estúdio da UEA, e configurado para atender às necessidades dos professores e estará disponível também nos municípios para que os alunos possam se cadastrar e responder às atividades disponibilizadas pelos professores.

Primeiramente, os professores titulares das disciplinas deverão acessar o Ambiente de Aprendizagem Eletrônica - TIDIA Ae, e realizar as atividades abaixo:

1. Cadastrar um login e senha no sistema;

2. Um site já é criado automaticamente, cabe ao professor alimentar o site com as informações e avisos da disciplina (uma única vez); 
3. Criar um projeto, com o nome da disciplina;

a. Adicionar as ferramentas exercício e quadro de notas, dentre diversas outras disponíveis;

b. Criar um banco de questões (visualizar figura 29);

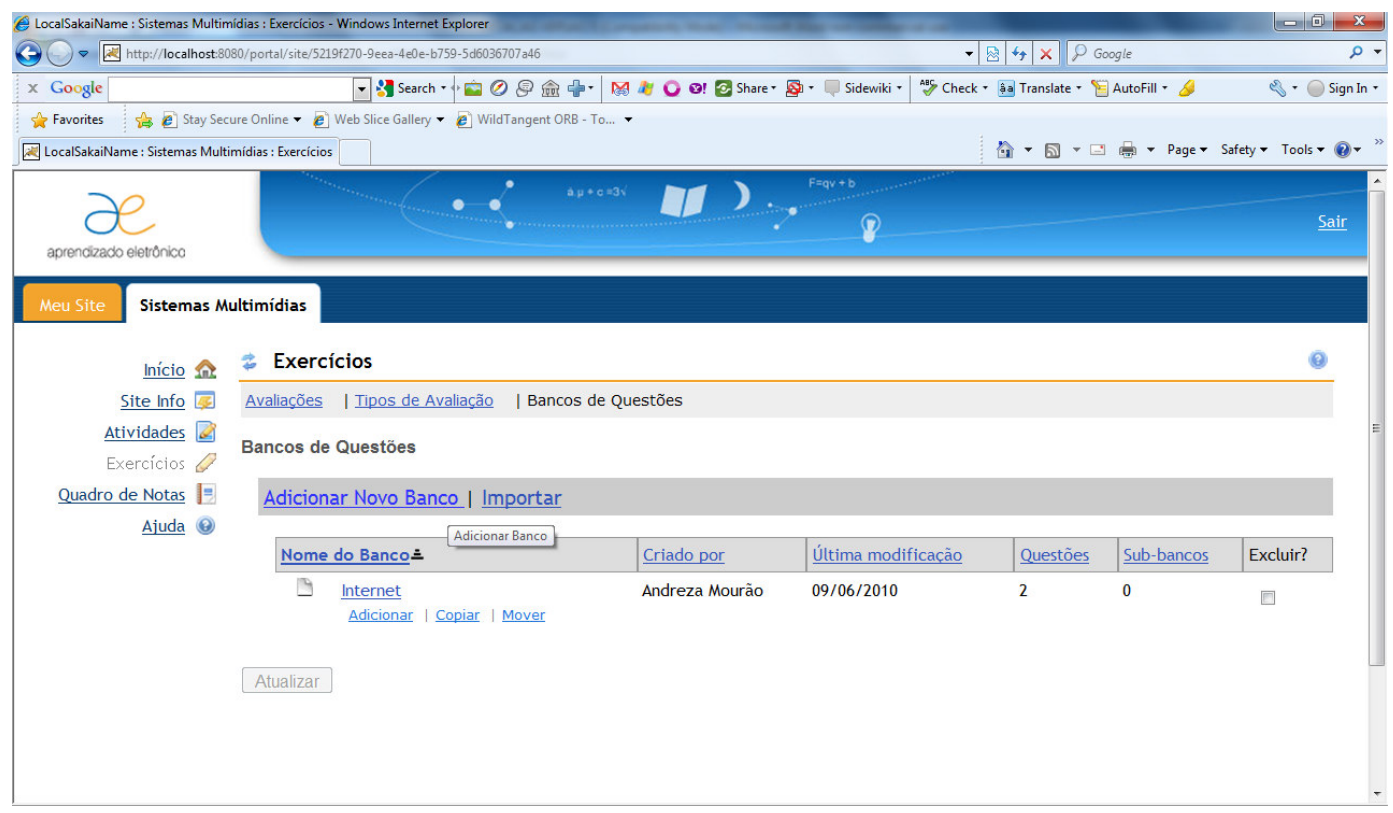

Figura 29 - Criar um banco de questões no TIDIA Ae.

Um banco de questões permite ao professor criar vários exercícios e armazenar no ambiente de aprendizado eletrônico e fazer uso destes exercícios quando necessário, facilitando assim a reutilização de questões. Podendo também importar outros bancos anteriormente criados, conforme se pode visualizar na figura acima. 
c. Criar um exercício e armazenar no banco de questões criado (visualizar figura 30);

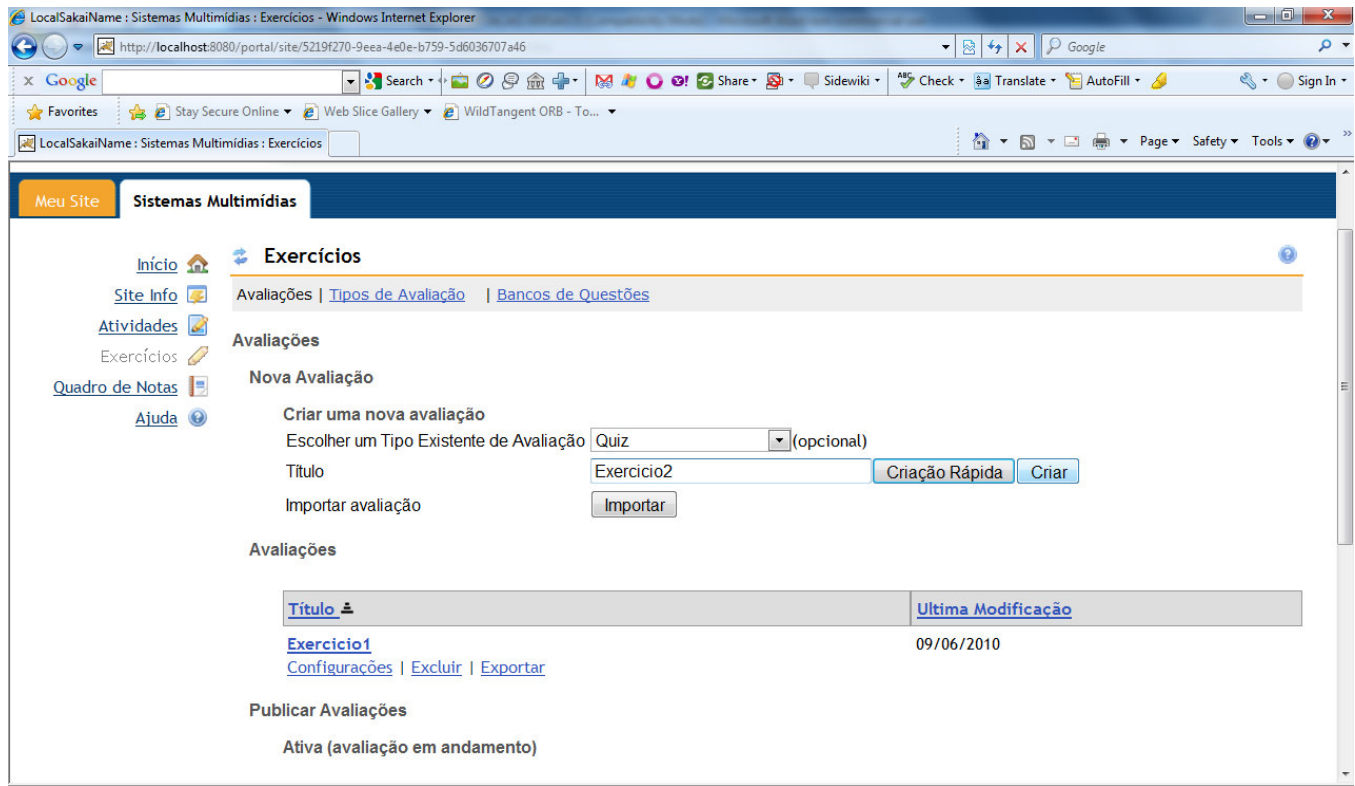

Figura 30 - Criar um exercício no TIDIA Ae.

Na figura 30 é possível visualizar a interface que permite realizar a criação de um exercício, escolher o seu tipo, dar-lhe um titulo e realizar a sua construção.

d. Exportar o exercício no formato XML (visualizar figura 31).

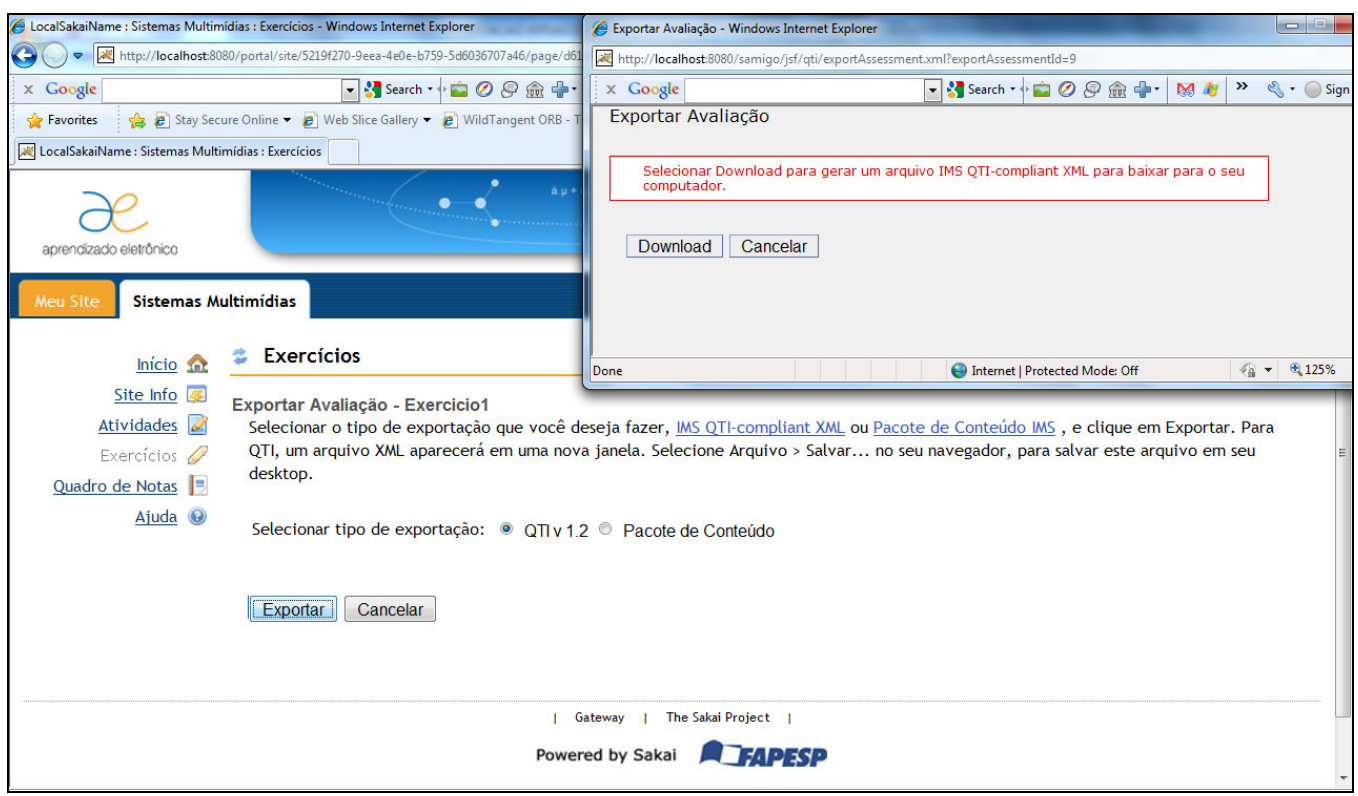

Figura 31 - Exportar em formato XML o Exercício1 criado no TIDIA Ae. 
Na figura 31 é possível visualizar a interface que permite realizar a exportação do exercício criado anteriormente, o sistema permite realizar dois tipos de exportação, sendo a opção QTI v1.2 ( padrão descrito no capítulo 3 seção 3.3.2.3) a indicada que gera automaticamente um arquivo no formato XML adequado para realização da leitura das informações necessárias.

\subsection{APLICAÇÃO TELEVISIVA}

A aplicação televisiva foi inicialmente concebida a partir da linguagem Java, utilizando a IDE do Eclipse ${ }^{40}$, utilizando as bibliotecas JavaTV e o emulador XletView ${ }^{41}$ para rodar os Xlets.

Alguns experimentos iniciais foram realizados e não finalizados em sua completude em virtude dos prazos não terem sido suficientes para o cumprimento das funcionalidades e dos testes de todos os módulos.

A interface mostrada na figura 32 a seguir refere-se à simulação desenvolvida para tecnologia de TV Digital. Na interface principal é carregada a imagem da disciplina, do professor ou do conteúdo (fica a critério do curso), mostrado por intermédio do emulador XleTView para Ginga J.

\footnotetext{
40 http://www.eclipse.org/galileo/

41 http://www.xletview.org/
} 


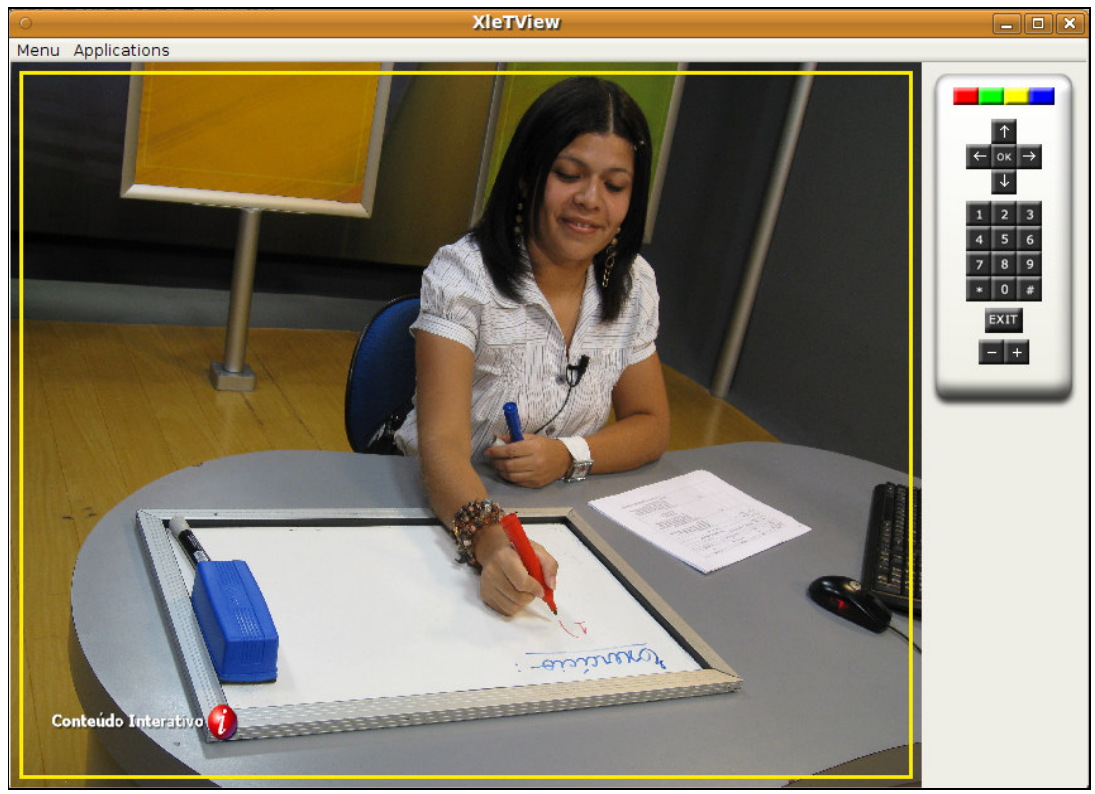

Figura 32 - Simulação da tela principal do Conteúdo Interativo emulado no XleTView.

O protótipo mostrado na figura 33 representa o formato do conteúdo que será mostrado na tela, ao ser disparada a chamada do exercício.

\section{TV INTERATIVA - UEA}

EXERCICIO 1 : O QUE É INTERNET ?

a) É uma rede de computadores.

b) É um meio de comunicação.

c) É um link.

d) N.d.a

Figura 33 - Protótipo da tela de exercício. 
O protótipo mostrado na figura 34 representa o formato do conteúdo que será mostrado na tela, ou seja, o resultado em percentual dos acertos e erros dos alunos por município.

\section{TV INTERATIVA - UEA}

EXERCICIO 1 : INTRODUÇÃO À INTERNET

ACERTOS

ERROS

$80 \%$

$20 \%$

MUNICÍPIO: SÃO GABRIEL DA CACHOEIRA

Figura 34 - Protótipo da tela de resposta dos exercícios por município.

\subsection{SISTEMA DE CÁLCULO DE RESPOSTAS INTERATIVAS - SCRI}

O SCRI funciona localmente em cada município, estando disponível também no estúdio de TV na capital, assim como a sua base de dados criada no MySql encontra-se no servidor central.

O professor titular tem acesso a todos os módulos do sistema podendo visualizar resultados, imprimir, realizar cálculos e mostrar o resultado na tela da TV. E de posse dessas informações poderá debater, esclarecer ou conversar com os alunos do curso. Na figura 35 é possível visualizar a tela principal do sistema. 


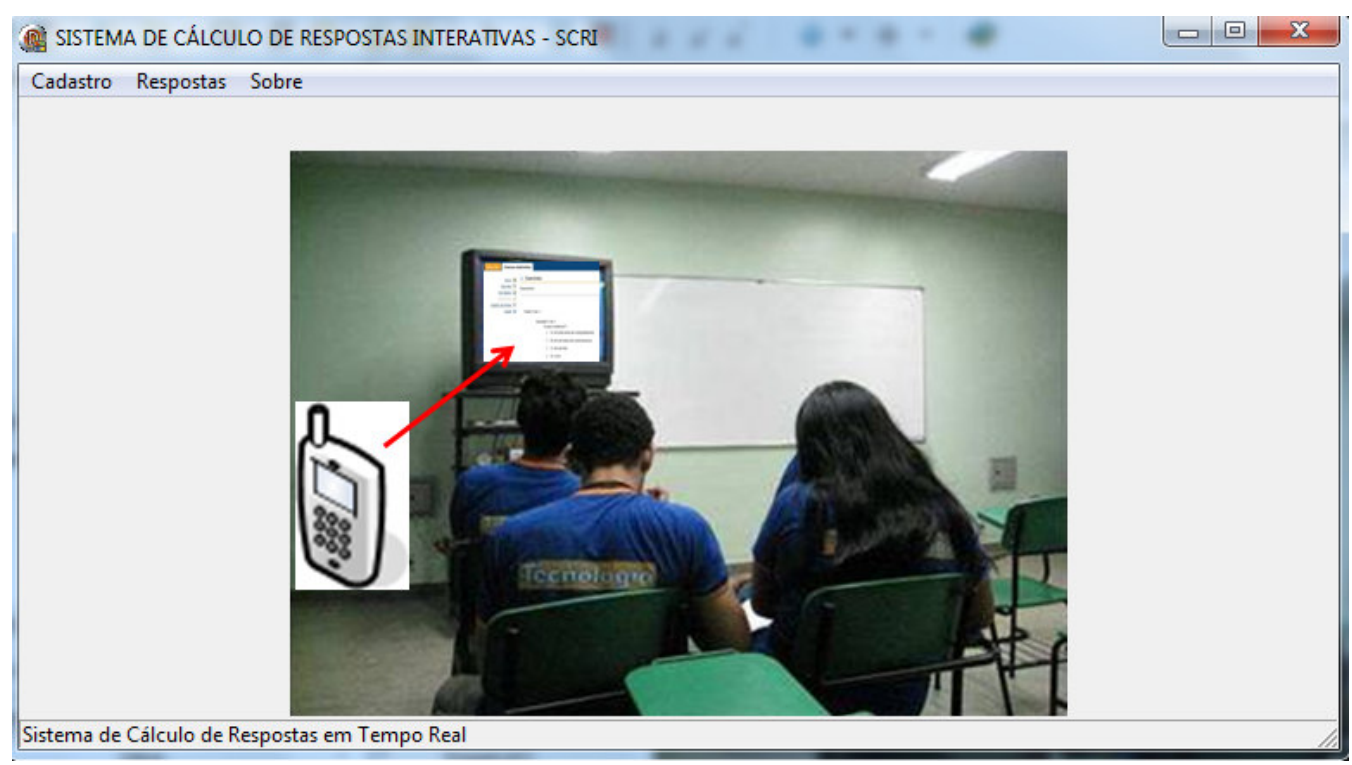

Figura 35 - Tela principal do SCRI.

O SCRI deve ser manipulado, pelas pessoas responsáveis e envolvidas no processo de aprendizagem. Na tabela 9 abaixo é possível visualizar as responsabilidades de cada profissional.

Tabela 9 - Descrição das responsabilidades no sistema SCRI.

\begin{tabular}{c|c}
\hline \multicolumn{1}{c|}{ RESPONSÁVEL } & DESCRIÇÃO \\
\hline PROFESSOR ASSISTENTE & $\begin{array}{r}\text { Responsável por inserir a quantidade de alunos presentes no } \\
\text { referido dia da aplicação do exercício. }\end{array}$ \\
\hline PROFESSOR TITULAR & $\begin{array}{r}\text { Responsável pela manipulação de importação de arquivos, } \\
\text { cálculo de respostas, impressão e geração de relatórios. }\end{array}$ \\
\hline ASSISTENTE PEDAGÓGICO & $\begin{array}{r}\text { Responsável pelo cadastro de professores assistentes, } \\
\text { municípios, disciplina, e tem acesso a todos os demais módulos. }\end{array}$ \\
\hline
\end{tabular}


A figura 36 refere-se à tela de cadastro de todos os municípios onde um determinado curso do SPMT possui transmissão de suas aulas.

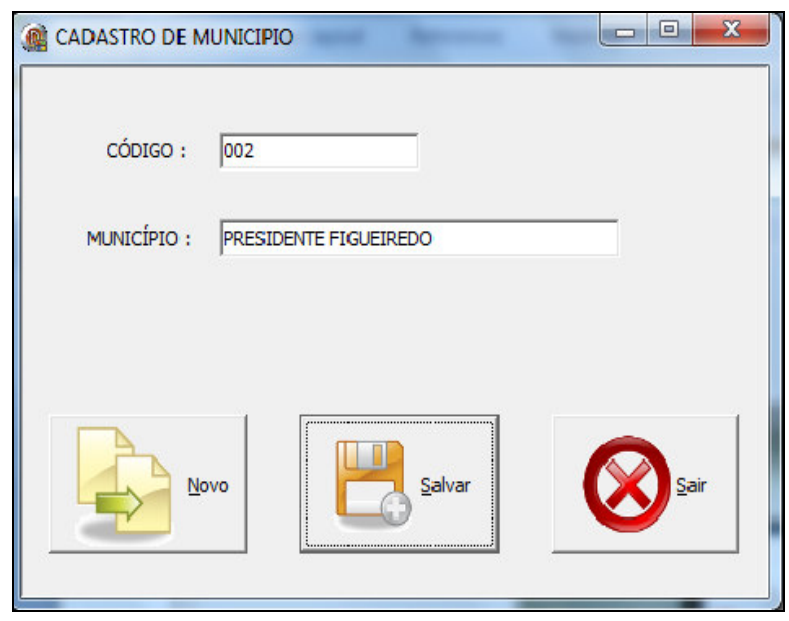

Figura 36 - Tela de Cadastro de Município.

A figura 37 refere-se à tela de cadastro de informação de município, onde associa-se o professor assistente que está locado e quantidade de alunos regularmente matriculados.

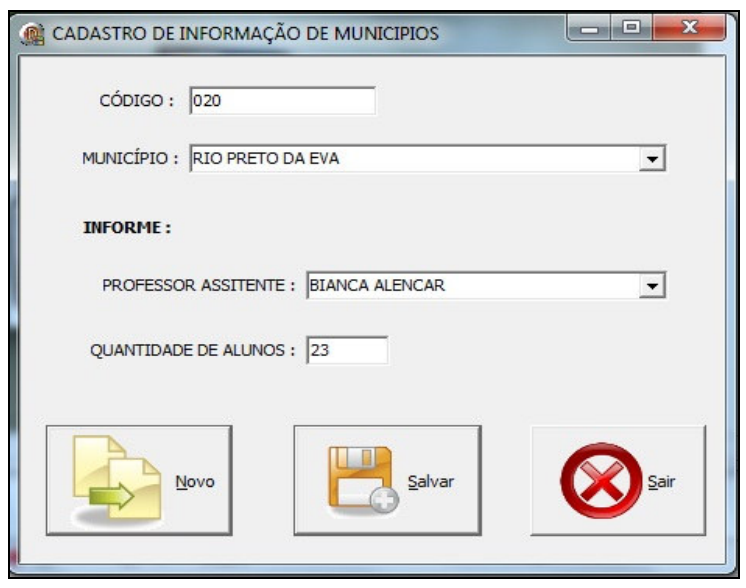

Figura 37 - Tela de Cadastro de Informação de Município. 
A figura 38 refere-se à tela de cadastro de professores assistentes que trabalham nos cursos, e estão lotados no interior do estado.

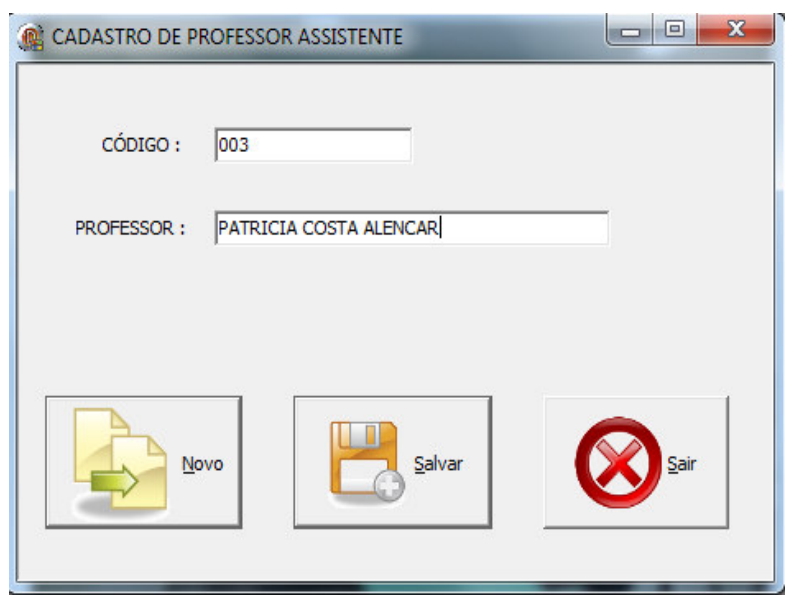

Figura 38 - Tela de Cadastro de Professor Assistente.

A figura 39 refere-se à tela de cadastro de disciplina, onde é possível adicionar o nome dos três professores titulares responsáveis.

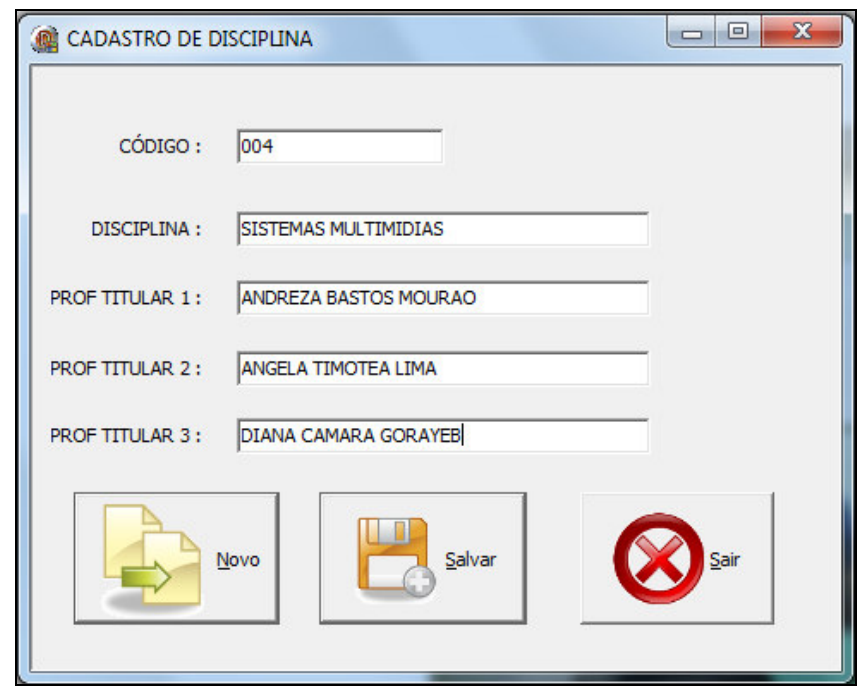

Figura 39 - Tela de Cadastro de Disciplina. 
O professor assistente é responsável por inserir no SCRI, a quantidade de alunos presentes em sala de aula no dia da aplicação dos exercícios. A figura 40 refere-se à tela onde a informação deve ser digitada, associada ao referido município.

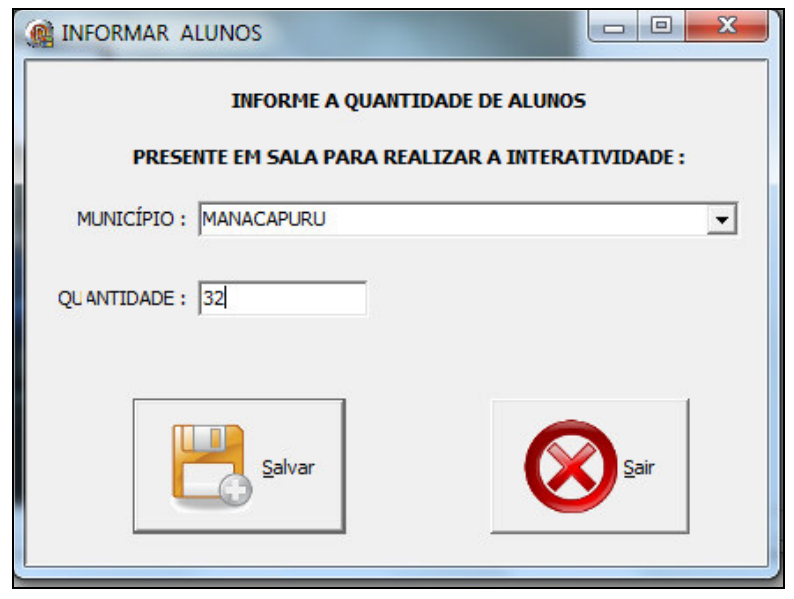

Figura 40 - Tela para informar a quantidade de alunos presentes em sala.

A figura 41 refere-se à tela de importação dos arquivos XML de respostas gerados pelos alunos ao responder um exercício que é lançado na TV. A importação também é realizada automaticamente.

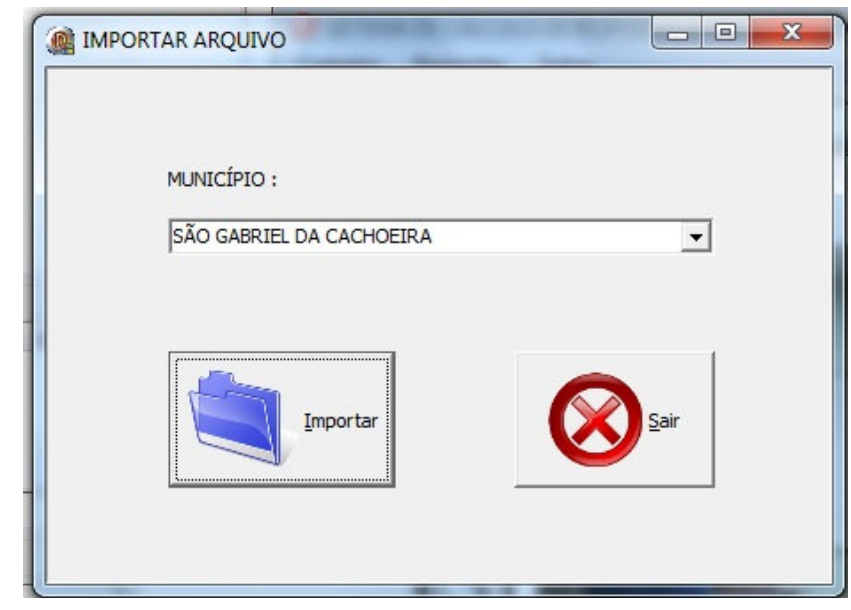

Figura 41 - Tela de Importação dos Arquivos de Resposta. 
A figura 42 refere-se à tela de cálculo de notas. Onde os valores são calculados por município, mas inicialmente deve realizar a leitura dos arquivos $\mathrm{XML}$ de resposta oriundos do dispositivo móvel dos alunos, carrega-se, calcula-se e envia para o servidor central, de onde será possível realizar a leitura do arquivo XML na tela da TV.

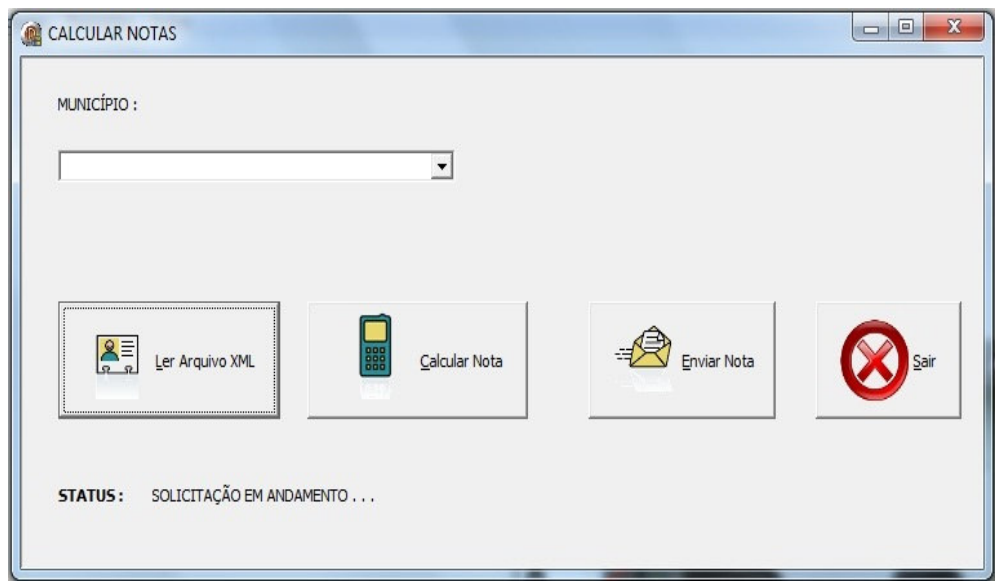

Figura 42 - Tela de Cálculo de Notas por Município.

A figura 43 refere-se à tela de consulta de notas, onde a leitura poderá ocorrer por Município (individualmente), ou por todos os municípios (geral).

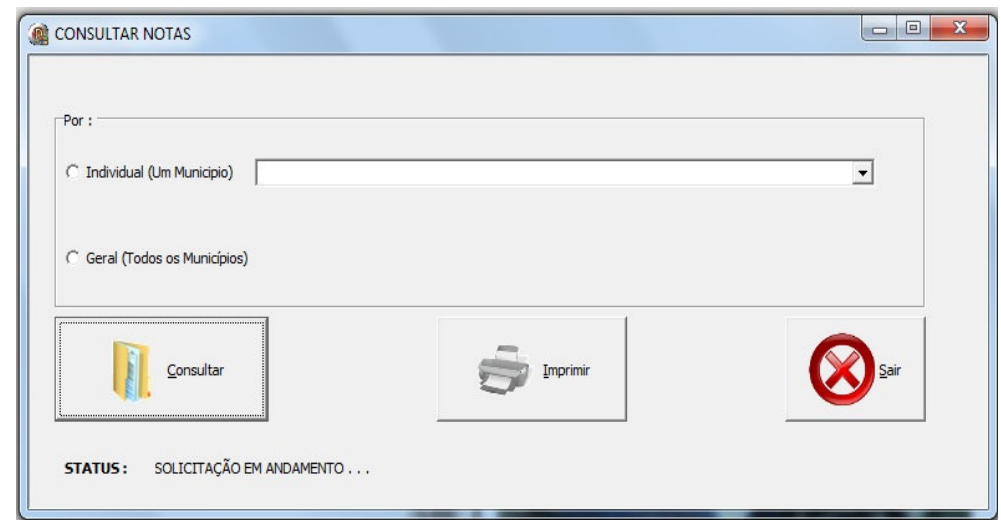

Figura 43 - Tela de consulta de notas.

As informações devem ser inseridas no sistema pelo assistente pedagógico dos cursos que alimentam todos os dados referentes ao seu quadro de professores, municípios e quantidade de alunos regularmente matriculados na disciplina por município. 


\subsection{RESULTADOS E DISCUSSÃO DO PROTÓTIPO}

Atualmente, cresce a quantidade de aplicações voltadas para conteúdos televisivos e interativos que utilizam o padrão do SBTVD.

Podemos citar como tecnologia em evidência e uso, o Ginga ${ }^{\circledR 42}$ (Middleware Aberto do SBTVD). Sendo constituído por um conjunto de tecnologias padronizadas que torna a especificação de middleware mais avançada.

O Ginga ${ }^{\circledR}$ é um middleware do sistema brasileiro de televisão digital - SBTVD, que permite a interatividade, seleção, consulta, venda, entre outros. O middleware está subdividido em dois subsistemas que permitem o desenvolvimento de aplicações, cujas funcionalidades requeridas dependem da aplicação a ser utilizada. Os subsistemas são conhecidos como Ginga-J (para aplicações procedurais Java) e o Ginga-NCL ${ }^{\circledR}$ (para aplicações declarativas NCL).

Uma aplicação televisiva pode ser realizada, utilizando qualquer um dos dois subsistemas. Pela facilidade e ampla difusão de material referente à linguagem Java, ela pode ser considerada adequada para implementar a solução proposta.

Alguns testes iniciais e simulações foram realizadas utilizando o paradigma do Ginga $J^{\circledR}$ que provê uma infraestrutura de execução de aplicações e extensões voltadas para o ambiente televisivo, o que revelou consideravelmente a aplicabilidade da solução.

Para a realização do experimento da aplicação voltada para TV Digital utilizou-se o ambiente de desenvolvimento Eclipse Galileo ${ }^{\circledR}$, e o emulador de TV XletView ${ }^{\circledR}$.

Foi possível assim criar uma interface que permitiu simular a interatividade com o controle remoto da TV, e realizar alguns testes para validar a leitura do conteúdo num arquivo de formato $\mathrm{XML}$, através de um parser, constatando assim a viabilidade da solução proposta.

${ }^{42}$ http://www.ginga.org.br/ 
Para interagir com a aplicação televisiva o aluno poderá utilizar um celular ou um netbook, ou outra tecnologia disponível com conexão Wireless. Após os alunos responderem via dispositivo móvel, a informação é enviada para um servidor local, disponível em cada município. Estes arquivos ficam armazenados no servidor e podem posteriormente serem manipulados.

O sistema SCRI proposto tem como objetivo tratar a resposta enviada pelos alunos, realizar cálculos, e enviar o resultado para o terminal de acesso localizado no estúdio da UEA, onde posteriormente é realizada a chamada pelo professor titular na tela da TV.

Há ainda a possibilidade dos alunos visualizarem a resposta dos exercícios pelo dispositivo móvel, selecionando a opção desejada e visualizando no visor do celular o resultado da questão. 


\section{CONCLUSÃO}

Este trabalho foi estruturado em tópicos que compreendem o cenário onde se pretende aplicar a proposta, relata o cenário do ensino presencial mediado por tecnologia no Amazonas, explora algumas tecnologias voltadas ao suporte do ensino, apresenta trabalhos relacionados com o contexto, apresenta a especificação dos requisitos, modelagem, o projeto e o desenvolvimento do protótipo do modelo interativo.

Dentre os vários artigos lidos pode-se constatar o crescimento da tecnologia de TV Digital, assim como as inúmeras aplicabilidades voltadas para tecnologia, porém já observa-se um aumento gradativo na literatura científica de experiências destacadas de uso da televisão digital na EAD. Conforme Litto (2009) destaca, a EAD presta serviços relevantes à cultura brasileira, uma vez que a ação cultural é de grande relevância na sociedade, ao democratizar o acesso a bens e serviços.

Observou-se também a importância de ferramentas síncronas e assíncronas voltadas para ambientes Web, que facilitam e colaboram para o aprendizado dos alunos. Segundo Kopke e Haguenauer (2001), uma das grandes caracteristicas do Ambiente Colaborativo de Aprendizagem é a sua preocupação com o uso de metodologias de trabalho que propiciem a colaboração e permitam a sua avaliação.

Com a realização dos levantamentos iniciais houve a possibilidade de se obter uma visão macro do SPMT da UEA, que permitiu a realização de uma especificação e análise bem detalhada dos requisitos.

Visando aprimorar este sistema, foram investigadas várias formas de realizar uma interatividade em tempo real, que permitisse um sincronismo entre alunos e professores, resultando em um aprendizado mais dinâmico e com uma retroalimentação imediata.

A proposta deste trabalho fundamenta-se na investigação de ferramentas e soluções que podessem permitir desenvolver um modelo de aprendizagem interativo utilizando recursos da tecnologia de TV Digital e que possibilitasse aos professores 
titulares dos cursos do sistema presencial mediado por tecnologia da UEA obterem uma realimentação em tempo real do aprendizado dos alunos.

O professor em tempo real poderá lançar questões na TV e visualizar as respostas, assim como responder, justificar e elogiar alunos e municípios que apresentaram um número expressivo de acertos. É como se as distâncias fossem ignoradas e o professor pudesse estar tão presente quanto em um sistema presencial.

O TIDIA Ae é um sistema de gerenciamento de aprendizagem composto de ferramentas multimidias diversificadas, capazes de prover interatividade. A sua escolha foi de grande relevância, pois a ferramenta de exercício escolhida condiz com as necessidades e expectativas desejada para ser aplicada no modelo televisivo.

As demais tecnologias levantadas que constituem a solução proposta, permitem um sincronismo de dados e troca de informações em tempo real, necessária para justificar a solução especificada. Utilizam ambientes e plataformas diferentes que convergem e justificam uma solução de interatividade em tempo real para o SPMT da UEA.

Foram estudadas e investigadas a viabilidade de uso e implementação de tecnologias voltadas para TV Digital, aprendizado eletrônico, aprendizado móvel, interatividade, redes híbridas, padrões e conceitos de aprendizagem pela Web e pela TV.

O modelo de ensino mediado por tecnologia em aplicação atualmente no estado do Amazonas, vem destacando-se e ganhando prêmios e reconhecimento por conseguir atingir localidades remotas e geograficamente distantes, oferencendo ensino fundamental, médio e superior por meio da televisão. Ministrar aulas na televisão não é uma tarefa fácil, principalmente quando o professor torna-se um mero apresentador de conteúdo. Apesar de o modelo recentemente contar com uma ferramenta que permite uma interatividade com os alunos por meio de chat e vídeo, muitas dificuldades são apresentadas, o professor pode interagir com um ou outro aluno, mais nem todos os municipios podem ser comtemplados em função do tempo e da quantidade de alunos que tornam fatores negativos para medir ou mensurar qualquer conhecimento obtido, ficando ainda muito obscuro para o professor titular 
que atua neste modelo, obter uma visão macro do conhecimento obtido pelo aluno sobre determinado conteúdo ministrado.

Esta proposta foi inicialmente traçada e motivada pela dificuldade que o professor titular apresentava em não obter de forma imediata uma realimentação sobre o aprendizado do aluno em relação à aula ministrada. O retorno inicial era oriundo de fax enviado pelos professores assistentes e ligações que os mesmos realizavam de seus municipios em um intervalo ou no final da aulas. Foi então que a UEA optou por utilizar a mesma ferramenta de interatividade já utilizada pela Seduc, o IP.TV ${ }^{\circledR}$, que proporcionou uma melhora nesta comunicação e interação do professor com os alunos, porém ainda não suficiente para que o professor titular podesse obter a informação desejada que permitisse uma melhoria na construção de processos de ensino aprendizagem satisfatórios.

A interatividade dos alunos por meio da televisão, levando em consideração o cenário apresentado pelo SPMT da UEA, é um assunto muito discutido em virtude da quantidade de alunos e de municipios da região. Este trabalho resultou no desenvolvimento de um modelo educacional interativo utilizando conceitos da tecnologia de TV Digital possibilitando aos professores titulares dos cursos do sistema presencial mediado por tecnologia da UEA obterem uma realimentação em tempo real do aprendizado dos alunos, solução que se adequa às necessidades apresentadas pelos especialistas envolvidos no processo, considerando fatores relevantes como os de cultura, distância, fatores climáticos e de tecnologia.

\subsection{CONTRIBUIÇÕES}

A solução poderá ser colocada em uso futuramente com o advento da tecnologia de TV Digital e permitirá aos professores dos cursos obterem uma realimentação imeditada de suas aulas, contanto com uma nova abordagem interativa por meio da aplicação de exercícios gerados em um sistema de gerenciamento de aprendizagem (TIDIA Ae). 
O modelo contribuirá para a melhoria da qualidade do processo de ensino e aprendizagem no SPMT, os professores titulares poderão assim dispor de informações relevantes e referentes ao aprendizado imediato dos alunos em relação a um determinado conteúdo ministrado na TV. Sims (2006) destaca como as interações podem ajudar a atingir os objetivos de um curso como os estilos de aprendizagem, a implementar estratégias e recursos que permitam a aplicação de diferentes preferências de aprendizagem, enfim construindo a partir da percepção da construção do ensino.

Com a implantação deste modelo haverá um ganho educacional de aprendizagem por parte do aluno e de realimentação imediata de conhecimento a ser evidenciada pelo professor titular que ministra aulas neste sistema.

O SPMT da UEA poderá contar com um framework de aplicações que utiiza padrões e-learning ao modelo t-learning, que integrados em sua totalidade podem trazer resultados acadêmicos satisfatórios para a Universidade e para a equipe do Projeto TIDIA Ae.

Outra contribuição refere-se a tomada de decisões possíveis, em relação as respostas dos alunos via dispositivo móvel, dados estes que podem compor uma tabela comparativa de aprendizagem baseada na ferramenta utilizada durante a aplicação de conteúdos de uma determinada disciplina. Os dados gerados quantativamente podem ser analisados pela coordenação pedagógica dos cursos permitindo gerar índices de aproveitamento, rendimento escolar, aprendizagem, metodologia pedagógica, dentre outros itens que apóiem em tomada de decisões adequadas para a melhoria e qualidade do processo de ensino-aprendizagem.

\subsection{TRABALHOS FUTUROS}

Com o desenvolvimento deste trabalho observou-se que há possibilidade de migrar outras ferramentas do TIDIA Ae para serem utilizadas neste cenário e contribuindo diretamente para o processo de ensino existente. Percebeu-se também como é completo o ambiente de aprendizado eletrônico do TIDIA Ae de ferramentas que 
auxiliam e contribuem no processo de ensino-aprendizagem e que uma futura integração com o sistema da universidade permitiria um controle de notas e exercícios direto no ambiente, possibilitando assim um controle maior de notas dos alunos individualmente e permitir a eles a utilização de mais um recurso tecnológico de grande porte.

As tecnologias de interatividade, assim como abordagem pedagógica fogem do escopo deste trabalho, porém vale ressaltar que todo um estudo e levantamento de ferramentas, ambientes e sistemas que permitam contribuir para a completude deste processo foram estudadas, levantadas e modeladas nos cenários apresentados como forma de validar a solução.

Uma das propostas de trabalhos futuros é a realização da implementação completa de todas as etapas que constituem o modelo apresentado em protótipos, agregando tecnologias móveis e concepção pedagógica, que resulta não somente em uma nova abordagem pedagógica constituída da união de conceitos, padrões, ferramentas, plataformas, como em uma solução promissora e tão somente esperada pelos professores que ministram aulas neste ambiente televisivo educacional, como também expandir para outras Instituições de Ensino Superior que trabalham com este conceito de aprendizagem, a idéia é dar continuidade a esta proposta em um projeto de doutorado e tentar aplicá-lo no SPMT por meio da empresa que presta serviços de telecomunicações para a UEA. 


\section{REFERÊNCIAS BIBLIOGRÁFICAS}

Advanced Distributed Learning. Sharable Content Object Reference Model (SCORM). Disponível em: <http://://www.adlnet.org/Pages/Default.aspx>. Acessado em: 10-10-2009.

ALVES, Luiz Gustavo Pacola. CollaboraTVware: Uma Infraestrutura Ciente de Contexto para Suporte a Participação Colaborativa no cenário da TV Digital Interativa. Dissertação de Mestrado em Engenharia Elétrica. Escola Politécnica da USP. 203p. 2008.

ALVES, Luiz Gustavo Pacola; SILVA, Fábio Santos da; BRESSAN, Graça. Análise comparativa de metadados em TV digital. In: SIMPÓSIO BRASILEIRO DE REDES DE COMPUTADORES. p.87-98, SBRC 2006:Curitiba - PR, 2006.

ARAÚJO, Adriana de Fátima. Internet 7.0: navegando com qualidade. 4. ed. Santa Cruz do Rio Pardo, SP: Editora Viena, 2008.

BARBOSA, Walmir de Albuquerque Barbosa. Proformar e a Educação no Amazonas. Manaus: UEA Edições / Editora Valer, 2008.

BATES, P. J. A study into TV-based interactive learning to the home. pjb Associates, UK. This study has been conducted with funding from the European Community under the IST Programme, 2003. 
BECKER, Valdecir. Concepção e desenvolvimento de aplicações interativas para televisão digital. Florianópolis, 2006. Dissertação (Mestrado em Engenharia e Gestão do Conhecimento) - Centro Tecnológico Federal de Santa Catarina, 2006.

BECKER, Valdecir. TV Digital e Interatividade: impacto na sociedade. T\&C Amazônia, Ano V, Número 12, Outubro de 2007.

BECKER, Valdecir; ZUFFO, Marcelo Knörich. Desenvolvimento de interfaces para TV digital interativa. In: SIMPÓSIO BRASILEIRO DE SISTEMAS MULTIMÍDIA E WEB, Vila Velha, ES, 2008.

B'FAR, Reza. Principles Designing and Developing Mobile Applications with UML and XML. First Edition, The Edinburgh Building, Cambridge: CAMBRIDGE UNIVERSITY PRESS, 2005.

Contos da Escola. Secretaria de Educação do Amazonas inova e mostra como se faz EAD que funciona. Disponível em: $<$ http://www.contosdaescola.net/secretaria-de-educacao-do-amazonas-inova-emostra-como-se-faz-ead-que-funciona/>. Acessado em: 10/09/2009.

CROCOMO, Fernando. TV Digital e produção interativa: a comunidade manda notícias. Florianópolis, Edufsc, 2007.

E-LEARNING. Disponível em: http://www.elearningbrasil.com.br/. Acessado em Fevereiro de 2009. 
FERREIRA, Leydson P. Utilizando Dispositivos Móveis e Bluetooth para Aplicação de Avaliações em Meio Digital. Technical Report: UFRN,2009.

FRANCISCATO, F. T.; Ribeiro; M. Avaliação dos Ambientes Virtuais de Aprendizagem Moodle, Teleduc e Tidia - Ae: Um Estudo Comparativo. RENOTE, 2008.

FREIRE, P. Pedagogia da autonomia: saberes necessários à prática educativa. São Paulo: Paz e Terra, 1996.

FRANTZI, M., et. al. "A Methodology for the Integration of SCORM with TVAnytime for Achieving Interoperable Digital TV and e-Learning Applications". Proceedings of the IEEE International Conf. on Advanced Learning Technologies. 2004.

GARRISON, R., VAUGHAN, H. Blended learning in higher education: Framework, principles and guidelines. San Francisco: Jossey-Bass, 2008.

GOMES, FÁBIO DE J. L.. Um objeto de aprendizagem construtivista para TV Digital. cadernos temáticos, Brasília: n. 15, p. 57-65, mar. 2007.

GOMES, Fábio de Jesus Lima; LIMA, José Valdeni de. O papel como interface para a TV Digital. ACM International Conference Proceeding Series; Vol. 323. Proceedings of VII Brazilian Symposium on Human Factors in Computing Systems. Natal, RN, Brazil. 2006. 
GRAHAM, C. Blended Learning Systems: Definitions, current trends and future directions. In C. Bonk \& C. Graham (Eds.), The handbook of blended learning: Global perspectives, local designs. San Francisco: John Wiley and Sons, 2006.

HARASIM, L. et al., Redes de Aprendizagem. São Paulo: Senac, 2005.

IEEE LSTC. P1484.12.1. Learning Objects Metadata WG. Disponível em: http://tsc.ieee.org/wg12/. 2002. Acessado em: 09 de Abril de 2010.

IMS-LD. IMS Learning Design Information Model. IMS Global Learning Consortium, Inc., 2003a. http://www.imsglobal.org/learningdesign/ldv1p0/imsld_infov1p0.html, Acessado em: Maio 2010.

IMS QTI. Disponível em: http://www.imsproject.org/question/. Acessado em Junho de 2010.

IMS Learning Design Best Practice and Implementation Guide. IMS Global Learning Consortium, Inc., 2003b. Disponível em: http://www.imsglobal.org/learningdesign/ldv1p0/imsld_bestv1p0.html, Acessado em: Maio 2010.

IMS Learning Design XML Binding. IMS Global Learning Consortium, Inc., 2003c. Disponível em: http://www.imsglobal.org/learningdesign/ldv1p0/imsld_bindv1p0.html, Acessado em: Maio 2010. 
KOPER, Rob. Modeling units of study a pedagogical perspective. The pedagogical meta-model behind EML. Technnical Report. Disponível em: http://eml.ou.nl. Acessado em Julho de 2010.

$\begin{array}{lllll}\text { IP.TV. } & \text { Sobre } & \text { o } & \text { IP.TV. } & \text { Disponivel }\end{array}$ $<$ http://www.ip.TV/ipTV_site/ptb/htm/plataforma.html\#oquee>. Acessado em: 07-092009.

KNOL - Centro de Mídias. Sobre o Centro de Mídias. Disponível em: $<$ https://knol.google.com/k/jose-augusto-de-melo-neto/centro-dem\%C3\%ADdias/8rqtn38ym0pl/2\#>. Acessado em: 10-09-2009.

LEITE, Maria Teresa Meirelles, COSTA, Silvia Maria Coelho, TARCIA, Rita Maria Lino, CARLINI, Alda Luiza. As "novas tecnologias" e as mudanças na prática pedagógica. In VI CONGRESSO BRASILEIRO DE ENSINO SUPERIOR A DISTÂNCIA. Maranhão, SL. VI ESUD, 2009.

LÉVY, Pierre. Cibercultura. São Paulo: Editora 34, 1999.

Licenciatura em Matemática: Sistema Presencial Mediado. 2pg, 2008. Disponível_em: <http://www.suporteeducacional.com.br/matematica>, Acessado em: julho 2009.

LITTO, Fredric M; FORMIGA, Marcos. Educação à Distância. São Paulo: Pearson Education do Brasil, 2009. 
LOPES, Paula Fernanda Rocha. As "novas tecnologias" e as mudanças na prática pedagógica. In VI CONGRESSO BRASILEIRO DE ENSINO SUPERIOR A DISTÂNCIA, 2009. Maranhão, SL. VI ESUD 2009.

LÓPES-NORES, Martin., et. al. "Technologies to Support Collaborative Learning over the Multimedia Home Platform". Advances in Web-Based Learning - ICWL, 2004.

LÓPES-NORES, Martin., et. al. A Core of Standards to Support T-learning. Proceedings of the IEEE International Conf. on Advanced Learning Technologies, 2006.

MAGNONI, A. F.; AFFINI, L. P.; AMÉRICO, M. Da Mobilidade a Ubiqüidade da Comunicação. In: XXX Congresso Brasileiro de Ciências da Comunicação. Intercom - Sociedade Brasileira de Estudos Interdisciplinares da Comunicação. Santos, 2007.

MARINHO, Fundação Roberto. Histórico do Telecurso. Disponível em: http://www.telecurso2000.org.br/telecurso/index.html\#/main.jsp?lumPageld=4028818 7141C7E3201141CBAC4D40CB3. Acessado em: em junho de 2008.

MASON, R., RENNIE, F. E-learning: The key concepts. London: Routledge, 2006.

MAHMOUD, Q. H. Integrating Mobile Devices into the Computer Science Curriculum. Proceedings of the Frontiers in Education Conference (FIE 2008), Saratoga Springs, NY, USA, pp. S3E-17- S3E-22. 
MELO, Ana Cristina. Desenvolvendo Aplicações com UML: Do conceitual à implementação. São Paulo: Brasport, 2002.

Middleware Aberto do Sistema Brasileiro de TV Digital (SBTVD). Disponível em: <http://www.ginga.org.br/>. Acessado em: 05/07/2009.

MONTEZ, C. BECKER, V. TV Digital Interativa: Conceitos e Desafios e Perspectivas para o Brasil. 2ed. Editora da UFSC. Florianópolis, 2005.

MOURÃO, Andreza B., MALVEZZI, William R., BRESSAN, Graça. Uma ferramenta Fuzzy de acompanhamento de estudantes em ambientes de aprendizagem no modelo presencial mediado por TV. In VI CONGRESSO BRASILEIRO DE ENSINO SUPERIOR A DISTÂNCIA, 2009. Maranhão, SL. VI ESUD 2009.

MOURÃO, Andreza Bastos, PONTES, Danielle Pompeu Noronha, GORAYEB, Diana Maria da Câmara. Análise e Projeto de Sistemas I. Manaus: Editora UEA Edições, 2009.

MOURÃO, Andreza Bastos, LIMA, Angela Timótea, GORAYEB, Diana Maria da Câmara. Sistemas Multimídia. Manaus: Editora UEA Edições, 2010.

NANOXML. A small XML parser for Java. Disponível em: http://nanoxml.sourceforge.net, Acessado em: Agosto de 2009. 
NETBEANS. Disponível em: http://www.netbeans.org/features/javafx/index.html. Acessado em Dezembro de 2009.

OLIVEIRA, J. A.; WAISMAN, T.; SILVA, F. S.; HORBE, B.; MAIA, O. B.; MORENGHI,F. T-learning in Amazon: The Interactive Education Project. In of the $4^{\text {th }}$ European Conference on Interactive Television: Beyond Usability, Broadcast, and TV. (EurolTV 2006), pages 290-295. 2006.

OLIVEIRA, L; MEDINA, R. Desenvolvimento de objetos de aprendizagem para dispositivos móveis: uma nova abordagem que contribui para a educação. Revista Novas Tecnologias na Educação, 2007.

PERRENOUD, Philippe. Avaliação: da excelência à regulação das aprendizagens - entre duas lógicas. Porto Alegre: Artes Médicas Sul, 1999.

PIAGET, J. Aprendizagem e conhecimento. Rio de Janeiro: Freitas Bastos, 1979.

PIAGET, J. Biologia e conhecimento. 2 ed. Petrópolis: Vozes, 1996.

Portal TIDIA-Ae. Disponível em: < http://tidia-ae.usp.br/portal>. Acessado em: Agosto 2009.

Portal SEDUC. Seduc amplia número de estações satelitais do Centro de Mídias. Disponível em: <http://www.seduc.am.gov.br/2008/noticia.php?cod=146>. Acessado em: 10-09-2009. 
POLAK, Ymiracy; MUNHOZ, Antonio Siemsen. Sociedade Tecnológica e Educação.Disponível em:<www14.unopar.br/unopar/static/mestrado_ead/turma1/ aula_ymiracy/Aula03/Unidade_III-texto_base.pdf>, Acessado em julho de 2008.

REY-LÓPEZ, M.; DÍAZ-REDONDO, R. P.; FERNÁNDEZ-VILAS, A.; PAZOSARIAS, J. J. Entercation Experiences: Engaging Viewers in Education through TV Programs. In of the 4th European Conference on Interactive Television: Beyond Usability, Broadcast, and TV. (EurolTV 2006), pages 310-319. 2006.

RIBEIRO FILHO, José Daniel Pereira, LOPES, Rafael Fernandes. Avaliação de Aprendizagem por meio da TV Digital Interativa. In VI CONGRESSO BRASILEIRO DE ENSINO SUPERIOR A DISTÂNCIA. Maranhão, SL. VI ESUD, 2009.

ROESLER, Valter. Educação através da TV Digital utilizando metadados. In XIX Simpósio Brasileiro de Informática na Educação, 2008, Fortaleza, CE. SBIE 2008.

SIAU K, ; Nah F. H. Mobile Technology in Education. University of NebraskaLincoln, 2008.

SILVA, F. S. Personalização de Conteúdo na TVDI Através de um Sistema de Recomendação Personalizada de Programas de TV (SRPTV). In: III Fórum de Oportunidades em Televisão Digital Interativa, 2005, Poços de Calda/MG. III Fórum de Oportunidades em Televisão Digital Interativa, 2005. 
SIMS, R. Beyond instructional design: making learning design a reality. In: Journal of Learning Design. Disponível em: http://www.jld.qut.edu.au/publications/vol1no2/documents/beyond\%20instructional\% 20design.pdf. Acessado em: Julho de 2010.

SHIINO, Erich Renato Santos; BRESSAN, Graça. Desenvolvimento de aplicação de TV interativa para educação à distância. In: SIMPÓSIO INTERNACIONAL DE INICIAÇÃO CIENTÍFICA DA UNIVERSIDADE DE SÃO PAULO, São Paulo, SP, 2004.

SOUTO MAIOR, Marcelo. A TV interativa e seus caminhos. Dissertação Final de Mestrado Profissional (Mestrado em Computação) - Instituto de Computação, Universidade Estadual de Campinas, 72 f, Campinas, 2002.

SOUZA F., et al. Ginga-J: The Procedural Middleware for the Brazilian Digital TV System, Journal of the Brazilian Computer Society, v12, n4. 2007.

SHARPE, R., BENFIELD, G., ROBERTS, G., \& FRANCIS, R. The undergraduate experience of blended learning: A review of UK literature and practice. Disponível em: http://www.heacademy.ac.uk/projects/detail//r_2006_sharpe, Acessado em: 12/04/2010.

STACEY, E., GERBIC, P. Teaching for blended learning: How is ICT impacting on distance and on campus education? In D. Kumar \& J. Turner (Eds.), Education for the 21st century - Impact of ICT and digital resources: IFIP 19th World Computer Congress, TC-3, Education, August 21-24, 2006, Santiago, Chile (pp. 225-234). New York: Springer. 
STARR, S. - Application of Mobile Technology in Learning \& Teaching: 'Mlearning'.Learning \& Teaching Enhancement Unit (LTEU), 2007.

STEUER, J. Defining Virtual Reality: Dimensions Determining Telepresence. Journal of Comunnication, v.42, n.4, 1992.

TV-ANYTIME. Disponível em: <http://www.TV-anytime.org>. Acessado em: Setembro de 2008.

VAUGHAN, N.. Perspectives on blended learning in higher education. International Journal on ELearning, 6 (1), 81-94, 2007.

VORDERER, P. Interactive entertainment and beyond. In Media Entertainment: The Psychology of Its Appeal, D. Zillmann and P. Vorderer, eds., Lawrence Erlbaum Associates, 21-36, 2000.

ZAINA, Luciana Aparecida Martinez. Acompanhmento do Aprendizado do Aluno em Cursos a Distância através da Web: Metodologias e Ferramenta. Universidade de São Paulo, São Paulo, 2002.

ZAINA, Luciana Aparecida Martinez. Avaliação do perfil do aluno baseado em interações contextualizadas para adaptação de cenários de aprendizagem. Universidade de São Paulo, São Paulo, 2008. 
XML (Extensible Markup Language). Disponível em: http://www.w3.org/XML/. Acessado em Novembro de 2009.

W3C. World Wide Web Consortion. Disponível em <http://www.w3.org/>. Acessado em Outubro de 2009.

W3SCHOOLS. XML Tutorial. Disponível em: <http://www.w3schools.com/xml> Acesso em: 07 ago 2009. 


\section{APÊNDICE}

Os Apêndices apresentam:

A - Os artigos aceitos (um defendido e outro a defender);

B - Os questionários aplicados na fase de elicitação de requisitos com os especialistas da Modalidade Presencial Mediada por TV da Universidade do Estado do Amazonas; 


\section{APÊNDICE A - ARTIGOS ACEITOS}

\section{Congresso Brasileiro de Ensino Superior à distância (ESUD 2009)}

Tema: Uma ferramenta Fuzzy de acompanhamento de estudantes em ambientes de aprendizagem no modelo presencial mediado por TV.

Andreza B. Mourão ${ }^{1}$, William R. Malvezzi ${ }^{1}$ e Graça Bressan ${ }^{1}$

${ }^{1}$ Laboratório de Arquitetura e Redes de Computadores (LARC)

Escola Politécnica da Universidade de São Paulo (EPUSP)

andreza.mourao@poli.usp.br, wmalvezzi@usp.br, gbressan@larc.usp.br.

Disponível em: http://www.uemanet.uema.br/artigos esud/ . Artigo número 57216.

Apresentado: 3 e 4 de Novembro de 2009.

FIE 2010 - The 40th IEEE Annual Frontiers in Education (FIE 2010) Conference.

Tema: Learning evaluation in classroom mediated by technology model using fuzzy logic at the University of Amazonas State.

William R Malvezzi ${ }^{1}$, Andreza B Mourão ${ }^{1}$ and Graça Bressan ${ }^{1}$

1University of São Paulo,

wmalvezzi@usp.br, andreza.mourao@poli.usp.br, gbressan@larc.usp.br.

Apresentação prevista: 30 de Outubro de 2010. 


\section{APÊNDICE B - QUESTIONÁRIOS}

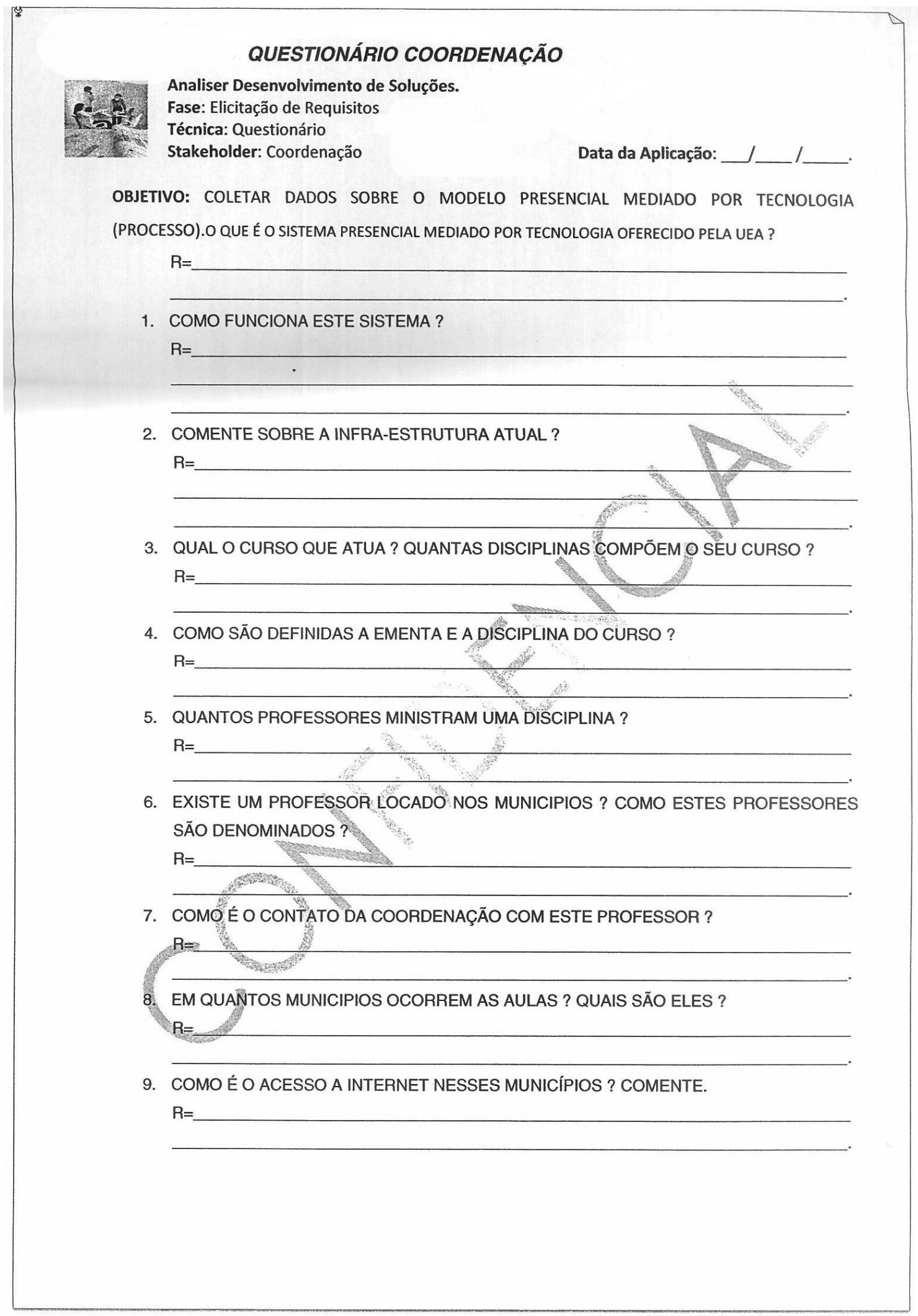


10. QUAIS SÃO OS MEIOS DE COMUNICAÇÃO EXISTENTES E A ESTRATÉGIA TRAÇADA PARA QUE HAJA A COMUNICAÇÃO ENTRE OS ALUNOS E PROFESSORES DO INTERIOR COM A COORDENAÇÃO DO CURSO?

$\mathrm{R}=$

11. O LOCAL QUE OS PROFESSORES MINISTRAM AS AULAS VIA TELEVISÃo É ADEQUADO ? COMENTE SOBRE A SUA ESTRUTURA FÍSICA?

$$
\mathrm{R}=
$$

12. COMO OCORRE O CONTATO DOS PROFESSORES TITULARES COM OS ALUNOS DOS MUNICIPIOS ?

$\mathrm{R}=$

13. COMO SE DÁ O RELACIONAMENTO ENTRE PROFESSORES TITULARES E COORDENAÇÃO?

$\mathrm{R}=$

14. CITE 3 PONTOS POSITIVOS DO MODELO?

$\mathrm{R}=$

15. CITE 3 PONTOS NEGATIVOS DO MODELO?

$\mathrm{R}=$

16. DÊ UM CONCEITO PARA ESTE MODELO DE ENSINO.
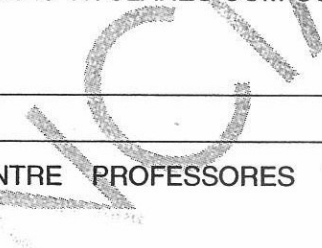


\section{QUESTIONÁRIO PROFESSOR TITULAR}

Analiser Desenvolvimento de Soluções.

Fase: Elicitação de Requisitos

Técnica: Questionário

Stakeholder: Professor Titular

Data da Aplicação:

OBJETIVO: COLETAR DADOS SOBRE A ATUAÇÃO, MÉTODOS UTILIZADOS, DIFICULDADES ENCONTRADAS ENTRE OUTROS FATORES NO SISTEMA PRESENCIAL MEDIADO POR TECNOLOGIA DA UEA (PROCESSO).

1. COMO É ENSINAR PELA TELEVISÃO? RELATE A SUA EXPERIÊNCIA ?

$R=$

2. QUAL A SUA OPNIÃO SOBRE A INFRA-ESTRUTURA ENCONTRADA?

$\mathrm{R}=$

3. CITE 2 PONTOS POSITIVOS E 2 NEGATIVOS EM RELAÇÃO AS AULAS MINISTRADAS ?

$\mathrm{R}=$

4. QUAL A METODOLOGIA ADOTADA PARA MINISTRAR AULAS PELA TELEVISÃO ?

$R=$

5. QUAIS FATORES INFLUENCIAM POSITIVA E NEGATIVAMENTE NO SEU DESEMPENHO DIANTE DAS CÂMERAS ? CITE 2.

$\mathrm{R}=$

6. QUAL ANÁLISE VOCÊ FAZ EM RELAÇÃO AO CURSO QUE TRABALHA (ACOMPANHAMENTO PEDAGÓGICO, MATERIAL, RECURSOS DISPONIVEIS, ETC.) ?

$\mathrm{R}=$

(3)

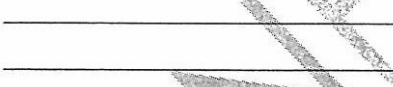

7. QUAL O SEU RELACIONAMENTO COM A COORDENAÇÃO DO CURSO ?

$\mathrm{R}=$

8. QUAL O SEU RELACIONAMENTO COM OS ALUNOS ?

9. QUAL O SEU RELACIONAMENTO COM OS PROFESSORES LOCADOS NOS
MUNICIPIOS?
$\mathbf{R}=$

10. CITE 3 FORMAS DE INTERATIVIDADE UTILIZADAS HOJE AO MINISTRAR SUAS AULAS ? $\mathrm{R}=$

11. HÁ UM AMBIENTE VIRTUAL DE APRENDIZAGEM ? QUAL A SUA IMPORTÂNCIA, LEVANDO EM CONSIDERAÇÃO O CONTEXTO ENSINO-APRENDIZAGEM ? $\mathrm{R}=$

12. QUAIS SÃO AS FORMAS DE AVALIAÇÃO REALIZADAS?

$\mathrm{R}=$ 
13. DÊ SUA OPNIÃO SOBRE O MODELO DE ENSINO PRESENCIAL MEDIADO POR TECNOLOGIA ADOTADO PELA UEA?

$\mathrm{R}=$

14. COMO OCORRE O FEEDBACK DA DISCIPLINA ?

$\mathrm{R}=$

15. É POSSIVEL REALIZAR UMA ANÁLISE EM RELAÇÃO AS AULAS MINISTRADAS?

$\mathrm{R}=$

16. QUAL POSTURA QUE VOCÊ ADOTA AO ENSINAR VIA TELEVISÃO? COMENTE SOBRE SUA EXPERIÊNCIA NO CONTEXTO DESTA NOVA ABORDAGEM.

$R=$

17. DÊ UM CONCEITO PARA ESTE MODELO DE ENSINO.
a. ( ) OTIMO
b. ( ) $\mathrm{BOM}$
c. ( ) REGULAR
d. ( ) HÁ MUITO QUE MELHORAR

18. DÊ UM CONCEITO PARA O RENDIMENTOO DOS ALUNOS NA SUA DISCIPLINA.
a. ( ) SATISFATÓRIO
b. ( ) BOM
c. ( ) INSATISFATÓRIO

19. VOCÊ ACREDITA NA CREDIBILIDADE ACADÊMICA DESTE MODELO DE ENSINO.

a. ( ) SIM

b. ( ) NÃO

c. ( ) OUTROS.

20. OUTRAS FERRAMENTAS DIDÁTICAS DE ENSINO SÃO NECESSÁRIAS PARA A MELHORIA DA QUALIDADE DE ENSINO.

a. ( ) SIM

b. () NÃO

Obrigado, por participar desta enquete.

A veracidade destas informações é de suma importância para a melhoria da qualidade de ensino do modelo presencial mediado por tecnologia da Universidade do Estado do Amazonas. 


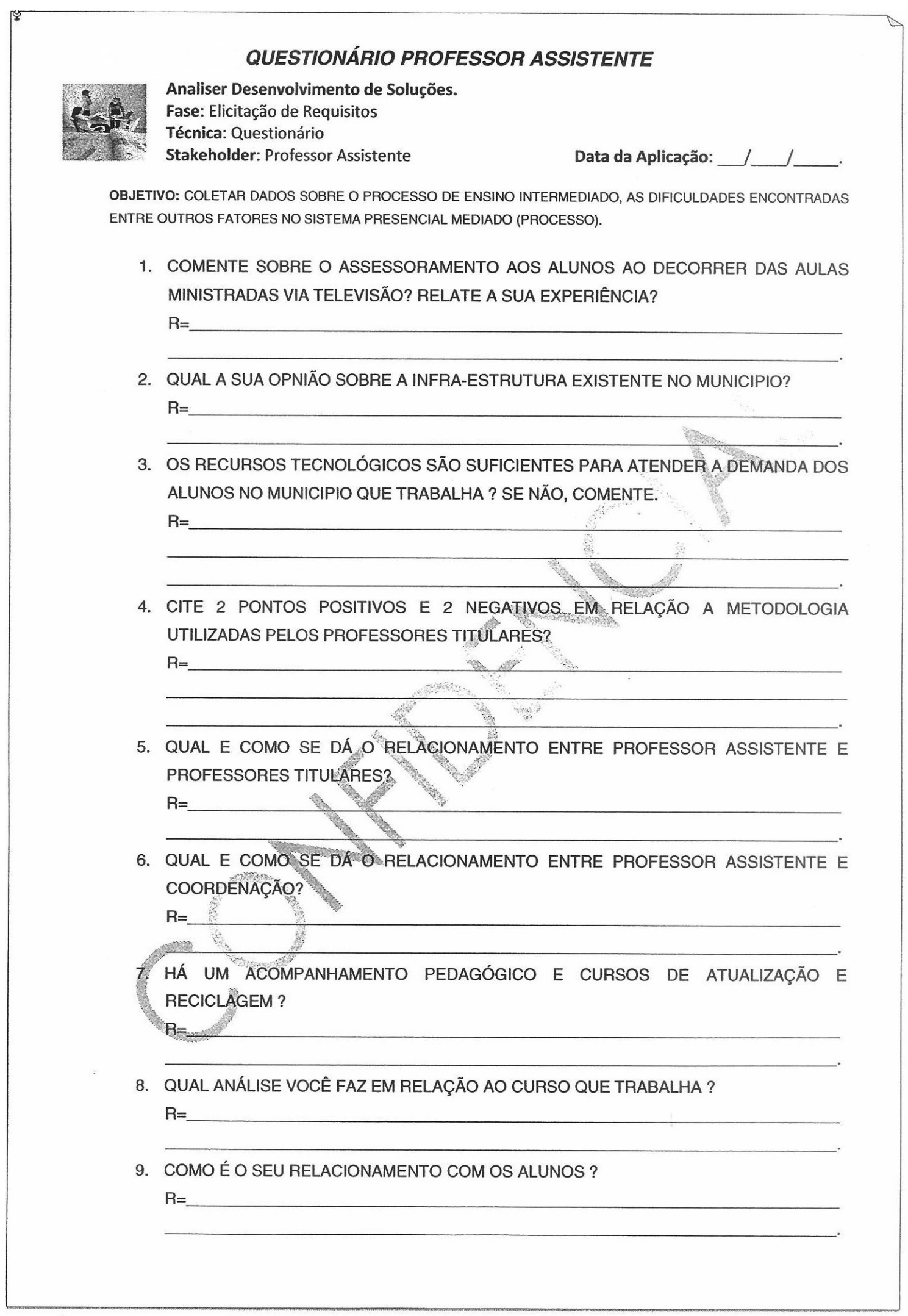


10. CITE 3 DIFICULDADES ENCONTRADAS NESTE MODELO DE ENSINO ?

$\mathrm{R}=$

11. COMENTE SOBRE AS AVALIAÇÕES REALIZADAS PELOS PROFESSORES TITULARES.

$\mathrm{R}=$

12. QUAIS SÃO AS FORMAS DE COMUNICAÇÃO EXISTENTES ENTRE PROFESSOR ASSISTENTE E TITULAR?

$\mathrm{R}=$

13. QUAL A SUA REAL ATUAÇÃO E CONTRIBUIÇÃO NO PROCESSO DE ENSINO APRENDIZAGEM?

$\mathrm{R}=$

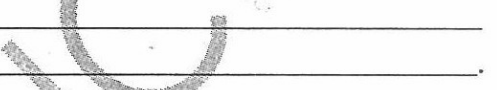

14. SUGIRA ALGO QUE POSSA CONTRIBUIR PARA A MELHORIA DO PROCESSO DE ENSINO.

$\mathrm{R}=$

15. DÊ UM CONCEITO PARA ESTE MODELO DE ENSINO.

a. ( ) OTIMO

b. ( ) BOM

c. ( ) REGULAR

d. ( ) HÁ MUITO QUE MELHORAR

16. DÊ UM CONCEITO PARA AS AULAS MINISTRADAS PELOS PROFESSORES TITULARES.

a. () SATISFATÓRIO

b. ( ) BOM

c. ( ) INSATISFATÓRIO

17. VOCÊ ACREDITA NA CREDIBILIDADE ACADÊMICA DESTE MODELO DE ENSINO.

a. (1) SIM

b. () NÃO

c. ( ) OUTROS.

18. OUTRAS FERRAMENTAS DIDÁTICAS DE ENSINO SÃO NECESSÁRIAS PARA A MELHORIA DA QUALIDADE DE ENSINO.

a. ( ) SIM

b. ( ) NÃO

Obrigado, por participar desta enquete.

A veracidade destas informações é de suma importância para a melhoria da qualidade de ensino do modelo presencial mediado por tecnologia da Universidade do Estado do Amazonas. 